ANNA CAROLINA LIMA DE ALENCAR

\title{
TUBERCULOSE E DIABETES MELLITUS: ABORDAGENS NA TRAJETÓRIA ESPAÇO-TEMPORAL
}

Dissertação apresentada ao programa de Pós-Graduação em Enfermagem da Universidade de São Paulo para obtenção do título de Mestre em Ciências.

Área de concentração: Saúde Coletiva.

Orientadora: Prof ${ }^{a}$. Dr ${ }^{\mathrm{a}}$. Maria Rita Bertolozzi 
AUTORIZO A REPRODUÇÃO E DIVULGAÇÃO TOTAL OU PARCIAL DESTE TRABALHO, POR QUALQUER MEIO CONVENCIONAL OU ELETRÔNICO, PARA FINS DE ESTUDO E PESQUISA, DESDE QUE CITADA A FONTE.

Assinatura:

Data:

Alencar, Anna Carolina Lima de

Tuberculose e diabetes mellitus: abordagens na trajetória espaço-temporal / Anna Carolina

Lima de Alencar. -- São Paulo, 2014.

$152 \mathrm{p}$.

Dissertação (Mestrado) - Escola de Enfermagem da Universidade de São Paulo.

Orientadora: Profa. Dra. Maria Rita Bertolozzi

Área de concentração: Saúde Coletiva

1. Enfermagem 2. Tuberculose 3. Diabetes Mellitus 4. Processo Saúde-Doença 5. Revisão Integrativa I. Título. 
Nome: Anna Carolina Lima de Alencar

Título: Tuberculose e Diabetes Mellitus: abordagens na trajetória espaçotemporal por meio de revisão integrativa.

Dissertação apresentada ao Programa de Pós-Graduação em Enfermagem da Escola de Enfermagem da Universidade de São Paulo para obtenção do título de Mestra em Ciências.

Aprovado em:

\section{Banca Examinadora}

Prof. ${ }^{a}$ Dr. ${ }^{a}$ Maria Rita Bertolozzi

Julgamento:

Prof. ${ }^{a}$ Dr. ${ }^{a}$

Julgamento:

Prof. ${ }^{a}$ Dr. ${ }^{a}$

Julgamento:
Instituição: Escola de Enfermagem da Universidade de São Paulo

Assinatura:

Instituição:

Assinatura:

Instituição:

Assinatura: 


\section{DEDICATÓRIA}

À minha mãe, Norma Pereira de Lima, por estar ao meu lado em todos os momentos da minha vida e nestes anos do mestrado, me dando força, me trazendo de volta à realidade, sendo meu alicerce e principalmente preenchendo meus dias difíceis com muito amor, "porque você é amor, e tira amor de onde menos se espera".

À minha Professora e amiga, Ms Carine Teles Sangaleti Miyahara, à quem devo o amor pela minha profissão e os grandes impulsos em minha carreira. Por ter ampliado minhas perspectivas, despertado o melhor em mim e, principalmente, acreditado na minha capacidade. Por ter sido capaz de me fazer querer. Querer fazer melhor, ir além e tornar possível. Por ter criado em mim novos valores e princípios que tento instituir não só nas minhas práticas acadêmicas, mas principalmente na minha vida. Por ter me ensinado a nunca me entregar à mediocridade que é viver como um profissional resignado. 


\section{AGRADECIMENTO ESPECIAL}

Á minha orientadora, Professora Dr. ${ }^{a}$ Maria Rita Bertolozzi, a quem devo a oportunidade de ter ingressado na Escola de Enfermagem da USP. Por ter compartilhado comigo parte de seu tão admirável conhecimento. Por admirá-la imensamente por sua postura profissional, mas principalmente por seu caráter e especialmente por ser, além de tudo, humana. 


\section{AGRADECIMENTOS}

Á minha amiga, Rafaela Gessner, por estar ao meu lado compartilhando todas as emoções de ser um pós-graduando. Por seu carinho e por ser meu suporte e me fortalecer todas as vezes em que o caminho se tornava mais difícil.

Á minha amiga, Patrícia Tavares, por sempre me trazer à realidade e me fortalecer com suas, sempre sábias, colocações. E por terem tornado São Paulo uma experiência incrível.

À Daiana Bomfim, por tudo que foi capaz de fazer por mim. 
[...] pensavam que mudariam nossos objetivos e conteriam nossas ambições, mas nada mudou em minha vida exceto isto: a fraqueza, o medo e a desesperança morreram. Força, poder e coragem nasceram.

(Malala Yousafzai) 
Alencar ACL. Tuberculose e Diabetes Mellitus: abordagens na trajetória espaço-temporal por meio de Revisão Integrativa [dissertação]. São Paulo: Escola de Enfermagem, Universidade de São Paulo; 2014.

\section{RESUMO}

Introdução: Estudos epidemiológicos tem elucidado a associação entre diabetes mellitus $(\mathrm{DM})$ e tuberculose $(\mathrm{TB})$, reacendendo o debate quanto à suscetibilidade de indivíduos com DM tipo 1 e tipo 2, em adquirir a doença. Progressivamente, o DM tem apresentado alta prevalência, revelando-se como mais uma epidemia a ser superada. Considerando-se a continuidade das altas taxas de TB, acredita-se que a convergência destas com as taxas de DM constitui-se como problema importante de saúde pública. A literatura científica tem mostrado sobejamente a explicação de tais enfermidades, substantivamente na perspectiva clínica e biológica, ainda que no caso da $\mathrm{TB}$, a sua associação às condições de vida adquira maior relevo. Entretanto, o que ocorre quando a TB e o DM encontram-se associadas? Quais são as tendências, na produção da literatura científica e que tipos de abordagens tem sido conduzidas para a interpretação de tais enfermidades? Destaca-se, portanto, a importância de analisar a produção científica mundial a respeito desta associação, em especial, buscando-se identificar se expõe a determinação social, quando estas enfermidades encontram-se associadas. Objetivo: Objetiva analisar como a literatura científica tem apresentado a associação entre o Diabetes Mellitus e a Tuberculose. Método: Trata-se de revisão integrativa. As buscas foram realizadas nas bases de dados PubMed, LILACS, CINAHL, Web of Science e Dedalus (USP). Resultados: Considerando-se o período de 2000 a 2012, foram identificadas e selecionadas 352 publicações por títulos e resumos, das quais 62 foram analisadas por ano de publicação e principal abordagem do estudo. As publicações foram classificadas nos seguintes enfoques: farmacológico (10; $16,1 \%)$, imunológico $(13 ; 20,96 \%)$, apresentação clínica $(13 ; 20,96 \%)$ ou epidemiológico $(26 ; 41,93 \%)$. Foram encontrados 7 estudos que foram reclassificados como enfoque social (6). Conclusão: Apesar de realizados em países com forte desigualdade social e desigualdades em saúde, como 
Índia, China, México, Malásia e municípios de fronteira entre Texas (EUA) e o México - localidades que apresentam bolsões importantes de pobreza, onde a incidência da TB permanece alta e a do DM se mantém crescente, a maior parte dos estudos $(96,77 \%)$ não considera a forte determinação social posta na causalidade destas doenças, bem como os determinantes sociais de saúde como condicionantes para a coexistência destas enfermidades.

PALAVRAS-CHAVE: Tuberculose. Diabetes Mellitus. Determinação Social. Processo Saúde-Doença. Revisão Integrativa. Enfermagem. 
Alencar ACL. Tuberculosis and Diabetes Mellitus: approaches in spatiotemporal trajectory [dissertation]. São Paulo: Nursing school, Universidade de São Paulo; 2014.

\begin{abstract}
Introduction: Epidemiological studies have clarified the association of diabetes mellitus (DM) with tuberculosis (TB), escalating the debate concerning the susceptibility of individuals with DM type 1 and type 2, to contract the disease. Progressively, DM has presented high prevalence, revealing as another epidemic to be overcome. Considering the steadily high rates of $\mathrm{TB}$, we believe that the convergence of them with $\mathrm{DM}$ rates constitutes an important issue for the public health. The scientific literature has widely shown the interpretation of such illnesses, mainly in clinical and biological perspectives, although in the case of $\mathrm{TB}$, its association with life conditions is highlighted. Nevertheless, what occurs when TB and DM are associated? What are the tendencies in the production of scientific literature and what types of approaches have been conducted to interpret such illnesses? Thus, the importance to analyze what is being produced worldwide concerning this association is pointed out, specially, seeking to identify whether the scientific literature exposes the social determination when these illnesses are associated. Objective: this study has as objective to analyze how the scientific literature has presented the association of Diabetes Mellitus with Tuberculosis. Method: it is an integrative review whose research was carried out on PubMed, LILACS, CINAHL, Web of Science and Dedalus (USP) data base. The study is based on the following questions: "What are the approach tendencies in the association of TB with DM, considering the period of 2000 to 2012?" and "Since the association TB-DM was first documented, what has been the tendencies approached in the health-illness process?" Results: 352 publications by titles and abstracts were identified and selected, from which 62 were analyzed considering the publication year and the main study approach, being therefore classified into pharmacological $(10 ; 16,1 \%)$, immunological $(13 ; 20,96 \%)$, clinical presentation $(13 ; 20,96 \%)$ or epidemiological $(26 ; 41,93 \%)$ approaches.
\end{abstract}


Depending on the emphasis of the variables considered and on the discussion emphasis, the studies were subdivided in social approach (7). Conclusion: Despite being carried out in countries with high social inequality and inequalities in health, such as India, China, Mexico, Malaysia and cities bordering Texas (USA) and Mexico - which are among the poorest municipalities in the USA, where TB incidence keeps high and DM increases, the majority of the studies $(96,77 \%)$ looked into TB-DM association in clinical and programming scope, without considering the strong social determination laid on the causality of these diseases, as well as the social determinants of health as constraints for the coexistence of these illnesses.

KEY WORDS: Tuberculosis. Diabetes mellitus. Social determination. Health-illness process. Integrative Review. Nursing. 


\section{LISTA DE FIGURAS}

Figura 1 - Descrição geral sobre o processo de revisão integrativa. 40

Figura 2 - Esquema de apresentação dos resultados. 48

Figura 3 - Esquema de apresentação dos resultados por enfoque 49

Figura 4 - Resultados de quantificação de publicações por país de pesquisa. 89 


\section{LISTA DE QUADROS}

Quadro 1 - Bases de dados incluídas na busca bibliográfica, de acordo com 43 a área de conhecimento, período de análise e tipo de publicação. São Paulo, 2013. 


\section{LISTA DE TABELAS}

Tabela 1 - Dados sobre a TB no Brasil. 2012. 


\section{LISTA DE ABREVIATURAS}

$\begin{array}{ll}\text { DM } & \text { Diabetes Mellitus } \\ \text { Mtb } & \text { Micobacterium tuberculosis } \\ \text { TB } & \text { Tuberculose }\end{array}$




\section{LISTA DE SIGLAS}

$\begin{array}{lll}\text { CDC } & - & \text { Centers for Diseases Control } \\ \text { CNDSS } & - & \text { Comissão Nacional sobre os Determinantes Sociais da Saúde } \\ \text { DSS } & - & \text { Determinantes Sociais de Saúde } \\ \text { DM } & - & \text { Diabetes Mellitus } \\ \text { DOTS } & - & \text { Tratamento Diretamente Observado } \\ \text { IDF } & - & \text { International Diabetes Federation } \\ \text { Mtb } & - & \text { Micobacterium tuberculosis } \\ \text { NO } & - & \text { Óxido Nítrico } \\ \text { OMS } & - & \text { Organização Mundial da Saúde } \\ \text { ONU } & - & \text { Organização das Nações Unidas } \\ \text { TB } & - & \text { Tuberculose } \\ \text { WHO } & - & \text { World Health Organization }\end{array}$




\section{SUMÁRIO}

1 INTRODUÇÃO

2 REFERENCIAL TEÓRICO 20

2.1 O REFERENCIAL TEÓRICO QUE ORIENTA A LEITURA DOS 20 ASPECTOS SOCIAIS: A DETERMINAÇÃO SOCIAL DO PROCESSO SAÚDE-DOENÇA

3 REVISÃO DA LITERAURA: ALGUNS ASPECTOS 23 FUNDAMENTAIS SOBRE AS ENFERMIDADES EM QUESTÃO

3.1 A TUBERCULOSE

3.1.1 Aspectos epidemiológicos 23

3.2.2 Aspectos imunológicos 25

3.2 O Diabetes Mellitus 26

3.2.1 Aspectos epidemiológicos 26

3.2.2 Aspectos imunológicos 28

3.2.3 A Obesidade e o Diabetes Mellitus 28

3.3 A ASSOCIAÇÃO ENTRE A TUBERCULOSE E O DIABETES $\mathbf{3 0}$ MELLITUS

4 PERGUNTA E HIPÓTESE DO ESTUDO 34

5 OBJETIVOS 36

5.1 OBJETIVO GERAL 36

5.2 OBJETIVOS ESPECÍFICOS $\mathbf{3 6}$

6 METODOLOGIA 37

6.1 DELINEAMENTO DO ESTUDO $\mathbf{3 7}$

6.2 QUESTÃO DE ESTUDO 40

6.3 ETAPAS DO ESTUDO $\mathbf{4 1}$

6.3.1 Etapa 1 41

6.3.2 Etapa 2 41

6.4 CRITÉRIOS DE INCLUSÃO $\quad \mathbf{4 2}$

6.5 CRITÉRIOS DE EXCLUSÃO $\mathbf{4 2}$

6.6 TIPOS DE PARTICIPANTES $\mathbf{4 2}$

6.7 FENÔMENOS DE INTERESSE $\mathbf{4 2}$ 
6.8 ESTRATÉGIAS DE BUSCA PARA IDENTIFICAÇÃO DOS ESTUDOS $\mathbf{4 3}$

6.9 SELEÇÃO E AVALIAÇÃO DA QUALIDADE DOS ESTUDOS 44

6.10 ANÁLISE DOS ESTUDOS PRIMÁRIOS $\mathbf{4 5}$

6.10.1 Comparação de estudos primários 45

6.11 ASPECTOS ÉTICOS $\mathbf{4 6}$

$7 \quad$ ANÁLISE DESCRITIVA DOS RESULTADOS DOS ESTUDOS 47 PRIMÁRIOS SEGUNDO O ENFOQUE

7.1 ENFOQUE IMUNOLÓGICO 49

7.2 ENFOQUE DE APRESENTAÇÃO CLINICA $\mathbf{5 5}$

7.3 ENFOQUE FARMACOLÓGICO

7.4 ENFOQUE EPIDEMIOLÓGICO

8 RESULTADOS E DISCUSSÃO

8.1 OS DETERMINANTES SOCIAIS E A COEXISTÊNCIA TB-DM $\mathbf{8 8}$

8.2 ANÁLISE ESPACIAL DA ASSOCIAÇÃO TB-DM

9 CONSIDERAÇÕES FINAIS

REFERÊNCIAS

APÊNDICES 


\section{INTRODUÇÃO}

Doenças infecciosas e parasitárias, a exemplo da tuberculose, têm sido substituídas de forma gradual e progressiva por doenças crônicodegenerativas, como causas de morbidade e mortalidade (Ponte et al., 2010). Se anteriormente observava-se maior prevalência de enfermidades crônicodegenerativas nos países desenvolvidos, tal quadro também vem acumulando-se ao perfil de maior prevalência de enfermidades infecciosas nos países subdesenvolvidos. Nestes últimos verifica-se sobreposição desses perfis, constatando-se aumento da prevalência de distúrbios metabólicos, como diabetes mellitus (DM), dislipidemias, obesidade, hipertensão arterial sistêmica (HAS) e síndrome metabólica (SM), paralelamente à permanência de doenças infecciosas e parasitárias, como hanseníase, tuberculose (TB), hepatites virais e HIV/Aids, que são endêmicas em diversas regiões (Ponte et al., 2010).

A tuberculose continua sendo fonte importante de morbidade e mortalidade em todo o mundo. Estima-se que um terço da população mundial esteja infectada com o Mycobacterium tuberculosis, cerca de nove milhões de pessoas desenvolvem a doença à cada ano, e quase dois milhões de pessoas morrem anualmente em decorrência da enfermidade (Baker et al., 2011; CDC, 2012). Gradativamente, estudos têm elucidado a associação entre o diabetes mellitus e a tuberculose, reacendendo o debate quanto à suscetibilidade de indivíduos com DM tipo 1 e tipo 2, em adquirir a TB (Baker et al. 2011; Dooley e Chaisson, 2009). Tais estudos ressaltam, também, as diferenças de apresentação, gravidade e resposta ao tratamento, quando da presença desta associação (Baker et. al. 2011; Dooley e Chaisson, 2009). Há evidências de que pessoas com tuberculose e diabetes têm piores resultados na evolução da tuberculose do que aqueles sem diabetes (Stevenson et al. 2007).

A contribuição substancial da diabetes na incidência da tuberculose pode ser ilustrada pela revisão sistemática realizada por Stevenson e colaboradores, em que o diabetes implicou risco relativo para tuberculose de 1,5 a 7,8 vezes (Stevenson et. al., 2007). Destaca-se, ainda, a revisão sistemática de Jeon e Murray (2008), baseada em meta-análise de 13 
estudos observacionais, em que a presença de diabetes foi associada a um risco relativo de 3,11 para a infecção ativa por tuberculose.

A incidência global da DM, como consequência do aumento da obesidade, padrões de dieta e atividade física alterados e envelhecimento populacional, está aumentando (Dooley, 2009), com prevalência estimada de 592 milhões até 2035, sendo que mais de $80 \%$ dos casos em adultos ocorrem em países subdesenvolvidos ou em desenvolvimento (International Diabetes Federation, 2013). Considerando-se a continuidade das altas taxas de tuberculose, acredita-se que a convergência das epidemias de tuberculose e diabetes mellitus pode levar a um aumento da incidência da tuberculose, com elevação do número de pessoas que apresentam ambas as enfermidades (Baker et al., 2011; Dooley, 2009).

Apesar dos estudos mencionados, constata-se que a associação diabetes-tuberculose encontra-se, de certa forma, negligenciada pelos formuladores de políticas de saúde. Assim, ressalta-se a importância desta associação como de imediata relevância para os Objetivos de Desenvolvimento do Milênio da ONU, que inclui estratégias para reduzir a taxa de mortalidade por tuberculose, e melhorar a sua detecção e tratamento (Stevenson et al., 2007).

De acordo com Stevenson et al. (2007), estabelecida a associação entre TB e DM, faz-se necessário adaptar os programas de controle da tuberculose, incorporando fatores de risco adicionais. A estratégia "Stop TB", da OMS, inclui indivíduos com diabetes nos "grupos de alto risco", e possui recomendações específicas sobre a relação entre as duas condições, expostas no "Collaborative Framework for Care and Control of Tuberculosis and Diabetes", recomendações estas ainda não amplamente implementadas na prática. A epidemia de diabetes pode levar ao ressurgimento da tuberculose em regiões endêmicas, especialmente em áreas urbanas, com implicações potencialmente graves para o controle desta última (Stevenson et al., 2007).

Diferentes abordagens têm sido divulgadas pela literatura científica sobre a interpretação dessas enfermidades: ora de cunho clínico, ora apresentando diferentes fatores que atuam na trama de causalidade. 
Acredita-se que a forma de interpretação das doenças orienta as intervenções: mais amplas, conduzindo à integralidade, ou pontuais e focais, sem que sejam propostas ações de caráter mais amplo. Há, portanto, necessidade de estudos para conduzir apropriadamente as políticas públicas e as práticas clínicas neste domínio.

Conforme verificar-se-á a seguir, este presente estudo foi desenvolvido a partir do entendimento de que ambas as enfermidades, a TB e a DM tem importante determinação social. A não observância de tal entendimento tem resultado em intervenções que não tem promovido impacto epidemiológico.

Considerando o impacto das condições socioeconômicas sobre o processo saúde-doença e sobre a situação epidemiológica dos agravos, em particular, no caso da tuberculose e do diabetes mellitus, que mais e mais se encontram justapostas, e entendendo que ambas tem importante determinação social, emerge a indagação: como a associação entre tais enfermidades tem sido explicada no âmbito da produção científica? Via de regra, a produção científica aponta o social como mais um fator na causalidade da tuberculose, mas como se coloca em relação ao diabetes mellitus? E o que ocorre quando se conjugam ambas as enfermidades?

Isto posto, iniciar-se-á a problematização do objeto, conforme coloca-se a seguir. 


\section{REFERECNIAL TEÓRICO}

\subsection{O referencial teórico que orienta a leitura dos aspectos} sociais: a Determinação Social do Processo Saúde-Doença

A Teoria da Determinação Social do Processo Saúde-Doença preconiza que o processo de adoecimento e morte da população é determinado pela forma como a sociedade está organizada, e como se estruturam os modos de produção e de reprodução social e, por consequência, a distribuição das pessoas nos grupos sociais, que por serem distintos em termos do acesso à produção e ao consumo, também terão diferentes fortalecimentos e desgastes e riscos ou potencialidades no desenvolvimento da vida. Todos estes acabam por manifestar-se no processo saúde-doença (Fonseca, Bertolozzi, 1997).

O embrião do surgimento desta Teoria dá-se no século XVIII, no movimento da "Medicina Social". Tal movimento considerava que a ciência médica é intrínseca e essencialmente uma ciência social e que as condições econômicas e sociais exercem um importante efeito sobre a saúde e a doença (Fonseca, Bertolozzi, 1997; Pellegrini Filho, 2007; Rosen, 1980). Propunha-se, portanto, "a articulação entre os processos sociais e políticos com o perfil de morbimortalidade, buscando explicar as intermediações entre o desenvolvimento econômico e social de uma dada sociedade/região/localidade e os perfis epidemiológicos" (Fonseca, Bertolozzi, 1997, p. 20).

Nessa linha, o objeto de estudo da Epidemiologia, denominada como Crítica ou Social, passa a ser o fenômeno saúde-doença como um processo decorrente da organização da sociedade. Assim, o conhecimento epidemiológico se desenvolve em torno do esforço para explicar os problemas de saúde-doença em sua dimensão social (Breilh, 1991 apud Fonseca, Bertolozzi, 1997).

Passa-se, dessa forma, a buscar considerar o caráter histórico da doença, superando os estudos das características dos indivíduos, comprovados empiricamente e de forma restritiva, na Epidemiologia Clássica, buscando-se análises de caráter profundo, integrando os processos 
gerais que ocorrem na coletividade humana (Laurell, 1976) e que se referem, entre outros, às formas como a sociedade se organiza para produzir e reproduzir socialmente. Para Laurell (1976), a natureza social da doença não se verifica no caso clínico, mas no modo característico de adoecer e morrer dos grupos humanos, representados nos perfis patológicos que os grupos sociais apresentam ao longo dos tempos, como resultantes das transformações da sociedade. Os perfis patológicos, segundo a autora, são diferentes entre as várias sociedades, em função de seu grau de desenvolvimento e organização social, destacando-se que também há diferenças no interior de uma mesma sociedade, na qual os grupos sociais que a compõem mostrarão condições de saúde distintas a depender de sua inserção social (Laurell, 1976).

Autores como Laurell, Breilh, Samaja, dentre outros, advogam a relação entre a estrutura da sociedade e o processo saúde-doença, assentados nos pilares do materialismo histórico e dialético, o que possibilita entender esse processo mediado pelos determinantes sociais econômicos e políticos que são historicamente determinados. Ademais, esse entendimento contribui para evidenciar os fatores protetores e os prejudiciais à saúde que são decorrentes de uma determinada forma de organização social (Barata, 2005).

Uma tangente da Teoria da Determinação Social da Saúde-Doença e que recentemente tem sido progressivamente incorporada para explicar a influência destacada das condições sociais sobre a saúde-enfermidade, é a dos Determinantes Sociais da Saúde, primeiramente elaborada no Reino Unido e incorporada pela Organização Mundial da Saúde, em 2005. No Brasil, foi abraçada pela Comissão Nacional sobre os Determinantes Sociais da Saúde (CNDSS), definindo os DSS como fatores sociais, econômicos, dentre os quais, a renda, o emprego e a organização da produção, os ambientes de convivência e de trabalho; os fatores culturais, étnicos/raciais, psicológicos e comportamentais que influenciam positiva ou negativamente na saúde dos agrupamentos populacionais e nos fatores de risco (Buss, Pellegrini Filho, 2007; Campos, 2007). 
Conforme anteriormente explicitado, compreender os determinantes sociais do processo saúde-doença favorece a realização de ações para o cuidado apropriado e possibilita responder às necessidades de saúde, no âmbito da promoção, prevenção, tratamento e recuperação da saúde, potencializando a redução de vulnerabilidades e de iniquidades em saúde (Vernasque, 2011).

Assim, considerando o impacto das condições socioeconômicas sobre o processo saúde-doença e sobre a situação epidemiológica dos agravos, em particular, no caso da tuberculose e do diabetes mellitus, que mais e mais se encontram justapostas, e entendendo que ambas tem importante determinação social, re-enfatiza-se a questão do estudo: como a associação entre tais enfermidades tem sido explicada no âmbito da produção científica? Mais do que isso, se emergem aspectos sociais envolvidos nessa trama, como são explicitados pela literatura científica? 


\section{REVISÃO DA LITERAURA: ALGUNS ASPECTOS FUNDAMENTAIS SOBRE AS ENFERMIDADES EM QUESTÃO}

\subsection{A Tuberculose}

\subsubsection{Aspectos epidemiológicos}

Apesar de decorridos anos do descobrimento do agente e da terapêutica eficaz, globalmente, o diagnóstico, tratamento e controle da tuberculose ainda apresentam imensas dificuldades, o que a torna uma das enfermidades infecciosas mais prevalentes em todo o mundo, destacando-se que é endêmica em muitos países (Moutinho, 2011; CDC, 2012).

O mecanismo de transmissão da tuberculose ocorre por meio da disseminação do Mycobacterium tuberculosis (Mtb) pelo ar, de uma pessoa a outra, no caso da tuberculose pulmonar, que é a forma contagiosa e de maior prevalência. Isto ocorre no ato da tosse, espirro ou fala (CDC, 2012).

Um terço da população mundial está infectada, sendo que 5 a $10 \%$ adoecerão (CDC, 2013). Em 2011, aproximadamente 9 milhões de pessoas, em todo o mundo, adoeceu com tuberculose, a maioria das quais (82\%) vivia em um dos 22 países com maior incidência da TB, incluindo o Brasil (CDC, 2013). Nesse mesmo ano, cerca de 1,4 milhões de mortes decorrentes da doença ocorreram em todo o mundo (CDC, 2013.

Apesar da grande possibilidade de cura e dos progressos significativos para a sua eliminação, a TB continua a ser um problema urgente de saúde pública em muitas partes do mundo, particularmente nos países denominados "em desenvolvimento" (CDC, 2012; Santos Júnior e Pereira, 2011).

No Brasil, dados da Organização Mundial da Saúde (OMS), contidos no Relatório de Estatísticas Mundiais de Saúde, registram 85.000 casos, com Coeficiente de Incidência de 43,0 por 100 mil habitantes em 2010 (WHO, 2011). O número de óbitos por tuberculose, excluindo pelo HIV, 
representou 5.000 casos. Outros dados do mesmo ano estão expostos na Tabela 1.

Tabela 1. Dados sobre a TB no Brasil. 2012.

\begin{tabular}{|lll|}
\hline Mortalidade (exclui HIV+TB) & Número (milhares) & Taxa (por 10³ hab.) \\
\hline Mortalidade (HIV+TB) & $4.9(4.6-5.2)$ & $2.5(2.3-2.6)$ \\
\hline Prevalência (inclui HIV-TB) & $2.5(2.2-3$ & $1.3(1.1-1.5)$ \\
\hline Incidência (inclui HIV+TB) & $120(51-210)$ & $59(25-107)$ \\
\hline Incidência (HIV+TB) & $92(76-110)$ & $46(38-55)$ \\
\hline Detecção de casos, todas as formas (\%) & $82(69-99)$ & $8(6.6-9.5)$ \\
\hline
\end{tabular}

Fonte: (WHO, 2013 p. 107).

Quanto à classificação brasileira, no ranking de carga por $\mathrm{TB}$, segundo o Relatório Global de Controle da Tuberculose, o País ocupava a $16^{a}$ posição em número de casos em 2006 , passando para a $18^{a}$ posição em 2009 e para a 17 $7^{\text {a }}$ posição em 2013 (Arcêncio et al., 2011; CDC, 2012; Ministério da Saúde, 2013). Contribuem para o agravamento do quadro da TB no Brasil: a infecção pelo HIV, o empobrecimento da população e o sucateamento da rede pública de assistência à saúde (Ruffino Netto, 1997). Por outro lado, a melhora da posição é atribuída, em parte, ao próprio avanço do Sistema Único de Saúde (SUS) na redução das iniquidades em saúde, permitindo o acesso das populações em situação de vulnerabilidade social aos serviços de saúde (Arcêncio et al., 2011).

Em 2006, no intuito de intensificar o controle da tuberculose, a OMS, por meio do Programa Stop-TB, lançou o Plano Global de Controle da TB. Tal Plano estabelece metas para o controle da doença até 2015, as quais, para serem atingidas, responsabilizam o País a investir não somente em estratégias conhecidas, mas também em ações inovadoras, incluindo o desenvolvimento e a avaliação de novos meios e estratégias de controle, diagnóstico e tratamento, com a finalidade de erradicar a doença (Selig, 2011; Castro et al., 2011). 
Embora sejam inegáveis os avanços ocorridos no Brasil, em especial a partir de meados dos anos 2000, em relação à conjuntura econômica e social, a TB ainda é uma realidade, permanecendo como um dos maiores desafios às políticas de saúde pública. A doença tem agravado o estado de pobreza das populações de baixa renda nos países em desenvolvimento, com impacto na economia destes países, especificamente por incidir na faixa etária economicamente ativa, com grande possibilidade de gerar desempregos, sequelas e óbitos nesse estrato (Arcêncio et al., 2011). Entretanto, o outro lado também é fato, uma vez que as situações de pobreza e de iniquidade social determinam condições de vida e de acesso aos serviços de saúde com repercussões no processo saúde-doença.

O agravamento desta condição está posto na associação da TB com o HIV, ainda reconhecido por muitos autores como o principal fator de risco para o ressurgimento da TB em países desenvolvidos (Moutinho et al., 2011).

Mais recentemente, o diabetes mellitus tem se apresentado como importante fator de risco para o desenvolvimento da TB, com o risco de convergência entre as duas últimas epidemias (Selig et al., 2012).

\subsubsection{Aspectos imunológicos}

A propensão para desenvolver tuberculose é maior em pacientes com imunodeficiências. Estima-se que a TB ativa ocorra em 5-10\% das pessoas infectadas pelo Mtb. As outras pessoas conseguem impedir a infecção eficientemente na fase de latência, quando não é contagiosa, mas a infecção pode sofrer reativação anos mais tarde, resultando em doença ativa (Algoog, Chan, Flynn, 2003).

A imunidade celular é o principal mecanismo de defesa contra o Mtb, por intermédio do reconhecimento de antígenos por receptores de células da imunidade inata e adquirida (Swaminathan et al., 2000 apud Moutinho et al., 2011). Desta forma, as manifestações da doença dependem do balanço entre a virulência do microrganismo e a competência imunológica da pessoa (Moutinho et al., 2011), além de outras condições que levam à vulnerabilidade. O uso de drogas imunossupressoras, carências 
nutricionais e a infecção pelo HIV são as causas mais frequentes de multiplicação de bacilos enclausurados no granuloma de indivíduos infectados, com consequente adoecimento (Teixeira et al., 2007).

Alterações na produção de citocinas regulatórias, como ocorre em pacientes diabéticos, que apresentam baixa produção de IL-1 e IL-6; em indivíduos com leucemia mielocítica crônica, com baixa secreção de IL-1 e aumento de IL-10; nos coinfectados pelo HIV, com diminuição da produção de IL-8 e baixa capacidade fagocítica de neutrófilos, podem diminuir ou suprimir a resposta protetora e aumentar a susceptibilidade à infecção por patógenos intracelulares como o Mtb (Martinez et al., 2001).

O êxito na eliminação do Mtb depende da interação entre a resposta inata e a adquirida, em que participam inúmeras células e ampla rede de mediadores químicos. (Moutinho et al., 2011). A variedade da apresentação clínica e a localização pulmonar ou extrapulmonar da TB dependem da virulência do bacilo e do estado imunológico prévio do hospedeiro, que inclui o estado nutricional, enfermidades concomitantes, deficiências intrínsecas da resposta imunitária e fatores genéticos (Moutinho et al., 2011).

Estes dados não esgotam a complexa trama que envolve a relação imunidade e tuberculose, apenas promovem mais elementos para adensar a problematização do objeto. Assim, apresentam-se, a seguir, algumas informações relevantes a respeito do Diabetes Mellitus.

\subsection{O Diabetes Mellitus}

\subsubsection{Aspectos epidemiológicos}

Antes prevalente em países desenvolvidos, as doenças crônicas não transmissíveis (DCNT) representam, já há algumas décadas, grave preocupação nos países em desenvolvimento (Malfatti e Assunção, 2011). A mudança no perfil epidemiológico brasileiro destaca as DCNT entre as principais causas de morbimortalidade (Marinho et al., 2011). Dentre estas, encontra-se o diabetes mellitus (DM) representando, junto à hipertensão 
arterial (HAS), uma das principais causas de óbito em todo o País (Malfatti, Assunção, 2011).

O Diabetes Mellitus (DM) é doença metabólica, caracterizada por níveis elevados de glicose no plasma, resultante da baixa secreção de insulina, da resistência à sua ação periférica, ou de ambas (American Diabetes Association, 2004). Considerando-se o atual estágio da transição demográfico-epidemiológica, o DM, ao lado de outras enfermidades crônicas, tem sido considerado um importante problema de saúde na atualidade, evidenciado na prevalência, incidência e mortalidade prematura, como pelos custos envolvidos no controle e no tratamento de suas complicações, fato observado não apenas em países desenvolvidos como também em países em desenvolvimento (Moraes et al. 2010; Teixeira et al., 2011).

Dados da International Diabetes Federation (IDF, 2013) indicam que o número de pessoas no mundo, que vivem com DM, deverá aumentar de 382 milhões em 2013 para 592 milhões em 2035. Na América do Sul e Central, 25,1 milhões de pessoas tem diabetes e a região gasta US\$20,8 bilhões em ações que envolvem a enfermidade, o que constitui cerca de 4,5\% das despesas globais (IDF, 2012). Devido à contínua urbanização e mudanças na idade das populações, o contingente de pessoas acometidas deverá aumentar em cerca de 55\% até 2035 (IDF, 2013). Acresce-se a isso, os modos de vida das pessoas dos centros urbanos que revelam práticas alimentares inadequadas, sedentarismo, stress, dentre outros.

Análises de custo do tratamento do diabetes, em países latinoamericanos, demonstraram a significante carga econômica da doença para os sistemas de saúde e para as sociedades (Arredondo et al., 2005; Marinho et al., 2011).

Em algumas das regiões mais pobres do mundo como a África, onde as doenças infecciosas têm sido, tradicionalmente, o foco dos sistemas de cuidados de saúde, os casos de diabetes devem aumentar em 109,1\% até 2035 (IDF, 2013). Dentre os países da América Latina, o Brasil tem, proporcionalmente, o maior número de pessoas com diabetes: 12,4 milhões, seguido pela Colômbia, Venezuela e Argentina (IDF, 2012). 
Os números apresentados revelam a necessidade de intensidade nas ações de prevenção, diagnóstico precoce e tratamento para o controle do $\mathrm{DM}$, sendo este elemento de risco para outros agravos, que acarretam altos custos, tanto do ponto de vista social quanto econômico: para as pessoas acometidas e para o País (Marinho, et al., 2011). Dentre as ações de prevenção e controle da enfermidade, destacam-se, prioritariamente, o controle metabólico rigoroso, associado a medidas preventivas e curativas, além de intervenções na forma como as pessoas vivem, destacando-se a atividade física e o padrão dietético, dentre outras (Malfatti, Assunção, 2011; Moraes et al. 2010;).

Malfatti e Assunção (2011) ressaltam a existência de fatores que agravam e dificultam a implantação de programas de prevenção e combate ao DM e outras DCNT, como a desigualdade social, somada à dimensão continental do Brasil.

\subsubsection{Aspectos imunológicos}

$\mathrm{O}$ estado de DM leva à diminuição das imunidades celular e humoral, com defeitos na função dos leucócitos polimorfonucleares, na quimiotaxia, na fagocitose e na atividade bacteriana intracelular. Tais reações imunológicas induzem ao diabético maior suscetibilidade à diversos tipos de infecção, entre as quais, as infecções respiratórias. Disto resulta a vulnerabilidade aumentada das pessoas que apresentam DM à TB. Segundo estudo de Ponte et al. (2010), tal associação ocorre de duas a quatro vezes mais do que na população em geral.

A interação entre o DM e a TB ocorre, também, no que concerne à terapia medicamentosa, sendo bem estabelecido que a terapêutica da tuberculose tem efeito hiperglicemiante e dificulta o controle metabólico do paciente com diabetes. Por outro lado, o DM pode alterar a farmacocinética das drogas utilizadas para o tratamento da tuberculose (Ponte et al., 2010).

\subsubsection{A Obesidade e o Diabetes Mellitus}

A obesidade está associada à resistência à insulina e à síndrome metabólica, além de contribuir para a hipertensão, para a elevação do nível 
de colesterol e para o maior risco de doença cardiovascular (DCV) (Carr et. al., 2004). O aumento no Índice de Massa Corporal (IMC) está também associado à graves consequências de saúde, como o Diabetes tipo 2, a doença coronariana e outras condições. Acredita-se que 1,7 bilhões de pessoas no mundo já apresentem peso elevado, o que acarreta aumento dos custos em saúde e alto impacto econômico (IDF, 2011; Karlsson, Beck, 2011).

O mecanismo pelo qual o excesso de gordura corporal atue na resistência à insulina e reduza o metabolismo da glicose não está claramente definido, mas as reservas de gordura, em particular, o tecido adiposo, são importante causa de aumento de AGL (ácidos graxos lipossolúveis) e TG (triacilglicerol) no músculo esquelético, o que prejudica a secreção de insulina, elevando os níveis de glicose no sangue e a probabilidade de desenvolver DM (IDF, 2011). O excesso de tecido adiposo também libera citocinas inflamatórias que aumentam a resistência à insulina nos músculos esqueléticos do corpo.

Quanto à obesidade central, deve-se considerar sua associação com a diminuição da produção de adiponectina, que é a molécula de colágeno do tipo adiposo-específico, responsável pelas funções antidiabética, antiaterosclerótica e anti-inflamatória (Matzuawa et al., 2004).

Segundo o International Diabetes Federation (2011), 85\% dos indivíduos obesos tem algum grau de resistência à insulina, que pode ser melhorada com a perda de peso. A inatividade também desempenha um papel importante, através do mecanismo de GLUT-4 (transportador de glicose insulino-sensível), um produto químico que facilita a absorção de glucose por células, reduzindo seus níveis e tornando-a menos eficaz (IDF, 2011). A falta de exercício pode também aumentar os níveis de ácidos graxos livres no sangue, havendo intensificação do armazenamento de gordura visceral, ambos implicados na etiologia da resistência à insulina e, consequentemente, do DM (IDF, 2011).

Embora a obesidade esteja bem estabelecida como um fator de risco para o aumento da morbidade e mortalidade, dados os seus efeitos sobre o metabolismo e sobre o sistema cardiovascular, seu impacto sobre a 
susceptibilidade aos processos infecciosos está apenas começando a ser compreendido (Karlsson, Beck, 2011). Karlsson e Beck (2011) afirmam que a resposta imunitária diminuída no hospedeiro obeso conduz à maior susceptibilidade à infecção em um certo número de agentes patogênicos diferentes, como no caso, por exemplo, da tuberculose adquirida na comunidade, na gripe, entre outros.

Ao considerar a obesidade como um fator de risco grave para o desenvolvimento do DM, e a susceptibilidade que pode causar às doenças infecciosas, além de sua condição de epidemia global, evidencia-se a necessidade de monitoramento e de pesquisas no que tange à convergência destas epidemias e a epidemia de tuberculose. Ainda que o DM esteja associado ao sobrepeso e à obesidade, com possíveis implicações na associação TB-DM, o presente estudo não focalizará especificamente esta questão, mas não seria razoável deixar de mencioná-la.

\subsection{A Associação entre a Tuberculose e o Diabetes Mellitus}

A associação entre o DM e a TB foi reconhecida há séculos (Dixon, 2007; Dooley, Chaisson, 2009). Em livro de Richard Morton, publicado em 1694, afirmava-se que uma associação entre as duas condições foi sugerida ainda nos tempos romanos (Dixon, 2007). Especulações acerca desta associação foram eclipsadas pela descoberta da insulina na década de 1920 , pela descoberta da estreptomicina, em 1940, e com o posterior desenvolvimento de outros antibióticos, o que reduziu substancialmente as taxas de letalidade para os indivíduos com DM ou tuberculose (Dooley, Chaisson, 2009; Restrepo, 2009). Houve, ainda, diminuição acentuada da incidência da TB, em consequência da melhoria de certas condições para certos grupos sociais, como saneamento, nutrição, e redução da aglomeração de populações (Dooley, Chaisson, 2009).

A tuberculose é importante problema em países de baixa renda, em que a mortalidade é alta, e evidencia sua íntima relação com a pobreza e a falta de acesso aos serviços de saúde. O DM tipo 2 emergiu como um problema crônico de saúde crescente em todo o mundo, mais recentemente, 
como consequência do aumento da obesidade, fruto da alteração dos padrões de dieta e atividade física e do envelhecimento populacional (Dooley, Chaisson, 2009). Para Dooley e Chaisson (2009), o efeito do diabetes, no desenvolvimento e na gravidade da tuberculose, e as interrelações complexas entre alimentação, obesidade, diabetes e tuberculose continuam a ser questões provocativas em saúde pública e na clínica. A crescente industrialização e urbanização tem levado ao aumento substantivo das taxas de obesidade e diabetes. Ademais, é fundamental considerar que as condições sociais e econômicas influenciam fortemente as opções de tratamento. Particularmente nos países de baixa e média renda, onde as altas taxas de tuberculose permanecem, há preocupação de que o DM tipo 2 represente uma ameaça ao controle global da TB (Dooley, Chaisson, 2009; Gonzales-Curiel, 2011;).

Ao considerar-se a associação clínica e/ou imunológica, constatamse evidências científicas de que o diabetes é fator de risco importante para a tuberculose ativa. Desta forma, tendo em vista as deficiências imunológicas encontradas nos portadores de DM e sua propensão à infecção por uma ampla gama de agentes patogênicos, incluindo-se o Mycobacterium tuberculosis, afirma-se que a incidência da TB é duas a cinco vezes maior em pacientes com DM do que naqueles sem diabetes (Gonzales-Curiel, 2011). De fato, estudos têm apontado para um impacto significativo do diabetes sobre a tuberculose: dados mostram consistentemente que a razão de chances de ter DM tipo 2, em pacientes com tuberculose ativa, varia de 1,3 a 7,8 vezes, indicando que o diabetes aumenta o risco de desenvolver tuberculose. Embora o risco do adoecimento por tuberculose seja menor, individualmente, para o diabetes, em comparação com a AIDS (113-170 vezes), os números absolutos de pacientes com diabetes têm um efeito igual ou maior na população, com consequências no âmbito da saúde pública (Restrepo, 2007).

O risco relativo para o desenvolvimento de tuberculose pulmonar é multiplicado por 3,47 e 5,15, respectivamente, no caso de todas as formas clínicas e no caso de formas bacteriologicamente confirmadas em pacientes 
diabéticos, em comparação com controles (Kim et al., 1995 apud Sibedé, 2007).

Para alguns autores, a prevalência de tuberculose em pacientes diabéticos é maior em homens do que em mulheres, de forma significativa, principalmente em homens com 40 (22\%) e 30 (21,3\%) anos, em comparação a outros grupos de idade (Ymaguchi et al., 1996 apud Sibedé, 2007).

Sibedé (2007) destaca a presença de evidências epidemiológicas de que o diabetes mellitus é uma das primeiras circunstâncias que promovem alta incidência de formas ativas de tuberculose pulmonar grave, o que justifica a importância do diagnóstico precoce (Sibedé, 2007).

Por outro lado, Restrepo (2007) aponta para a dificuldade de interpretar, a partir do que vem sendo publicado, o efeito da DM tipo 2, na apresentação clínica da tuberculose, bem como na resposta ao tratamento. Segundo este autor, vários estudos indicam que pacientes com tuberculose e diabetes apresentam maior carga bacilar no escarro, e taxas mais elevadas de resistência de TBMR. O autor recorre a esses estudos que indicam que pacientes com tuberculose e diabetes podem apresentar maior gravidade na evolução da tuberculose e representam maior risco de propagação de micobactérias, principalmente as fármaco-resistentes, na comunidade (Restrepo, 2007).

A inter-relação imunológica entre o DM e a tuberculose também pode ser esclarecida através do estudo de Sibedé (2007). Neste, o autor relata que a susceptibilidade de portadores de DM à infecção por tuberculose, está relacionada à deficiência funcional de leucócitos polimorfonucleares (Chea et. al., 1985 apud Sidebé, 2007). Há, também, uma diferença no perfil de secreção de citocinas entre os pacientes com tuberculose e diabetes, sugerindo-se a presença de um mecanismo imunológico que favorece a patogênese da tuberculose (Tsukaguchi et al., 1997 apud Sidebé, 2007). A produção de IL-1 beta, TNF alfa e IL-6, em pacientes com tuberculose, é significativamente mais elevada do que a observada em indivíduos saudáveis. Em pacientes com tuberculose e diabetes, as taxas de produção de tais elementos são mais baixas do que as 
observadas em pacientes que têm apenas TB. Além disso, a produção de IL1 beta e TNF alfa, em pacientes com tuberculose e diabetes, com controle glicêmico, está inversamente correlacionada à hemoglobina glicada (Tsukaguchi et al., 1992 apud Sibedé, 2007).

$\mathrm{O}$ autor aponta outro aspecto importante, que se refere ao fato de que pesquisas clínicas demonstraram que retinopatias estavam presentes em $52 \%$ dos pacientes com diabetes e tuberculose. Prossegue, ainda, relatando que muitos estudos mostram um espessamento da membrana basal epitelial alveolar e capilar pulmonar e diminuição da elasticidade do pulmão, nos pacientes que apresentam a associação TB-DM e, outros, mostram anormalidades funcionais e o desenvolvimento de alterações histopatológicas que levam à redução da capacidade de difusão e elasticidade pulmonar (Sibedé, 2007).

Diante das evidências da associação entre a TB e o DM, postas nos estudos mencionados, destaca-se a sua relevância, no que diz respeito aos Objetivos de Desenvolvimento do Milênio da ONU, que apontam a necessidade de redução da taxa de mortalidade por tuberculose, além de melhorar a sua detecção e tratamento até 2050 (WHO, 2012). O impacto do diabetes sobre a tuberculose é, portanto, já significativo, e as previsões de uma epidemia de diabetes sugerem um aumento na incidência desta associação (Stevenson, 2007). 


\section{PERGUNTA E HIPÓTESE DO ESTUDO}

Diante do que foi apresentado e, conforme sugerido no referencial teórico do presente estudo, pensar a associação entre doenças infecciosas, à exemplo da Tuberculose, e Doenças Crônicas Não Transmissíveis (DCNT), como o Diabetes Mellitus, requer a análise da rede de causalidade destas enfermidades. Isto porque é fato a relação entre as condições sociais e a Tuberculose. Também o DM apresenta, progressivamente, elementos que possibilitam o entendimento de que é enfermidade socialmente mediada, mas o que ocorre quando a TB e o Diabetes Mellitus encontram-se associadas? Como a literatura científica vem explicando tal associação? Quais são as tendências da produção da literatura científica, considerando-se o espaço e o tempo?

Destaca-se a importância de analisar o que está sendo produzido mundialmente a respeito desta associação, em especial, buscando-se identificar se a literatura científica expõe a determinação social quando estas enfermidades encontram-se associadas.

Tem-se como hipótese, o fato de que os processos sociais, dentre os quais, o modo de produção predominante e os processos decorrentes, como a intensa industrialização e urbanização, além dos processos econômicos vigentes, dentre outros, acabam por determinar a configuração de distintos grupos sociais com distintos acessos ao consumo e às possibilidades de enfrentamento dos processos de desgaste, com repercussões importantes sobre os modos de vida e de saúde-doença, com consequências para a assunção da associação da tuberculose com o diabetes mellitus.

Diante dessas considerações apresenta-se como hipótese deste estudo:

- Ainda que na prática cotidiana constate-se que aspectos sociais estão substantivamente envolvidos na associação entre tuberculose e diabetes mellitus, não se verifica correspondente desenvolvimento na abordagem científica.

Este estudo, portanto, visa identificar como se apresenta a literatura científica, quando procede à abordagem da associação entre a TB e o 
DM, acreditando-se que proveria de elementos para ampliar a interpretação dessa associação e a concomitante resposta em termos de intervenções apropriadas em saúde. 


\section{OBJETIVOS}

\subsection{Objetivo Geral}

Analisar como a literatura científica tem apresentado a associação entre

o Diabetes Mellitus tipo II e a Tuberculose, no período de 2000 a 2012.

\subsection{Objetivos Específicos}

a. Identificar o caráter das abordagens: clínica, farmacológica, imunológica ou epidemiológica;

b. Identificar, na produção analisada, as causas da ocorrência da comorbidade.

c. Identificar, na produção que apresente aspectos sociais envolvidos, como estes se explicitam. 


\section{METODOLOGIA}

\subsection{Delineamento do estudo}

Trata-se de estudo de Revisão Integrativa (RI) empírica.

As revisões de literatura consistem em modo organizado de revisão das evidências sobre um tema, caracterizando-se por ser uma pesquisa científica em bases de dados bibliográficas de textos científicos (Pereira, 2011). Como métodos de revisão mais conhecidos tem-se: revisões sistemáticas, metaanálises, metassíntese, revisão integrativa.

Acredita-se que métodos de revisão como as revisões sistemáticas e as meta-análises, embora importantes para a prática baseada em evidências, não abrangem a profundidade e amplitude da pesquisa em enfermagem, por exagerarem no julgamento clínico randomizado e na hierarquização de evidências (Torraco, 2005; Whittemore, Knafl, 2005). As revisões sistemáticas podem ser consideradas limitadas a certos escopos de pesquisa, pois sua metodologia permite apenas a análise através da integração de resultados de estudos estruturados de maneiras semelhantes. Na metasíntese há integração de estudos qualitativos e, na metanálise, a integração de estudos quantitativos.

Em contraste a estes métodos, as revisões integrativas permitem a análise, a crítica e a síntese de estudos primários, com o objetivo de contribuir para o desenvolvimento de teorias, e de novas perspectivas sobre o tema pesquisado, tendo aplicabilidade direta para a prática e para o estabelecimento de políticas (Torraco, 2005; Whittemore, Knafl, 2005). A revisão integrativa permite a inclusão de diversas metodologias de pesquisa (experimental e não-experimental) e contribui para a apresentação de perspectivas variadas sobre um fenômeno de interesse (Whittemore, Knafl, 2005).

A amplitude do método de revisão integrativa não a exime da responsabilidade sobre o rigor metodológico e na análise. Nessa abordagem, a transparência e o rigor metodológico são elementos que orientam os estudos, além de delimitação conceitual acerca do fenômeno de pesquisa. Para alcançar o rigor metodológico, aplicam-se estratégias para evitar 
vieses, limitar distorções em pontos potencialmente vulneráveis das revisões tradicionais, e objetivar reunir resultados e conclusões da forma mais objetiva possível (Pereira, 2011; Jadad, Cook, Browman, 1997).

Além de permitir a combinação de dados teóricos e de literatura empírica, esta metodologia de revisão pode incorporar uma ampla gama de propósitos: definir conceitos, rever teorias, analisar evidências e analisar assuntos metodológicos de um determinado tópico (Whittemore, Knafl, 2005). Para tanto há a necessidade de se basear a revisão em um referencial teórico (Jackson, 1980; Torraco, 2005).

Ao definir os objetivos do artigo, as revisões integrativas analisam o fenômeno de interesse através de uma ótica pautado no referencial teórico, o que direcionará o leitor para aspectos específicos da pesquisa primária, que serão criticamente examinados e avaliados. Como resultado, a revisão deve propiciar a descrição dos achados, analisando-se criticamente a literatura e chegando-se a conclusões específicas sobre o assunto (Torraco, 2005).

A revisão integrativa empírica consiste em revisão crítica de estudos empíricos quantitativos e/ou qualitativos sobre um tema particular e com análise de resultados e relação entre variáveis (Whittemore, Knafl, 2005).

Etapas da revisão integrativa

A revisão integrativa da literatura deve ser orientada por critérios confiáveis, previamente estabelecidos pelos pesquisadores, que são os mesmos de uma investigação científica tradicional. De maneira simplificada, uma revisão integrativa é sistematizada nas etapas: identificação da questão de pesquisa e do objetivo; busca extensiva de literatura, avaliação dos artigos primários, análise dos artigos primários e apresentação dos resultados (Torraco, 2005; Whittemore, Knafl, 2005).

A Figura 1 ilustra as etapas de uma revisão integrativa. 
Figura 1. Descrição geral sobre o processo de revisão integrativa (Torraco, 2005;

Whittemore, Knafl, 2005).

\section{Estágio 1 - Identificação da questão de pesquisa}

Identificação clara do problema e do propósito da revisão. Estruturação conceitual coerente ao tópico. Requer adoção de uma teoria de orientação ou de um ponto de vista sobre o assunto. Determinar neste estágio, o método e as variáveis de interesse.

\section{Estágio 2 - Busca extensiva de literatura}

Identificar as bases de dados a serem consultadas; definir palavras-chave e estratégias de busca. Buscar o máximo de artigos primários elegíveis. Estabelecer critérios para a seleção dos artigos a partir da busca: delimitação de tempo; desenhos de estudo; população, tratamento, intervenção ou desfecho de interesse.

Seleção dos artigos em acordo com critérios previamente determinados, justificar possíveis exclusões.

\section{Estágio 3 - Avaliação dos artigos primários}

Extrair dados comuns nos estudos primários, se possível, por observadores independentes, para análise crítica subsequente. Procedimentos de análise válidos e confiáveis são essenciais para garantir o rigor metodológico.

\section{Estágio 4 - Análise dos artigos primários}

Síntese e análise narrativa dos resultados. Neste estágio deve-se ordenar, categorizar e resumir os dados dos estudos primários individualmente, de acordo com o problema de pesquisa. Os dados codificados de cada estudo devem ser comparados por similaridades ou diferenças, de acordo com as varáveis e interesse.

\section{Estágio 5 -Apresentação dos resultados}

Interpretação e apresentação dos resultados segundo padrão próprio, que pode ser um sumário (apresentação descritiva que diferencia os achados por categorias ou temas), análise ou síntese (criação de um novo modelo para o tema de interesse. .

\subsection{Questão de estudo}

No delineamento do presente estudo foi definida como pergunta: 
- Quais as tendências na abordagem da associação entre tuberculose e diabetes mellitus, considerando o período de 2000 a 2012 ?

\subsection{Etapas do estudo}

O estudo está dividido em duas etapas.

6.3.1 Etapa 1 - Pesquisa exploratória para identificar o estado da arte e orientar o estudo e verificar a possibilidade de se realizar uma revisão sistemática. Para serem incluídos nessa primeira busca, os estudos deveriam apresentar resumo em inglês e estar escritos em português, inglês, espanhol, italiano ou francês. Nos casos em que o título e o resumo não foram suficientes para definir a primeira seleção, a publicação na íntegra foi buscada. Nesta etapa, que se refere à pesquisa exploratória, foram incluídos estudos publicados nos cinco anos antecedentes à pesquisa, compreendendo o período entre janeiro de 2007 e dezembro de 2011.

No que se refere ao conteúdo teórico, os estudos deveriam abordar a associação entre tuberculose e diabetes mellitus como foco principal. Quanto à metodologia, foram incluídos todos os tipos.

6.3.2 Etapa 2 - A segunda etapa envolveu a incorporação e análise da totalidade das produções com vistas a atingir os objetivos. Contemplou os estudos publicados de 2000 a 2012. Estipular um intervalo de tempo justifica-se pela restrição de tempo para a elaboração da presente pesquisa, o que limita a abrangência na investigação. Determinar estudos publicados a partir do ano 2000 teve por justificativa a maior relevância epidemiológica do DM a partir dessa época, resultando em maior número de publicações referentes à associação a partir desde período. A restrição da década anterior deu-se também pela dificuldade de acesso aos artigos publicados, bem como restrição de idioma de publicação, visto que a maioria dos artigos encontrados em busca referente à década de 1990 foram publicados em idiomas não incluídos nos critérios de inclusão desta pesquisa, como chinês, russo, japonês e ucraniano. 


\subsection{Critérios de inclusão}

- artigos com resumo em inglês e escritos em português, inglês, espanhol, italiano ou francês. Nos casos em que o título e o resumo não foram suficientes para definir a primeira seleção, a publicação na íntegra foi buscada.

- quanto ao conteúdo teórico, deveriam abordar a associação entre tuberculose e diabetes mellitus como foco principal do estudo. Todos os tipos de desenho de pesquisa foram incluídos.

\subsection{Critérios de exclusão}

Os critérios de exclusão a seguir são válidos para ambas as etapas do estudo.

- estudos que se referiam apenas ao Diabetes mellitus tipo I, determinado predominantemente por fatores genéticos;

- estudos que tinham crianças como sujeitos da pesquisa;

- estudos que tiveram a TB primeiramente e a DM como decorrência;

- estudos que considerassem a coexistência de DM e HIV;

- estudos que tratavam de tuberculose multi-resistente (TBMR)

- estudos que tratavam de tuberculose extrapulmonar.

- artigos duplicados de pesquisas previamente publicadas;

- estudos que não apresentassem resumo e cujo texto na íntegra não estivesse disponível;

- estudos nos quais o título não deixava clara a associação entre a TB e o DM e cujo resumo e texto na íntegra não estivessem disponíveis.

\subsection{Tipos de participantes}

A revisão não teve como foco um grupo particular de participantes.

\subsection{Fenômenos de interesse}

O fenômeno de interesse é a abordagem da associação e identificação de como se evidencia na literatura a explicação da apresentação da tuberculose e diabetes mellitus, com destaque para a explicação das enfermidades baseada na determinação social da saúde-doença. 


\subsection{Estratégias de busca para a identificação dos estudos}

Para verificar se uma revisão sistemática sobre a mesma temática está sendo realizada ou já foi concluída por outros pesquisadores realizou-se, na Etapa 1, uma busca prévia de artigos na base de dados LILACS e no portal MEDLINE/PubMed. As bases de dados do Joanna Briggs Institute e da Biblioteca Cochrane também foram verificadas, com a finalidade de averiguar a existência de revisões sistemáticas publicadas ou protocoladas. Para a Etapa 2, foram incluídas as bases de dados CINAHL, Web of Science e a biblioteca digital Dedalus (USP).

O Quadro 1 descreve as estratégias de busca utilizadas em cada base de dados. A estratégia de busca foi realizada segundo a lógica booleana, ou seja, vinculando as palavras determinadas (ex. "tuberculosis", "diabetes mellitus") a operadores como AND e OR, que indicam a relação desses conceitos entre si.

Quadro 1 - Bases de dados incluídas na busca bibliográfica, de acordo com a área de conhecimento, período de análise e tipo de publicação. São Paulo, 2013.

\begin{tabular}{|c|c|c|}
\hline Base de dados & \multicolumn{2}{|c|}{ Descrição } \\
\hline \multirow[b]{2}{*}{ CINAHL [www.cinahl.com] } & Áreas: & $\begin{array}{l}\text { Tipo de } \\
\text { publicação: }\end{array}$ \\
\hline & $\begin{array}{l}\text { Enfermagem e } \\
\text { saúde relacionadas } \\
\text { à: educação em } \\
\text { saúde, terapia } \\
\text { ocupacional, } \\
\text { serviço social na } \\
\text { atenção à saúde. }\end{array}$ & $\begin{array}{l}\text { Artigos, relatórios } \\
\text { técnico-científicos. }\end{array}$ \\
\hline DEDALUS [http://dedalus.usp.br] & $\begin{array}{ll}\text { Engloba todas } & \text { as } \\
\text { áreas } & \\
\text { conhecimento. } & \end{array}$ & 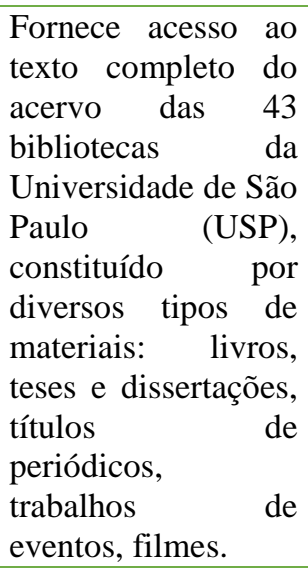 \\
\hline LILACS [www.bireme.br] & Ciências da saúde & Teses, capítulos de \\
\hline
\end{tabular}




\begin{tabular}{|l|l|l|}
\hline & $\begin{array}{l}\text { no âmbito da } \\
\text { América Latina e } \\
\text { do Caribe. }\end{array}$ & $\begin{array}{l}\text { teses, livros, } \\
\text { capítulos de livros, } \\
\text { anais de congressos } \\
\text { ou conferências, } \\
\text { relatórios técnico- } \\
\text { científicos e } \\
\text { publicações } \\
\text { governamentais. }\end{array}$ \\
\hline MEDLINE/Pubmed [www.pubmed.gov] & Ciências da vida. & $\begin{array}{l}\text { Artigos, periódicos. } \\
\text { Web of Science [apps.webofknowledge.com] }\end{array}$ \\
$\begin{array}{l}\text { Todas as áreas do } \\
\text { conhecimento. }\end{array}$ & Periódicos. \\
\hline
\end{tabular}

\subsection{Seleção e avaliação da qualidade dos estudos}

A primeira etapa do estudo contou com um revisor para a seleção dos estudos encontrados. Após avaliação dos títulos e dos resumos (abstracts), obedecendo aos critérios de inclusão e exclusão, foram selecionados os artigos. Para artigos que não dispunham do resumo ou que o título ou resumo não deixassem claro o objetivo do estudo, o artigo foi buscado na íntegra.

$\mathrm{Na}$ segunda etapa foi realizada leitura dos artigos selecionados e posterior análise. Os artigos foram separados por ano de publicação, tipo de estudo, idioma de publicação, local do estudo e enfoque de abordagem.

A descrição do enfoque foi feita com elementos advindos de área de metodologia de pesquisa e com base na descrição de desenhos epidemiológicos (Pereira, 2011; Medronho, 2008):

- Apresentação Clínica - pesquisas relacionadas ao âmbito clínico ou às características clínicas, apresentação clínica ou fisiopatológica, sinais e sintomas, desfecho do tratamento. Pesquisas realizadas com seres humanos ou em animais.

- Farmacológico - pesquisas abordando aspectos farmacológicos, bioquímicos e moleculares, relacionadas também à associação entre o tratamento de pacientes com TB e DM, bem como à interação medicamentosa ou desfecho do tratamento, quando relacionado à droga. Pesquisas realizadas com seres humanos ou em animais. 
- Imunológico - pesquisas relacionadas ao âmbito citopatológico, patofisiológico ou microbiológico, que abordam aspectos imunológicos. Pesquisas realizadas com seres humanos ou em animais.

- Epidemiológico - estudos de investigação da relação entre TB e DM; estudos de prevalência, estudos de incidência.

- Social - abordagem dos determinantes sociais, correlacionando aspectos socioeconômicos, culturais, determinantes individuais.

No que concerne ao enfoque epidemiológico, a distinção entre abordagem social se faz seguindo o seguinte conceito:

Se distingue por investigar explicitamente os determinantes sociais do processo saúde-doença. O que distingue a epidemiologia social das outras abordagens epidemiológicas não é a consideração de aspectos sociais, pois, bem ou mal, todas reconhecem a importância desses aspectos, mas a explicação do processo saúde-doença. Tratase portanto de uma distinção no plano teórico (Barata, 2005).

A categorização dos estudos em enfoques levou em consideração os objetivos da presente investigação e a principal tônica da discussão.

Tendo em vista o entendimento de que ambas as enfermidades são admitidas, a priori, pela pesquisadora, no estudo, como fortemente determinadas pelos fatores sociais, as investigações que apresentavam indícios ou aproximações com essa leitura foram destacadas como enfoque epidemiológico social.

\subsection{Analise dos estudos}

A análise dos estudos primários foi realizada através leitura na íntegra das publicações.

\subsubsection{Comparação de estudos primários}

Como sistema de comparação dos estudos foram utilizados dois parâmetros: o objetivo e a discussão das pesquisas. Secundariamente, a estrutura metodológica (variáveis, população), bem como a caracterização do contexto em que cada estudo foi realizado, foram considerados. Cada uma destas estruturas foi codificada de acordo com a tônica dada à pesquisa. 
$\mathrm{Na}$ metodologia procurou-se analisar quais as variáveis foram consideradas e se entres estas os determinantes sociais de saúde estavam presentes. A população de estudo, bem como o local onde estava inserida, também foram considerados.

$\mathrm{Na}$ discussão dos estudos observou-se a correlação estre os resultados e a tônica dada à apresentação dos mesmos. Se os resultados encontrados ou se as variáveis consideradas foram considerados sob uma ótica social da associação ou com maior direcionamento para os outros enfoques.

A integração dos resultados (de busca, da seleção e de análise) destes estudos se deu por classificação dos enfoques.

\subsection{Aspectos éticos}

A presente pesquisa assegura os aspectos éticos, garantindo a autoria dos artigos pesquisados, utilizando para citações e referências, as normas da Associação Brasileira de Normas Técnicas (ABNT). 


\section{ANÁLISE DESCRITIVA DOS RESULTADOS DOS ESTUDOS PRIMÁRIOS SEGUNDO O ENFOQUE}

Foram identificados e selecionados 352 publicações por títulos e resumos, dos quais 239 foram excluídas por não estudar a associação entre tuberculose e diabetes, ou por não contemplarem os critérios de inclusão.

$\mathrm{Na}$ busca utilizando-se os descritores MeSH 1. tuberculosis and 2. diabetes mellitus, na base Pubmed/ MEDLINE foram encontrados 649 publicações correspondentes aos anos de 2000 a 2012, sendo selecionados 186 resultados por título ou resumo. Na base Web of Science, de 343 publicações foram selecionadas 130 por título ou resumo. Na base CINAHL de 103 resultados, 32 foram selecionados por título ou resumo. No Lilacs foram 19 resultados, sendo selecionados 3 por título e, no DEDALUS USP, de 11 resultados, apenas 1 foi selecionado por título. Desta forma somaramse 352 artigos nesta primeira etapa.

Nesta primeira etapa da pesquisa, referente à primeira análise dos estudos, foram excluídas 239 publicações por não se enquadrarem nos critérios de inclusão: 12 estudos publicados em russo; 9 estudos publicados em chinês; 6 estudos publicados em japonês; 4 publicados em ucraniano e 1 estudo publicado em sérvio; 32 por conteúdo; 78 duplicados, 17 triplicados e 3 quadruplicados; 2 por formato da publicação. Estudos que não apresentavam resumo, o artigo na íntegra não estava disponível ou que não estavam disponíveis pelo Virtual Private Network (VPN) da Universidade de São Paulo (USP) foram 52.

Para a segunda etapa do estudo, que compreendeu análise mais aprofundada das 113 publicações restantes, 37 artigos foram excluídos por conteúdo, sendo que: 2 por referirem-se ao DM tipo 1; 2 por referirem-se à TBMR; 7 por referirem-se à TB extrapulmonar; 12 por não tratarem da associação TB-DM como foco principal; 3 por tratarem a associação inversa; 3 por não distinguirem entre DM tipo 1 ou DM tipo 2; 1 por tratar a coexistência DM-HIV, 4 por não possuírem metodologia descrita; 13 revisões de literatura; e 3 estudos duplicados. 
Figura 2 - Esquema de apresentação dos resultados.

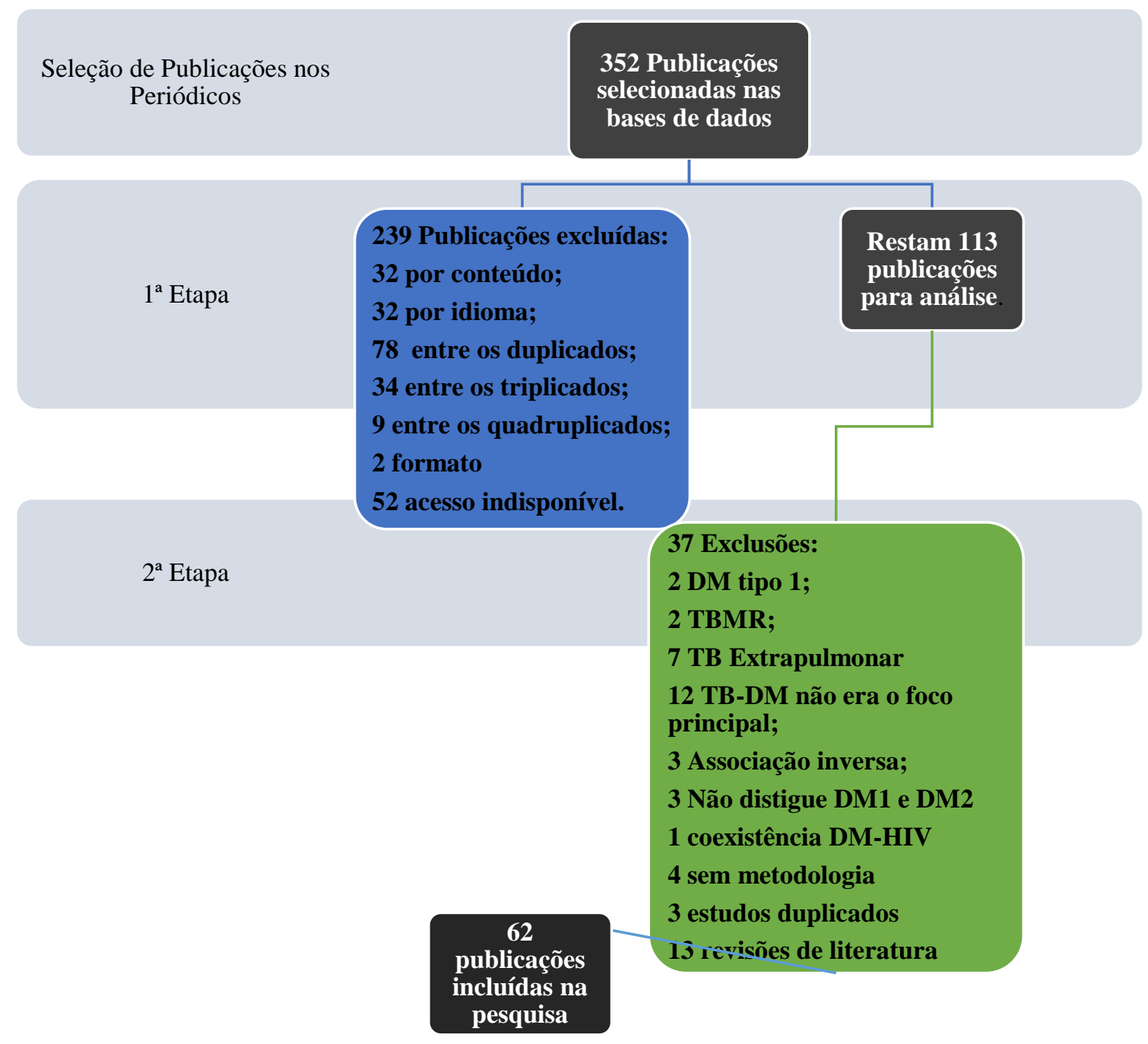

Os 62 estudos incluídos na análise foram analisados por ano de publicação e principal abordagem do estudo. Para tanto, foram classificados em enfoque farmacológico, imunológico, apresentação clínica ou epidemiológico.

O quadro de apresentação dos resultados, classificando-os por ano de publicação, autor, procedência, idioma, local do estudo, enfoque e respectivos resumos, encontra-se no Apêndice A.

Das 62 publicações incluídas na pesquisa, 16 foram classificadas com enfoque imunológico, 7 com enfoque farmacológico, 14 com enfoque de apresentação clínica e 25 com enfoque epidemiológico. 
Quanto à classificação em enfoque epidemiológico social, 5 estudos epidemiológicos e 1 estudo farmacológico, foram classificados com este enfoque.

Os estudos de revisão de literatura não foram considerados na apresentação de resultados, porém, por terem sido considerados importantes para a discussão desta pesquisa, foram igualmente classificados e apresentados em forma de tabela no Anexo 2.

Figura 3 - Esquema de apresentação dos resultados por enfoque.

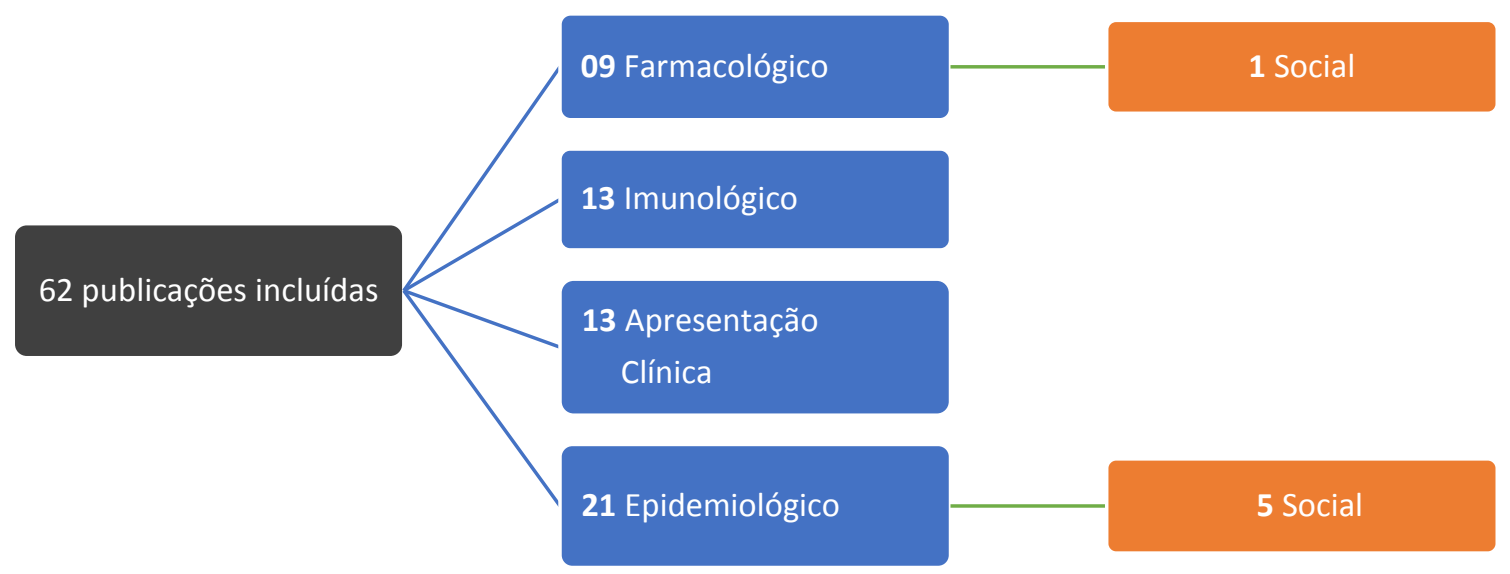

Os estudos primários foram agrupados segundo categoria de enfoque, conforme segue.

\subsection{Enfoque Imunológico}

O objetivo predominante, entre os estudos classificados com enfoque imunológico, foi o de verificar a suscetibilidade de indivíduos com diabetes mellitus (DM) em adquirir infecção por tuberculose (TB), ocorrendo em 6 dos 15 estudos com este enfoque. Com este objetivo, Suguwara, Yamada e Mizuno (2004) realizam um estudo experimental em animais para verificar se ratos diabéticos $\mathrm{GK} / \mathrm{Jcl}$ são mais suscetíveis à infecção por Mycobacterium tuberculosis $(M t b)$ do que ratos não-diabéticos. Os ratos diabéticos foram infectados com $M t b$ por aerossóis e foi avaliada sua capacidade de controlar o crescimento de micobactérias, formação de granulomas, secreção de citocinas pelos macrófagos alveolares e óxido 
nítrico (NO). O mesmo foi realizado por Yamashiro et al. (2005) e Vallerskog, Martens e Kornfeld (2010), só que utilizando-se de modelo de ratos murinos, nos quais o DM foi induzido pela administração de estreptozotocina (STZ). Os resultados de ambos os estudos foram semelhantes: no primeiro ocorreu o desenvolvimento de grandes granulomas nos pulmões, fígado ou baço, o que é consistente com um aumento significativo no número de unidades formadoras de colônias de $M t b$ nos pulmões $(\mathrm{p}<0,01)$. Tal aumento de colônias foi visto também no fígado e baço dos ratosdo segundo estudo. Os níveis de expressão INF- $\gamma$, TNF-alfa e IL-12 foram menores nos ratos diabéticos GK/Jcl, bem como nos ratos murinos, do que nos controles.

Agregadores de leucócitos foram encontrados nos locais de infecção em ratos diabéticos, em estudo de Vallerskog, Martens e Kornfeld (2010). As células do baço de ratos murinos diabéticos infectados com Mtb produziram quantidade significativamente menor de IFN- $\gamma$, após reestimulação com derivados da proteína purificada (PPD) nos ratos não diabéticos infectados (Yamashiro et al., 2005). Nestes ratos murinos, o controle dos níveis de glicose no sangue, por terapia com insulina, resultou em melhora da proteção do hospedeiro e síntese de citocinas Th1relacionadas. A resistência do hospedeiro contra a infecção por $M t b$ foi diminuída, e foi associada à redução da produção de citocinas Th1relacionadas, incluindo IL -12 e IFN- $\gamma$, e NO e anomalias no desenvolvimento de células Th1 (Yamashiro et al., 2005). Os estudos demonstraram estreita associação entre a TB experimental e a DM em animais, além de fornecerem evidências sobre o mecanismo de resistência do hospedeiro à infecção atenuada de $M t b$ em hospedeiros com DM, demonstrando a produção reduzida de IL -12 e IFN- $\gamma$ e a expressão de iNOS prejudicada nos tecidos infectados (Sugawara, Yamada, Mizuno, 2004; Yamashiro et al., 2005).

Estudo de Arce-Mendoza et al. (2008), diferentemente dos anteriores, foi realizado em indivíduos, e a expressão de CD64, CD206 e do receptor AGE (RAGE) foi medida em células aderentes (CA), derivadas de monócitos do sangue periférico de pacientes com DM2, infectados com $M t b$ 
(DMTB). Estes foram comparados com pacientes com TB isolada (PTB) e com um grupo controle, com a finalidade de descrever se o DM contribui para o aumento da suscetibilidade ao $M t b$ no nível destes receptores. Quando o DMTB foi comparado ao PTB, ocorreu diminuição significativa na expressão RAGE. O DM afeta a expressão dos três receptores. (ArceMendoza et al., 2007).

Stalenhoef et al. (2008) testou, também em humanos, que a hipótese de suscetibilidade é devida a defeito na resposta da citocina Th1 pró e antiinflamatória. Quatro grupos de indivíduos foram analisados na Indonésia: com TB, com DMTB, com DM e controles saudáveis. Produção ex-vivo de INF-y, fator de necrose tumoral-alfa (TNF) e interleucina (IL)-1beta, 6, 10, 12 e -4 foram medidas, após estimulação com o $M t b$. Em doentes com TB ativa foram detectados níveis baixos de IFN- $\gamma$ e aumento da produção de outras citocinas pró-inflamatórias e IL-4, ambos na presença e na ausência de DM2. Os doentes com DM2 sem TB mostraram produção de IFN- $\gamma$ não específica fortemente reduzida, resultado essencial para a inibição do crescimento inicial de $M t b$. Pode-se supor que a redução da produção de IFN-y não específica no DM tipo 2 contribui para o aumento da suscetibilidade para desenvolver TB ativa (Stalenhoef et al., 2008). Na mesma linha de Stalenhoef et al. (2008), Restrepo et al. (2008) testou, na fronteira entre o sul do Texas e o norte do México, a hipótese de que um grupo de pessoas com DMTB, em comparação a pacientes PTB, apresentariam respostas alteradas de níveis de citocinas inata e adaptativa, secretadas em resposta à estimulação in vitro com derivado protéico purificado de $M t b$. Foram consideradas características sóciodemográficas (idade, sexo, país de Origem - EUA ou México, duração do tratamento, presença de vacina de BCG, presença de DM, presença de hiperglicemia, valor de IMC), achados clínicos e DM auto-relatada, não havendo diferenças em relação às características sócio-demográficas e os sintomas de TB. Mostrou-se que, entre os pacientes com TB, havia diferenças nas respostas de citocinas inatas e celulares da estimulação com PPD de $M t b$, que são associadas ao DM (Restrepo et al., 2008). 
Em 2012, QU et al. (2012) realizam, também na fronteira dos EUA com o México, onde altas taxas de DM e TB são encontradas, estudo longitudinal de DM, tendo sido investigada a expressão de genes em indivíduos mexicanos-americanos notificados com TB. Dois genes, HK2 e CD28, surgiram como possíveis responsáveis pelo aumento da suscetibilidade à TB em pacientes diabéticos, com redução estatisticamente significativa na expressão de tais genes em todos os participantes com DM. Este estudo concluiu que a diminuição da expressão de CD28, em indivíduos diabéticos pode prejudicar a ativação de células T CD4+ e a resposta Th1, aumentando, desta forma, a suscetibilidade à TB (QU et al., 2012).

Outra tendência, encontrada em quatro das 15 publicações com enfoque imunológico, foi evidenciada no objetivo de identificar os mecanismos imunopatológicos envolvidos na associação DMTB. Martens et al. (2007) propuseram-se a investigar o efeito da hiperglicemia na imunidade adaptativa de pacientes com TB. A associação entre DM e TB foi modelada, infectando-se ratos com DM aguda (<1 mês) ou crônica ( $>3$ meses), com uma dose baixa de aerossol de $M t b$. O DM foi induzido pelo tratamento com estreptozotocina (STZ) em ratos. Pulmões de ratos com DM aguda e euglicêmicos tiveram cargas bacterianas, perfis de expressão de citocinas e histopatologia semelhantes. Em contraste, os ratos com DM crônica tiveram maior carga bacteriana $(>1 \log )$ e maior inflamação no pulmão em comparação aos ratos euglicêmicos. A expressão da imunidade adaptativa foi retardada em ratos com DM crônica, em comparação aos ratos euglicêmicos no primeiro mês de infecção. No entanto, após 2 meses com $\mathrm{TB}$, os níveis de citocinas pró-inflamatórias foram maiores em ratos com DM crônicado que nos euglicêmicos. Os dados indicam que o início da imunidade adaptativa é prejudicado pela hiperglicemia crônica, resultando em maior carga de estado estacionário de $M t b$ no pulmão. Os autores argumentam contra um efeito adverso direto de hiperglicemia, sugerindo que a defesa do hospedeiro é diminuída em consequência da hiperglicemia persistente (Martens et al., 2007). 
A expressão de genes peptídio CAMP, DEFA1, DEFB4 e DEFB103A foi analisada por Gonzalez-Curriel et al. (2011) em 60 pacientes, de ambos os sexos, com TB com e sem DM tipo 2. A expressão do gene peptídio antimicrobiano aumentou durante a TB, o que para os autores indica um possível biomarcador para reativação. Em contraste, pacientes com DM2 demonstraram menor expressão do gene antimicrobiano, sugerindo que a falta de sua produção adequada, nesses pacientes, contribuiu para aumentar o risco de reativação da TB (GonzalezCurriel et al., 2011).

Sob a hipótese de que as diferenças significativas nos sintomas clínicos, achados de imagem, bem como os efeitos de tratamento, em pacientes com $\mathrm{DM}$ que desenvolvem $\mathrm{TB}$, podem estar relacionadas à maior frequência de células T reguladoras (Treg), estudo de Sun et al. (2012) objetivou determinar se a expressão de células T CD4 + CD25 + CD127 (Treg) está associada à TB. A citometria de fluxo foi utilizada para determinar as frequências das células Treg no sangue periférico, no lavado broncoalveolar (LBA) e em derrame pleural de 120 pacientes. As freqüências de Treg no sangue periférico foram significativamente mais frequentes no grupo DMTB ( $\mathrm{P}<0,01$ para todos) do que no grupo controle. Para ou autores, nos pacientes com TBDM, o desequilíbrio entre Treg e células $\mathrm{T}$ efetoras, em sítios patológicos, pode estar associado à imunidade prejudicada e às manifestações clínicas da TB (Sun et al., 2012).

Outro mecanismo imunopatológico avaliado foi o encontrado em estudo de Gomez et al. (2012), que avaliou se a interação inicial entre fagócitos mononucleares e monócitos com o $M t b$ foi afetado em diabéticos pareados por idade e sexo. A associação de $M t b$ com monócitos foi significativamente menor nos diabéticos $(19,2 \pm 6,1)$ do que nos nãodiabéticos $(27,5 \pm 7,9, p=0,02)$. A análise multivariada para o controle de características sócio- demográficas, presença de DM e lipídeos séricos indicou que o sexo masculino $(\mathrm{p}=0,04)$ e o DM mal controlado (alta $\mathrm{HbA}$ (1c) e hiperglicemia, $\mathrm{p}=0,01$ ) foram significativamente associados à menor interação de $M t b$ com monócitos (Gomez et al., 2012). 
Quatro estudos objetivaram identificar uma forma de diagnóstico da TB em indivíduos diabéticos. Mustafa et al. (2008) objetivou avaliar a resposta imune mediada por células (CMI) em pacientes com TB e DM tipo 2 e em não diabéticos (TB) e em indivíduos saudáveis, em resposta aos antígenos de $M t b$ complexos, fracionados e únicos. Os pacientes com TB diabéticos e não-diabéticos reagiram à secreção de antígeno de baixo peso molecular ESAT6 de $M t b$, indicando que este antígeno pode ser útil no diagnóstico de TB em ambos os grupos. Outra ferramenta imunológica foi proposta por Tan (2010), um enzyme-linked immunospot de INF- $\gamma$ (ELISPOT), para diagnóstico em pacientes com DM. Cinquenta e um $(60,7 \%)$ pacientes foram considerados com TB pulmonar, incluindo 42 (50\%) com TB confirmada e $9(10,7 \%)$ com TB provável. O total de sensibilidade, especificidade, valor preditivo positivo e valor preditivo negativo do ensaio ELISPOT foram 84,3\%, 66,7\%, 79,6\% e 73,3\%, respectivamente, com valor preditivo negativo significativamente maior em pacientes com controle glicêmico adequado ( $90 \%$ vs 56,3\%), o que demonstra que a ferramenta pode fornecer suporte útil no diagnóstico da TB pulmonar em pacientes diabéticos, especialmente aqueles com controle glicêmico adequado (Tan et al., 2010).

Outro marcador de diagnóstico não-invasivo confiável para TB ativa foi a medição das células T Natural-Killer (NKT), descoberto em estudo realizada por Zhang et al. (2011). O estudo caso-controle examinou a frequência de $\mathrm{V} \alpha 24(+) / \mathrm{V} \beta 11(+)$ de células do sangue periférico e lavado broncoalveolar na TB pulmonar em pacientes com ou sem DM selecionados aleatoriamente em um hospital em Shanghai, China. Células NKT tanto no sangue periférico quanto no lavado broncoalveolar foram significativamente maiores em pacientes com DMTB em comparação com pacientes com TB não-diabéticos, o que pode ser devido à carga bacilar geralmente superior em doentes DMTB (Zhang et al., 2011). O mesmo tipo de pesquisa foi realizada por Walsh et. al. (2011), porém com foco na sensibilidade dos ensaios de liberação de INF-y (IGRA) para detecção da infecção pelo $M t b$ ou na TB ativa. Visando determinar se a sensibilidade do IGRA está comprometida pela alteração no sistema imunológico em pacientes com 
DM, Walsh et. al. (2011) avaliaram-na entre amostras de pacientes com DMTB e PTB microbiologicamente confirmados. Pacientes com DM, hiperglicemia crônica ou com sobrepeso/obesidade foram mais de duas vezes mais propensos a ter resultados positivos em modelos multivariados $(\mathrm{P}<0,05)$ e a sensibilidade IGRA não foi comprometida pelo DM em pacientes com $\mathrm{TB}$, o que a torna um mecanismo adequado para o diagnóstico de infecção por TB em pacientes com DM (Walsh et al., 2011).

\subsection{Apresentação Clínica}

Neste enfoque, o objetivo predominante, encontrado nas publicações avaliadas, foi determinar se o DM altera as manifestações clínicas e radiográficas em pacientes com $\mathrm{TB}$, sendo representado por 7 dos 15 estudos. Bacakoglu et al. (2001), além desse objetivo, também buscaram definir os determinantes do envolvimento dos campos pulmonares inferiores, através de análise retrospectiva de registros médicos hospitalares, em que os achados radiográficos e bacteriológicos foram os principais parâmetros investigados, em pacientes com e sem DM. Jabbar et. al. (2006) também tinham o mesmo objetivo e delineamento de estudo, porém, em pacientes paquistaneses de Karachi e, Golshah (2011), com pacientes hospitalizados de Golestan, Irã.

Em estudo de Bacakoglu et al. (2001), os parâmetros comparados entre os grupos TBDM e TB foram: duração dos sintomas, positividade da cultura de escarro, resistência à medicamentos anti-TB, tempo de conversão da cultura de escarro para tornar-se negativo, resultados dos testes tuberculínicos e apresentações radiográficas incluindo localização e características de infiltrações, presença de envolvimento pleural, duração da hospitalização e tratamento além de dados demográficos (idade, sexo e doenças concomitantes) (Bacakoglu et. al., 2001).

Seguindo outro delineamento eainda com o mesmo objetivo, foram encontrados três estudos caso-controle retrospectivos. No estudo de PérezGuzmán et al. (2001), realizado no México, os parâmetros comparados entre os dois grupos foram: evolução da TB e do DM em anos, contagem (em 
cél/mm³) de leucócitos, linfócitos e outros leucócitos. Já Touré et al. (2007) compararam as apresentações radiológicas em 100 pacientes com TB e DM, havendo predominância de pacientes com DM tipo 2 (82\%), em comparação com pacientes com TB isolada, pareados por idade e sexo, em um hospital no Senegal. Carreira et al. (2012) realizaram a mesma análise em Portugal com 123 pacientes em cada grupo.

Em estudo na Turquia, a presença de DM não resultou em efeito sobre a sintomatologia dos pacientes, os resultados bacteriológicos, reação à tuberculina e localização de infiltrações pulmonares (Bacakoglu et. al., 2001). Um número menor de pacientes diabéticos teve baciloscopia positiva e menor quantidade de opacidades reticulonodulares, comparados aos pacientes do grupo controle (Bacakoglu et. al., 2001).

Cavitação ocorreu com frequência significativamente menor em diabéticos $(72 \%)$ do que nos controles $(88 \%)(\mathrm{p}=0,04)$, no estudo de Touré et al. (2007) e no de Carreira et al. (2012) $(63,4 \%$ vs $82,1 \%, p=0,01)$, sendo o mesmo evidenciado no estudo de Bacakoglu et. al. (2001) com os pacientes com DM tipo 1. Em contraste com estes resultados, verificam-se os estudos de Pérez-Guzmán et al. (2001), Jabbar, Hussain e Khan (2006) e Golshah et al. (2011), que apresentaram maior frequência de cavitações em pacientes com DM tipo 1 e 2, sendo estas multilobares neste último estudo. A maior incidência de cavitações em pacientes do sexo masculino foi observada no estudo de Jabbar, Hussain e Khan (2006), com 32\% dos pacientes DMTB, no estudo de Touré (2007), com $60 \%$ dos pacientes com idade média de 51 anos (73\%).

Em estudo de Rawat, Sindhwani e Biswas (2011) o sexo masculino foi predominante entre os pacientes com TB isolada. Os autores discutiram como possível explicação para a predominância masculina, a realização, por parte dos homens, de maior número de atividades sociais, culturais e de trabalho do que as mulheres, que os predispõem a uma taxa de transmissão mais elevada de Mtb (Rawat, Sindhwani, Biswas, 2011). A proporção masculino:feminino foi menor em pacientes TBDM (1.16:1 vs 2.05:1, P = 0,101), justificada pelos autores pela maior prevalência de DM tipo 2 em mulheres com idade maior que 50 anos. Já a proporção de cavitações foi 
significativamente maior do que nos pacientes com TB isolada $(\mathrm{P}=0.003 \mathrm{e}$ $P=0,005$, respectivamente)

Tuberculose no campo pulmonar inferior foi mais frequentemente observada em 5 dos 7 estudos, sendo, em pacientes turcos, significativamente associada ao sexo feminino e, em pacientes com mais de 40 anos, tendo sido mais frequentemente observada em diabéticos; nos pacientes mexicanos representou um quinto da amostra TBDM (Bacakoglu et. al., 2001; Perez-Guzman et al., 2001; Jabbar, Hussain, Khan, 2006; Rawat, Sindhwani, Biswas, 2011; Carreira et al. 2012). Em estudo de Carreira et al. (2012), essa prevalência de TB no campo pulmonar inferior foi de 10,6\% em diabéticos, em comparação com 3,3\%, de pacientes não diabéticos $(\mathrm{p}=0,03)$. Esta apresentação radiológica pode mascarar o diagnóstico da tuberculose, com o consequente atraso na escolha de tratamento adequado.

Jabbar, Hussain e Khan (2006) encontraram uma prevalência de TB em pacientes com DM de 11,9\%, 10 vezes mais comum do que naqueles sem DM. O resultado da terapia anti-TB, com menor quantidade de bacilos e melhora nas cavidades foi mais positivo no grupo de pacientes com DM tipo 1, quando comparado ao grupo com DM tipo 2: após 6 meses, 5/9 (56\%) pacientes com DM tipo 1 mostraram diminuição no número de bacilos em comparação com 32/84 (40\%) pacientes com DM tipo 2 (Jabbar, Hussain, Khan, 2006).

Quanto ao aumento da gravidade da doença observou-se maior frequência de manifestações extrapulmonares de TB (28,5\% vs 16,3\%, p = $0,02)$ e maior mortalidade em diabéticos do que nos controles $(8,1 \%$ vs $0,8 \%, p=0,01)$ no estudo de Carreira et al. (2012). O aumento na mortalidade foi apresentado também por Touré et al. (18\% vs 6\%) (Touré, 2007).

Park et al. (2011) realizaram estudo semelhante aos apresentados, em um hospital na Coréia do Sul, porém, os grupos de indivíduos com TB eram diferenciados de acordo com o controle do DM: de 124 pacientes com TB diagnosticados com DM (25,2\%), 74 pacientes (59,7\%) não realizavam controle desta enfermidade ( $\mathrm{HbA} 1 \mathrm{C} \geq 7,0) ; 25$ pacientes $(20,2 \%)$ o faziam 
(HbA1C < 7.0), e os níveis de HbA1c não foram avaliados nos 25 indivíduos restantes (20,2\%). Não houve diferenças nos sintomas clínicos, achados radiográficos ou resultados AFB entre diabéticos e não-diabéticos. Semelhante ao estudo já citado de Jabbar, Hussain e Khan (2006), no estudo de Park et al. (2011) os diabéticos não controlados apresentaram mais lesões cavitárias $(\mathrm{p}=0,008)$, maiores taxas com baciloscopia positiva $(\mathrm{p}<0,001) \mathrm{e}$ maiores taxas de cultura positiva para Mycobacterium tuberculosis aos 2 meses de tratamento em comparação aos não-diabéticos (Park et al., 2011).

Através de estudo prospectivo, Alisjahbama et al. (2007) acompanharam, em um ambiente urbano na Indonésia, 737 pacientes com TB pulmonar, sendo que 14,8\% apresentavam DM. Após dois meses, os diabéticos apresentaram maior frequência de positividade de BAAR $(18,1 \%$ vs 10,0\%). Após 6 meses, 22,2\% das amostras de escarro de pacientes diabéticos em cultura foram positivas para o Mtb. Após ajuste para possíveis fatores de confusão, incluindo idade, sexo, estado nutricional, acessibilidade aos cuidados de saúde (resultando em atraso no diagnóstico) e comorbidades, o autor constatou que o DM foi associado a maior número de sintomas, mas não ao aumento da gravidade da TB, com efeito negativo sobre o resultado do tratamento anti-TB. O autor discute a necessidade de melhorar o atendimento de pacientes portadores da associação DM e TB, especialmente em países em (Alisjahbana et al., 2007).

Sulleiman et al. (2012) e Walsh et al. (2009) realizaram estudos semelhantes, sendo o primeiro, realizado em comunidade com sujeitos chineses, malaios e indianos e, o segundo, em nível hospitalar e ambulatorial, com sujeitos japoneses. A primeira pesquisa tinha recorte transversal e prospectivo e foram captados dados de prontuários de pacientes PTB, DMTB e DM, sendo acompanhados 200 indivíduos de cada um dos grupos, por dois anos. Variáveis relacionadas à TB incluíram a duração dos sintomas de tuberculose, forma de infecção da TB, duração de tratamento, período de seguimento, baciloscopia, resultado da terapia, e localização anatômica da infecção. As taxas de prevalência de HIV e DM entre pacientes com TB foram de 7,7 e 30\%, respectivamente. Os pacientes TB diabéticos foram mais propensos a apresentar escarro positivo (74\% vs. 
$51 \%$ não-DM), a desenvolver a TB pulmonar (87\% vs. 59\% dos PTB) e a apresentar taxa de mortalidade mais elevada (7,5\% vs. $1 \%$ do PTB e $2 \%$ do DM isolado). As variáveis sócio-demográficas consideradas foram: sexo, raça, tabagismo, abuso de drogas e consumo de álcool, mortalidade. As mesmas variáveis foram consideradas em estudo de Wang et al. (2009), que consideraram também sintomas anteriores ao tratamento, como tosse, expectoração, febre, perda de peso, dispnéia, anorexia, hemoptise, dor no peito, fadiga e suor noturno (Wang et al., 2009).

Sulleiman et al. (2012) observaram maior número de chineses e indianos com DMTB e TB, e maior número de malaios entre os indivíduos PTB (64\%). A prevalência de tabagismo foi significativamente maior em pacientes com DMTB (44,5 contra 33,5\% dos PTB, P < 0,01). Observou-se maior número de fumantes do sexo masculino. A DM antecedeu a TB por um período médio de quatro anos. Uma significativamente maior proporção de casos com escarro positivo (BAAR) ( $\mathrm{P}<0,001)$ e maior envolvimento pulmonar $(\mathrm{P}<0,001)$ foram observadas em indivíduos DMTB, em comparação com pacientes não diabéticos, bem como mortalidade mais elevada $(\mathrm{P}<0,001)$, especialmente entre idosos. Esta última evidência também foi encontrada em estudo de Wang et al. (2009). Maior comprometimento pulmonar foi observado em homens (Sulleiman et al., 2012). Tais dados são justificados pelos autores devido, possivelmente, à fatores sociodemográficos, pela maior tendência dos homens em serem fumantes e consumirem mais drogas e álcool (Sulleiman et al., 2012).

Objetivando melhor entender a influência do diabetes no desfecho do tratamento de pacientes com TB pulmonar, além dos aspectos clínicos, foram encontrados 3 estudos. Houve prevalência de estudos retrospectivos, em que foram buscados em registros médicos de pacientes: características pessoais e demográficas, apresentação clínica, resultados bioquímicos séricos, exame de escarro para BAAR, incluindo padrão de suscetibilidade à droga, achados radiográficos e formas e desfecho do tratamento. Na Arábia Saudita, registros hospitalares de 692 pacientes (187 pacientes com DM, comparados a 505 pacientes sem DM) com baciloscopia positiva foram revisados em um estudo caso controle retrospectivo (Singla et al., 2006). 
Em Maryland (EUA) estudou-se uma coorte retrospectiva com 297 pacientes com TB ativa, dos quais 42 (14\%) eram portadores de DM (Dooley et al., 2009). No primeiro estudo, no grupo TBDM, 65,2\% dos pacientes tiveram numerosos bacilos álcool-ácido resistentes (BAAR) no esfregaço do escarro, em comparação a $54,1 \%$ no grupo controle $(\mathrm{P}=$ 0,008). Estes pacientes TBDM apresentaram tendência de aumento do tempo de conversão da cultura em ambos os estudos. No estudo de Singla et al. (2006), os pacientes TBDM alcançaram taxas de conversão de escarro mais elevadas ao final de 3 meses de tratamento $(98,9 \%$ versus $94,7 \%, \mathrm{P}=$ $0,013)$

Resultados favoráveis (curado/tratamento concluído), fracasso e morte foram semelhantes tanto no grupo TBDM quanto no grupo TB nos estudos de Singla et al. (2006) e Tatar et al. (2009), porém a taxa de resistência às drogas foi maior nos casos com TBDM, no último estudo. Em contraste, no estudo de Dooley et al. (2009), o insucesso do tratamento ocorreu em $4,1 \%$ dos pacientes sem diabetes e $6,7 \%$ dos pacientes com diabetes $(\mathrm{P}=0,51)$. Os pacientes com $\mathrm{DM}$ apresentaram 2,0 vezes maior probabilidade de morte do que os pacientes sem DM (95\% intervalo de confiança [IC] 0,74-5,2, p = 0,18) (Dooley et al., 2009).

\subsection{Farmacológico}

O objetivo predominante nos estudos classificados neste enfoque foi a avaliação da farmacocinética de medicamentos anti-TB em pacientes diabéticos. Nijiland et al. (2006) compararam a farmacocinética da rifampicina em dezessete pacientes indonésios adultos com DMTB e em 17 pacientes PTB pareados por idade e sexo, durante a fase de continuação do tratamento da TB. Com o mesmo delineamento e objetivo, RequenaMenézes et al. (2012) realizaram estudo transversal com 105 pacientes de centros de saúde de Lima, Peru, sendo 50 TB sem co-morbidade, 26 TBDM, e 29 TB-HIV (Requena-Menézes et al., 2012). Ruslami et al. (2010) compararam a farmacocinética da rifampicina, pirazinamida e do etambutol, 
entre pacientes indianos com TBDM e PTB, pareados por sexo e peso corporal. Todos os pacientes do estudo de Nijland et al. receberam $450 \mathrm{mg}$ de rifampicina (10 mg / kg) e $600 \mathrm{mg}$ de isoniazida, 3 vezes por semana. Concentrações plasmáticas de rifampicina em seu estado estacionário e de seu metabólito desacetil-rifampicina foram avaliadas nas $0,2,4$ e 6 horas após a ingestão da droga. As médias geométricas de exposição rifampicina (área sob a curva de tempo de concentração no plasma, desde o tempo $0 \mathrm{~h}$, até 6 horas após a dose, AUC0 -6 h) foram 12,3 mg h/L (95\% IC, 8,0-24,2) em pacientes com DMTB e 25,9 mg h/L (IC $95 \%, 21,4$ - 40,2) em pacientes com TB. No estudo peruano, a mediana global dos níveis de rifampicina nas 2-6 h foram de 1,6 e 3,2 mg/l, respectivamente, e o pico de concentração foi em 6 horas ( absorção lenta), ao invés de 2 h (rápido absorção) para 61 pacientes (62,2\%) (Requena-Menezes et al., 2012). A maior parte da população do estudo peruano exibiu farmacocinética à rifampicina diferente dos estudos convencionalmente relatados, com a absorção retardada e baixas concentrações plasmáticas, independentemente da presença de HIV ou DM (Requena-Menezes et al., 2012).

A análise de regressão linear no estudo indonésio revelou que maior peso corporal, presença de DM, e concentração de glucose no plasma correlacionaram-se com a exposição à rifampicina, que apresentou-se $53 \%$ menor em pacientes TBDM. Isto significa que os pacientes com TBDM, que têm maior peso corporal, podem requerer dose mais elevada de rifampicina (Nijland, 2006). Os estudos indiano e peruano corroboram com este achado, de que o maior peso corporal dos pacientes TBDM desempenhe um papel importante na alteração da farmacocinética de medicamentos contra a TB (Ruslami et. al. 2010; Requena-Menézes et al., 2012).

Ruslami et al. (2010) elaboraram o mecanismo possível da alteração da farmacocinética de rifampicina, e avaliaram o efeito do controle glicêmico sobre a farmacocinética de medicamentos anti-TB em pacientes com TBDM. Os autores concluíram que o DM não altera a farmacocinética dos medicamentos anti-TB durante a fase intensiva do tratamento da TB. Foram encontradas meias-vidas de rifampicina, pirazinamida e etambutol entre pacientes com TB diabéticos e não diabéticos na fase intensiva do 
tratamento da TB. Para a rifampicina, a biodisponibilidade oral e o metabolismo foram semelhantes em pacientes com TBDM e PTB (Ruslami et. al. 2010).

Outra tendência encontrada foi a de estudos em que o objetivo era analisar ou comparar as taxas de conversão de escarro (baciloscopia, cultura) em períodos específicos do tratamento anti-TB. Rekha et al. (2007) compararam a taxa de conversão de escarro no final da fase intensiva do regime Categoria-1 (CAT-I) (2E3H3R3Z3/4R3H3), entre pacientes indianos PTB ou TBDM com pacientes com diabetes mellitus tipo 2 ou portadores de TB-HIV. Também da Índia, Balasubramanian et al. (2007), em estudo de coorte observacional prospectivo, avaliaram a adequação do regime CAT-I em pacientes com baciloscopia positiva para TB, que apresentavam DM tipo 2 concomitante, durante 3 anos, no Centro de Pesquisa da TB de Chennai (TRC). Com o mesmo objetivo, Restrepo et al. (2008) analisaram retrospectivamente dados sociodemográficos e de cultura de todos os pacientes com TB notificados no sul do Texas, nos EUA, entre 1996 e 2002. Os resultados do primeiro estudo mostraram que o esfregaço conversão da cultura, no final da fase intensiva de regime CAT-I, foi similar em pacientes PTB, com ou sem DM associada ou co-infecção pelo HIV (Rekha, 2007). Não foi observada diferença no esfregaço e conversão da cultura entre diabéticos e não-diabéticos, em nenhum dos dois estudos indianos, apesar de terem controle inadequado da diabetes, com sucesso do tratamento de 94\% e $4 \%$ de recaídas em 30 meses de seguimento no estudo de Balasubramanian et al. (2007). Desta forma, os autores consideram aceitável a política uniforme de tratamento de todos os novos pacientes com baciloscopia positiva com CAT-1, independentemente da c-mrbidade (Rekha et al., 2007, Balasubramanian et al., 2007).

Os resultados do estudo com os texanos com TB revelou que o DM continuou a ser significativamente associado à depuração bacteriana atrasada em pacientes com TB, durante a primeira fase da estratégia DOTS, durante a qual o tratamento deveria tornar o paciente não-infeccioso. Tal atraso na depuração bacteriana poderia se traduzir em aumento da exposição na comunidade, especialmente quando há grande número de pacientes com 
DM. Outro achado evidenciou que os sujeitos com TBDM eram mais frequentemente mulheres com maior idade, sem riscos sociais clássicos para TB (prisão, abuso de drogas e álcool); mais propensas a ter baciloscopia positiva no diagnóstico. Segundo os autores, um importante fator de risco para o DM é a história familiar. Desta forma, o achado em relação às mulheres de maior idade pode implicar em maior exposição dos membros domiciliares, colocando-os em risco aumentado para a TB causada por DM (Restrepo et al., 2008).

Saindo das tendências de objetivos de pesquisa anteriores, Kota et al. (2011) demonstram a correlação entre baixos níveis de vitamina D e a TB pulmonar (PTB) e os baixos níveis de vitamina $\mathrm{D}$ e resistência à insulina, através da avaliação sérica dos efeitos da suplementação de vitamina $\mathrm{D}$ em pacientes com DM tipo 2 com TB pulmonar. Os autores concluíram que a vitamina $\mathrm{D}$ pode servir como tratamento adjuvante de $\mathrm{TB}$ em diabéticos (Kota et. al., 2011).

Numa linha distinta das publicações anteriores, Gnanasan et al. (2011) realizaram estudo em um hospital na Malásia, que teve como objetivo determinar a viabilidade da prestação de serviço de atenção farmacêutica aos pacientes com TB e DM. A prevalência de DM entre os pacientes recém-diagnosticados com TB foi de $15 \%$ (53/352). O projeto de assistência farmacêutica seguiu sete passos: (1) estabelecimento de relação farmacêutico-paciente, (2) coleta de dados do paciente, análise e interpretação, (3) descobrir problemas relacionados com a medicação, (4) estabelecimento de objetivos e metas de terapia em conjunto com o paciente; (5) definir possíveis alternativas de farmacoterapia e preparar um plano de monitoramento, (6) implementação do regime de farmacoterapia individual e plano de monitoramento; (7) acompanhamento do tratamento. Foram consideradas as variáveis: gênero, etnia, estado civil, fatores determinantes para TB (tabagismo, abuso de drogas intravenosas, profissão). O resultado mais significativo foi que, apesar dos obstáculos logísticos, a prestação do serviço de atendimento farmacêutico era viável, e estes profissionais desempenharam um papel importante na integração da prestação de cuidados individualizados aos pacientes com TB e DM. Além 
das questões predominantes de cuidados farmacêuticos como a não-adesão, DM descontrolada, e reações adversas aos medicamentos, as necessidade de atendimento farmacêutico variaram entre os pacientes e foram consideradas individualmente. Foi também realizada pesquisa qualitativa para avaliar as necessidades de assistência farmacêutica dos pacientes com TB e DM, explorando-se crenças e preocupações sobre a medicação dos pacientes. Experiências dos profissionais de saúde na gestão de pacientes com TB e DM também foram investigadas. Os resultados da investigação qualitativa destacam que uma solução abrangente de gestão de assistência farmacêutica, que incorpora conteúdos educativos e de aconselhamento ao paciente, o acompanhamento das reações adversas e das interações medicamentosas, além da revisão da medicação e o cuidado centrado no paciente são necessários (Gnanasan et al., 2011).

\subsection{Epidemiológico}

O objetivo prevalente das pesquisas com enfoque epidemiológico foi verificar a existência da associação TBDM, com variáveis específicas, mais comumente para idade e sexo. Perez-Gúzmán et al. (2003) realizaram estudo com 226 pacientes em um hospital de nível terciário no Centro Nacional de Referência para Doenças Respiratórias, na cidade do México, México. Análise Bivariada de regressão logística foi aplicada para corroborar a associação idade-gênero (Pérez-Guzmán et al., 2003). Pacientes TBDM eram significativamente de maior idade (51,2 vs. 43,2 do grupo TB, $\mathrm{P}=0,001)$, e possuíam menor proporção masculino:feminino em comparação aos pacientes com TB (Pérez-Guzmán et al., 2003). Essa prevalência de pacientes do sexo masculino variava quando ajustada para os grupos etários. Os grupos 1 (15-29 anos) e 2 (30-39 anos) apresentaram maior prevalência do sexo masculino, porém nos quatro grupos seguintes notou-se um declínio estável na porcentagem de pacientes do sexo masculino (Pérez-Guzmán et al., 2003). A predominância de pacientes do sexo masculino no grupo TB é justificada pelos autores pela maior atividade social exercida pelos homens, o que os predispõe a risco aumentado de 
contato a tuberculose. Condições socioeconômicas e culturais são postuladas nesta pesquisa como fatores que causam menor acesso aos serviços de saúde pelas mulheres, resultando em subdiagnósticos e subnotificações.

Os mesmos resultados foram encontrados em estudo de Restrepo et al. (2007), e em pesquisa com pacientes malaios, por Nissapatorn et al. (2005), em que o grupo TBDM possuíamédia de idade de 51,5 anos (faixa de 18-88) e o grupo TB de 37,5 anos (faixa de 14-95), com proporção masculino:feminino de 2,2:1 vs. 1,9:1. A prevalência de TB pareceu aumentar progressivamente com a idade em pacientes diabéticos em comparação com os não-diabéticos.

Em estudo em Cronaky, na Guiné, a idade média em pacientes com TBDM foi de 47 anos $(\mathrm{P}=0,000003)$ comparado ao grupo apenas TB (30 anos), diferenciando-se por não apresentar influência do sexo (Baldé et al., 2006).

Para Pérez-Guzmán et al. (2003), uma das explicações para tais achados é o maior nível de atividade social em homens, o que os predispõem a uma taxa de transmissão mais elevada de $M t b$. Os autores discutem que as condições socioeconômicas e culturais são consideradas fatores que causam menor nível de acesso das mulheres com TB aos serviços de saúde, resultando em subdiagnóstico e subnotificação (PérezGuzmán et al., 2003). Tal afirmação já não seria verdadeira para o estudo de Nissapatorn et al. (2005), em que os grupos estudados, mesmo estratificados por idade ou sexo, apresentaram semelhanças em termos de sexo, raça, estado civil, endereço atual e ocupação. Para estes autores, os pacientes nãodiabéticos podem ser afetados pela possibilidade de subdiagnóstico e subnotificação, considerandoas condições socioeconômicas e culturais gerais da Malásia, país em desenvolvimento e com nível intermediário de carga de TB (Nissapatorn et al., 2005).

Também no México, Ponce-de-León et al. (2004) realizou estudo de coorte prospectiva de base populacional com pacientes portadores de TB pulmonar submetidos à avaliação clínica e microbacteriológica (isolamento, identificação, testes de suscetibilidade à droga, e genotipagem). O estudo 
relacionou-se à Pesquisa Nacional de Saúde 2000 (ENSA2000), um inquérito probabilístico nacional domiciliar da população civil, não institucionalizada. Características sóciodemográficas, clínicas e terapêuticas foram comparadas em 581 pacientes diagnosticados com cultura $\mathrm{Mtb}$, sendo que $29,6 \%$ tinham sido previamente diagnosticados com DM. As taxas estimadas de TB para a área de estudo foram maiores para os pacientes com TBDM do que para os indivíduos não diabéticos (209,5 vs 30,7 por 100.000 pessoas-anos, $\mathrm{p}=0,0001)$. Verificou-se, em relação aos sujeitos com TBDM: prevalência de homens; origem indígena; trabalhadores rurais e industriais; cicatriz Bacilo Calmette-Guérin; residência em abrigos e com seguridade social; aglomeração domiciliar; domicílios com chão de terra, uso de álcool. Os autores discutem que, como havia diferenças sócioeconômicas significativas entre pacientes diabéticos e não diabéticos, é possível que as pessoas com melhor acesso aos serviços de saúde fossem mais propensas a serem diagnosticadas com ambas DM e TB. No entanto, neste estudo, os pacientes com TB foram ativamente procurados, e a análise prévia mostrou que a TB é mais comumente diagnosticada em indivíduos com menor nível socioeconômico. Portanto, não houve oportunidade diferencial para o diagnóstico da TB, de acordo com a disponibilidade dos serviços de saúde (Ponce-de-Leon et al., 2004).

Nissapatorn et al. (2005) conduziram estudo a fim de comparar a epidemiologia e os impactos clínicos da TB entre 241 indivíduos com TBDM e 1.410 indivíduos com TB isolada, em Kuala Lumpur, na Malásia. As variáveis consideradas foram: relacionadas às características sóciodemográficas; apresentação clínica; tratamento, medicamentos utilizados e duração e adesão do paciente à terapia, bem como o resultado da resposta terapêutica. Entre os fatores determinantes para presença de TB, uma menor proporção de pacientes com TBDM teve consumo de álcool $(0,5 \%)$, uso de drogas injetáveis $(3,6 \%)$, a vacinação BCG $(44,1 \%)$ e teste tuberculínico $(32,4 \%)$. O sucesso do tratamento e cura em período igual ou maior a 6 meses para a TB pulmonar $(38,4 \%)$ e em período igual ou maior que 9 meses na TB extrapulmonar $(4,6 \%)$ foram mais comuns nos pacientes com TB, enquanto que o grupo cm TBDM mostrou maior taxa de sucesso 
do tratamento e cura $(33,3 \%)$, particularmente na TB pulmonar de duração mais longa ( $\geq 9$ meses). Os autores discutem um aumento da suscetibilidade à TB em pacientes com DM devido ao envelhecimento, os avanços da tecnologia médica, que permite avanços no diagnóstico, ou mudanças na dieta e na vida social (Nissapatorn et al., 2005).

Além de verificar a existência, estudo de Alisjabahna et al. (2006) pesquisou a extensão da associação entre DM e TB em clínicas ambulatoriais (não hospitalares) de área urbana em Jakarta, na Indonésia. Assistentes sociais selecionaram aleatoriamente um grupo controle pareado por idade e sexo, que viviam no mesmo ambiente urbano (superlotado, em sua maioria) e de mesmo contexto sóocioeconômico. Foi realizado teste de glicemia em jejum em todos os envolvidos, casos e controles, havendo diagnóstico de DM se a glicemia fosse superior a 126mg/dl. Foram consideradas como variáveis: idade, sexo, IMC, presença de contato com TB na família ou no domicílio, renda e número de indivíduos por residência. Sexo, renda e superlotação das moradias não alteraram significativamente a razão de chance (OR), desta forma, os autores consideraram improvável que a associação TB-DM esteja relacionada a outros fatores como os socioeconômicos, condições de moradia e presença de comorbidades (Alisjabahna et al., 2006).

Em contraste ao estudo anterior, Perez, Brown III e Restrepo (2006) embasam seu estudo no fato de que a associação positiva entre DM e TB tem sido relatada especialmente em populações com baixo nível socioeconômico e altas taxas de incidência de ambas as doenças. Nesse contexto, o estudo foi realizado na população de 14 condados fronteiriços Texas-México, que estão entre os mais pobres dos Estados Unidos, além de possuírem taxas elevadas de incidência de TB e alta prevalência de DM, em relação aos municípios não fronteiriços do Texas. Uma análise de casocontrole foi realizada, com dados transversais, utilizando-se o banco de dados de alta hospitalar do Texas dos anos 1999-2001. As características demográficas da população incluíram idade, sexo, raça/etnia e tipo de seguro (segurados, Medicare [seguro do governo federal para os aposentados, com 65 anos de idade ou mais, viúvos e deficientes], Medicaid 
[seguro do governo para os pobres], privado e outros [compensação do trabalhador]). As variáveis raça e etnia foram combinadas como co-variável: brancos, hispânicos, afro-americanos, e outros. Fatores de co-morbidade incluíram: insuficiência renal crônica, uso de álcool e drogas, qualquer tipo de câncer e déficit nutricional. A distribuição dos casos e controles, por tipo de seguro/status, foi diferente entre as regiões de fronteira e não fronteiriça ( $\mathrm{p}<0,001)$. Possuir Medicaid (OR 0,80, IC 95\%,65-0,99) e seguro privado (OR 0,24 IC 95\% 0,20-0,29) foram associados com menor risco para TB em comparação com os não-segurados na região de fronteira. Possuir seguro federal, como compensação do trabalhador, seguro militar e seguro de veteranos, foi um fator de risco para a TB na região não-fronteiriça. Medicare e seguros privados foram associados com menor risco de TB em ambas as regiões, após o ajuste para sexo, idade e raça/etnia. A prevalência de TB era menor em áreas geográficas que apresentavam maior percentual de diplomados do ensino médio ou universitários, após o ajuste por idade, sexo e raça/etnia (Perez, Brown III, Restrepo, 2006).

Quando ajustado para a presença de diabetes mellitus, este estudo de Perez, Brown III e Restrepo (2006) demonstrou que, na região de fronteira, os pacientes TBDM tiveram risco para tuberculose aumentado em duas vezes em comparação com os pacientes sem diabetes. Este risco foi 1,5 vezes maior nos municípios não fronteiriços. Qualquer TBDM vivendo na região de fronteira tinha risco aumentado 1,3 vezes para tuberculose em comparação com pacientes TBDM de municípios não fronteiriços (OR 1,27; IC 95\% 1,05-1,53). Quando ajustados para etnia, independentemente de viver em regiões fronteiriças ou não fronteiriças, os pacientes TBDM hispânicos tiveram mais de duas vezes o risco de tuberculose, quando comparados aos pacientes sem diabetes (Perez, Brown III, Restrepo, 2006).

O estudo já citado de Baldé et al. (2006), foi realizado em Conakry, Guiné, com 388 pacientes com TB, selecionados por amostragem aleatória simples, a partir do registro de casos diagnosticados. Foi investigado o histórico médico pessoal e familiar (diabetes, hipertensão e obesidade), fatores de risco cardiovasculares (obesidade, hipertensão, tabagismo, estilo de vida sedentário), e sintomas de DM. Histórico familiar de DM, obesidade 
e estilo de vida sedentário foram fatores positivamente associados ao DM. A prevalência de DM relatada entre pacientes com TB foi maior $(3,35 \%$; IC $95 \%$ 1,35-5,35) do que as estimativas da OMS $(1,1 \%)$ para a população geral da Guiné em 2000, sendo que o DM tipo 2 representou $85 \%$ dos casos da pesquisa. $\mathrm{O}$ diagnóstico de $\mathrm{DM}$ precedeu o de $\mathrm{TB}$ em uma média de 5 anos (Baldé et al., 2006). As características clínicas da TB (exposição freqüente a infecção, TB pulmonar ou extrapulmonar, proporção de casos novos e retratamentos) não diferiram para os pacientes TBDM e não diabéticos. Os pacientes diabéticos foram significativamente mais velhos e quanto à proporção de pacientes TBDM de cada sexo foi de: 3,5\% dos homens e 3,1\% das mulheres (Baldé et al., 2006).

Em outro estudo realizado nos EUA, também na região no sul do Texas, e também no nordeste do México, foram analisados dois grandes conjuntos de dados, compreendendo toda a população de pacientes com TB dessas regiões. Os autores colocam como principais fatores de risco para a TB nos países em desenvolvimento: infecção por HIV e/ou pobreza. Em contraste, nos países desenvolvidos, como os Estados Unidos, o controle da TB destina-se mais a grupos de risco bem definidos, para além daqueles citados: jovens do sexo masculino com história de falta de moradia, abuso de álcool ou substâncias, encarceramento, e imigração recente. A análise identificou DM como a principal comorbidade, com pacientes que apresentam características clínicas e microbiológicas distintivas daquelas apresentadas em pacientes com TB isolada. Dados demográficos autorelatados, fatores de risco sociais e médicos, dados clínicos e microbiológicos, exames de imagem, tipo de tratamento, medicação e desfecho do tratamento foram registrados para cada paciente. Os dados do México incluíam as características sóciodemográficas auto relatadas (sexo e idade) e comorbidades como DM, HIV, uso de drogas e álcool, entre outros. Sinais e sintomas clínicos foram verificados em uma análise de regressão logística múltipla, para avaliar o grau de associação com casos e controles. A análise univariada mostrou que os casos com TBDM no Texas eram mais propensos a ser os hispânicos de origem mexicana, e menos propensos a ter os fatores de risco sociais típicos associados com TB apenas, como o 
encarceramento, ou falta de moradia. As manifestações clínicas e laboratoriais da TB eram mais graves em casos de TBDM quando comparados ao grupo controle com TB (Restrepo et al., 2007).

A situação do Texas já foi colocada em estudo de Perez, Brown III e Restrepo (2006), e a população mexicana, estudada por Restrepo et al. (2007) compartilha as características de pobreza, aumento da obesidade e DM, e a carência de medicamentos apresentadas pela população texana. Para este contexto, Retrepo et al. (2007) argumentam que, por tanto a $\mathrm{Tb}$ quanto o DM afetarem os menores estratos sócioeconômicos, as comunidades mais pobres, pode-se estar observando um grau de coincidência em vez de real associação entre TB e DM. Sua conclusão é corroborada por haverem distinções claras entre os grupos etários e sociais/fatores de risco comportamentais para TB, ou seja, uso de álcool e de drogas e tempo prisão foram mais frequentes entre os pacientes mais jovens, e DM em pacientes mais velhos. Há também diferenças na identificação e notificação de TB e os fatores de risco associados em ambos os países (Restrepo et al. 2007).

Dois estudos buscaram a incidência de TB em grupos de pacientes com DM, através das variáveis raça/etnia e idade. Em pesquisa canadense de Dyck et al. (2007), a existência de uma relação entre TB e DM foi buscada entre aborígenes (população OSKP) e não-aborígenes (RI) de Saskatchewan. Já na Inglaterra, Walker et al. (2010) estimaram a proporção de casos de TB pulmonar atribuíveis à DM entre homens e mulheres asiáticos, negros e brancos, através da construção de um modelo epidemiológico, utilizando-se dados de um grande estudo de coorte sobre a incidência de TB.

No primeiro estudo, as mulheres diabéticas com idade entre 20-59 anos tiveram maiores taxas de incidência média anual de TB do que mulheres não-diabéticas, independente da etnia, mas as proporções de TB em mulheres diabéticas comparadas às não-diabéticas foram significantes apenas para aquelas com idade entre 50-59 anos (2,7 [IC 1,28, 5,72] em RI e 3,9 [IC 1,58, 9,67] em OSKP). Nenhum outro subgrupo diabético teve taxas significativamente mais altas de $\mathrm{TB}$, diferindo dos estudos anteriormente 
apresentados, em que a incidência de TB entre pacientes com DM era maior em homens. O único subgrupo diabético de homens, que teve maior taxa de TB foi RI mais OSKP, com idades entre 50-59 anos. Em geral, o diabetes precedia a TB em 87/111 dos indivíduos com ambas as doenças (p $<0,0001)$. Quando considerou-se a população total, somando as populações RI e OSKP, observaram-se taxas mais elevadas de TB em mulheres nãodiabéticas do que nas diabéticas nos grupos etários de 20-59 anos (Dyck et al., 2007).

No estudo inglês, a Fração Populacional Atribuível (PAF) estimada de DM para a TB pulmonar foi maior para os homens asiáticos $(19,6 \%$, IC $95 \%$ : 10,9-33,1\%) e mulheres $(14,2 \%$, IC $95 \%: 7,1-26,5)$. O PAF para todas as idades foi semelhante em homens brancos e negros $(6,9 \%$, IC $95 \%$ : $3,1-12,4 ;$ e $7,4 \%$, IC $95 \%$ 4,6-12,9, respectivamente) e nas mulheres $(8,2 \%$, IC $95 \%$ : 3,0-15,6; e 8,9 \%, IC de $95 \%: 5,3-15,6$, respectivamente). A semelhança entre estes valores globais, apesar de maior prevalência de DM na população negra, reflete uma média de idade muito mais jovem da TB pulmonar na população negra. De 3.461 novos casos de TB pulmonar, na Inglaterra, em 2005, 384 (11,09\%) foram estimados como atribuíveis à DM (Walker, Unwin, 2010).

Uma coorte de 42.116 sujeitos, com idade entre 65 anos ou mais, matriculados em 18 Centros de Serviço de Saúde do Idoso em Hong Kong, foram acompanhados prospectivamente por meio dos registros, em todo o território, quanto ao desenvolvimento da TB, a partir de 3 meses após a inscrição. Os efeitos do DM e seu risco para a TB foram avaliados com ajuste para variáveis de base sóciodemográfica e outras. O Diabetes Mellitus foi associado, após ajuste de taxas de risco, a um aumento modesto no risco de TB ativa (1,77 [IC de 95\%: 1,41; 2,24]), TB confirmada por cultura $(1,91$ [IC de 95\%: 1,45; 2,52]), e TB pulmonar (com ou sem envolvimento extrapulmonar) de (1,89 [IC de 95\%: 1,48; 2,42), mas não extrapulmonar (com ou sem envolvimento pulmonar), (1,00 [IC de 95\%: 0,54; 1,86]) (Leung et al., 2008).

Estudo caso-controle de base populacional, no norte da Dinamarca, de 1980 a 2008, incluiu 2.950 pacientes com diagnóstico inicial de TB ativa, 
incluindo 156 indivíduos diabéticos (5,3\%), e 14.274 indivíduos de controle populacional, dos quais 539 tinham diabetes $(3,8 \%)$. Realizou-se análise estratificada por sexo e grupos etários. O OR ajustado para a TB ativa, entre indivíduos com DM foi de 1,18 (IC 95\% 0,96-1,45), em comparação aos indivíduos não-diabéticos. Foi encontrado aumento de risco de DM em 843 (29\%) casos de TB em imigrantes (OR 1,23 [IC 95\% 0,78-1,93]). Em um subgrupo de dados laboratoriais, os indivíduos diabéticos com hemoglobina glicada entre 7,0; 7-7,9, e 8,0\% tinha OR de 0,91 (0,51-1,63), 1,05 (0,412,66), e 1,19 (IC 0,61-2,30), respectivamente, comparados aos indivíduos sem diabetes. Apesar do controle para fatores de confusão, os autores acreditam que os resultados podem ter sido afetados por diversas variáveis, incluindo: estilo de vida, estado civil, fatores exógenos, tais como: tabagismo, padrão de vida, IMC, história de prisão, falta de moradia, urbanização (rural, urbana, provincial), viagens em áreas endêmica de TB, e história de vacinação contra BCG (Leegard et al., 2011).

Em quatro das 25 pesquisas objetivaram descrever prioritariamente a prevalência da associação entre TB e DM. Destas, Marks et al. (2011) estudaram TB e DM auto-relatadas, a partir do National Health Interview Survey dos EUA, e analisaram a história de associação TB-DM, controlando raça/etnia e idade, região de nascimento, fatores socioeconômicos associados, nacionalidade estrangeira, elevado abandono escolar, histórico de falta de moradia ou encarceramento, sem diagnóstico de câncer, tabagismo, abuso de álcool, seguro de saúde e presença de HIV.

Estudo transversal de Alladin et al. (2011) ocorreu entre pacientes com $\mathrm{TB}$, que frequentavam clínicas de tórax na Guiana, especificamente em Georgetown, Linden, e em Amsterdam. Os autores descreveram a epidemiologia da associação TBDM e a apresentação clínica da TB em pacientes com DM de forma quantitativa com enfoque em resultados de incidência e prevalência de variáveis. Já Balakrishnan et al. (2012) seguem o mesmo desenho de estudo em Kerala, com pacientes indianos, e também avaliam se a triagem de rotina para DM em pacientes com TB pode gerar casos de DM anteriormente não diagnosticados, oferecendo uma oportunidade para a detecção precoce e tratamento do DM. Também na 
Índia, em Tamil Nadu, Viswanathan et al. (2012) buscaram determinar a prevalência de DM e pré-diabetes em uma coorte de pacientes com TB, registrados no Programa Nacional de Controle da Tuberculose.

Marks et. al. (2011) demonstraram que os pacientes TBDM eram mais propensos a ter idade maior ou igual àa 45 anos, ter tido câncer, baixa escolaridade, ser negro ou ser do sexo masculino, fatores também associados com a incidência de TB EUA. A análise dos fatores associados à TB e ao DM demonstrou que os diabéticos tiveram $40 \%$ maior chance de ter TB, controlando para os fatores de confusão de raça/etnia e idade (Marks et al., 2011).

Pacientes com TB relataram altos níveis de uso de álcool (44\%), desemprego (44\%), não-uso de drogas injetáveis (19\%), falta de moradia (15\%), e encarceramento (18\%). Pacientes TBDM tendiam a ser mais velhos (mediana de 44 anos vs 36,5 anos), eram mais propensos a estar encarcerados no momento do diagnóstico da TB $(35,7 \%$ vs $15,1 \%$, p = 0,06) e suscetíveis à apresentação de nível elevado de açúcar no sangue do que os não-diabéticos. Clinicamente, o DM não influenciou a apresentação da TB. Os pacientes com TB, nesta amostra, pertenciam a grupos socialmente desfavorecidos, com alta prevalência de desemprego, moradores de rua e história de encarceramento. Da mesma forma, os fatores de estilo de vida, tais como uso de álcool, tabagismo e uso de drogas ilícitas eram frequentes entre os pacientes com TB (Alladin et al., 2011).

A amostra de Balakrishnan et al. (2012), de pacientes com TB diagnosticados e registrados em 2011, no Estado de Kerala, na Índia, ocorreu em 22 unidades rurais de TB e em 8 unidades predominantemente urbanas. Dos 552 pacientes com TB, 243 (44\%) tinham DM. A prevalência pacientes TBDM foi maior em ambiente urbano e entre os homens, maiores de 50 anos e entre aqueles com cultura positiva de escarro, principalmente entre os casos de recaída de TB. Dos 243 diabéticos, 128 (23\%) pacientes com TB relataram diagnóstico prévio de DM e 115 (21\%) foram diagnosticados recentemente com DM. Os autores colocam que a associação entre a prevalência do DM com a residência urbana pode indicar práticas de 
vida que predispõem ao DM ou ao melhor acesso e diagnóstico de DM (Balakrishnan et al., 2012).

Em Tamil Nadu, Índia, todas as unidades de TB foram estratificadas, dependendo de sua localização, em áreas semi-urbanas (2 urbanas e 1 semiurbana) e rurais (2). Características sóciodemográficas, fatores de risco habituais (tabagismo, consumo de álcool, uso do tabaco), história familiar de TB e DM, nível educacional e ocupacional e renda mensal, foram coletados. Também foram registrados tipo de TB, estado e categoria do tratamento da TB. O estudo mostrou que as taxas de prevalência de DM e pré-diabetes eram de $25,3 \%$ e $24,5 \%$, respectivamente, entre os pacientes de TB registrados. O Diabetes é prevalente entre homens do que em mulheres (27,5\% vs 20,2\%), enquanto que não houve diferença de gênero na prevalência de pré-diabetes. A maior prevalência de DM entre os homens do que nas mulheres pode ser um efeito cumulativo de outros fatores de risco, como o tabagismo, e o consumo de álcool, que têm impacto tanto na TB como no DM. IMC, história familiar de DM e ocupação sedentária, foram os fatores de risco mais comuns associados ao DM em pacientes com TB. Os fatores de risco associado ao DM, entre a população em geral, que não foram observados nesse estudo foram habitação urbana e status de renda. As maiores razão de chance (OR) foram encontradas para a faixa etária 41-45 anos $(6,96)$, circunferência da cintura (OR 3,05), e tabagismo (OR 1,92) para a pré-diabetes em pacientes com TB (Viswanathan et al., 2012).

Diferentemente dos estudos anteriores, Lin et al. (2012) organizaram um projeto de implementação observacional prospectivo, realizado em cinco clínicas de DM, em serviços de saúde primários na China, de setembro de 2011 até março de 2012, para testar a viabilidade de se realizar a triagem dos pacientes com DM para TB. Em três trimestres, como resultado de investigação, obtiveram: $72 \%$ dos 3.174 pacientes, $79 \%$ dos 7.196 pacientes e $68 \%$ dos 4.972 pacientes foram registrados como tendo sido rastreados para a TB, resultando em 7 pacientes que já eram conhecidos por terem TB, 92 pacientes com sintomas positivos para a TB e 48 pacientes recémdiagnosticados com TB (Lin et. al., 2012). 
Artigo de Maurice (2011) descreve uma estrutura de Cuidados e Controle da Tuberculose e Diabetes. Tal estrutura, proposta pela Organização Mundial da Saúde, em colaboração com outras entidades, tem dois objetivos: no nível individual, aumentar o número de pessoas que recebem diagnóstico preciso e tratamento adequado para ambas as enfermidades. Na esfera da saúde pública, ajudar a reduzir a incidência das doenças. Nesta esfera, a epidemia de DM pode ser um motivo pelo qual os esforços para reduzir a incidência global de TB tem apresentado efeito limitado, apesar das taxas de detecção de casos e da alta taxa de cura de TB. Com a detecção de uma média global de cerca de $65 \%$ do número estimado de novos casos de TB e cura de $86 \%$ destes casos, a redução da incidência de TB deveria ser de 5-10\% por ano, de acordo com modelagem matemática. Desde 2004, a incidência está diminuindo de forma constante, mas por apenas $1 \%$ ou menos por ano. Além disso, em oito dos 22 países com alta prevalência de TB, o DM é responsável por uma maior proporção de casos de TB do que a do HIV. Para o autor, é necessário garantir que a triagem para ambas as doenças torne-se integrada na política de governo em todos os países, devendo ser implementada em todos os níveis de cuidados de saúde mas, sobretudo, no âmbito primário. Entre os países que já manifestaram interesse nesse sentido, estão o Brasil, a China, a Índia, o México e o Sri Lanka. Ressalta, ainda, que deve assegurar-se que todos os profissionais de saúde estejam treinados para o manejo dessas enfermidades e que as instalações para o diagnóstico e terapêutica sejam disponíveis (Maurice, 2011).

O artigo de Sullivan et al. (2012) compartilha dois pontos-chave para o manejo da associação TB-DM, que foram também propostos por Maurice (2011). O primeiro seria rastrear sistematicamente o DM em de pacientes com $\mathrm{TB}$, e posteriormente, rastrear os pacientes com DM para a TB, quando esta for sintomática. O segundo seria a utilização dos esforços recentes para aumentar a presença de força de trabalho no nível primário de atenção à saúde em todo o mundo, como uma oportunidade para a formação e para a implementação de esforços contra a TB, o HIV e doenças crônicas não- 
transmissíveis, capacitando-os para o manejo simultâneo de doenças infecciosas e crônicas (Sullivan et al., 2012).

Outro artigo de reflexão sobre a associação entre TB e DM é o de Magee, Blumberg e Narayan (2011), que considera que a ocorrência destas pandemias representa um novo fenômeno na transição epidemiológica clássica, uma consequência do rápido crescimento das doenças não transmissíveis, um resultado da transição de estilos de vida para uma maior ingestão de calorias e menor atividade física, juntamente com a incapacidade de reduzir a carga global da TB. Discute que as agendas de saúde pública, quanto à gestão das doenças transmissíveis e nãotransmissíveis, bem como a reorientação das estruturas dos sistemas de saúde, devem ser influenciados pelas mudanças na epidemiologia, na sociologia e na assistência clínica do concorrente estado TB-DM. Coloca, por fim, que interações entre rápido crescimento econômico, urbanização e má nutrição, predispõe as populações de países de baixo e médio desenvolvimento, que ainda têm grande carga de TB, ao aumento do risco para o DM e à taxas mais elevadas de DM para uma proporção cada vez maior de casos de TB atribuíveis ao DM. Afirma que deve-se reconhecer, desta forma, o impacto da globalização sobre o rápido aumento das doenças crônicas não-transmissíveis, e gerar soluções inovadoras que integrem abordagens para a prevenção e controle das doenças não-transmissíveis e infecciosas (Magee, Blumberg, Narayan, 2011).

Numa outra perspectiva, pesquisa transversal de Goldhaber-Fiebert et al. (2011) avaliou a relação entre o DM e a TB, usando dados populacionais de 46 países, priorizando aqueles de renda mais baixa. Seus objetivos foram avaliar o impacto dos aumentos longitudinais da prevalência do DM sobre as mudanças na prevalência e incidência de TB, e identificar os países potencialmente "de risco" para as interações TB-DM devido à alta prevalência de ambas. Consideraram que a prevalência de TB é mediada por determinantes sociais e estratégias de saúde pública. Para os autores, as interações entre o aumento do DM, impulsionado por mudanças na dieta e estilo de vida, e permanência da epidemia de TB, alimentada pela resistência às drogas, HIV/AIDS e pelas desigualdades sociais, demandam 
avaliação, devido aos riscos individuais, aos determinantes sociais e aos impactos na saúde da população (Goldhaber-Fiebert et. al., 2011).

O modelo de Goldhaber-Fiebert et. al. (2011) incluiu co-variáveis que tinham sido previamente associadas à TB: sexo, idade, IMC, escolaridade, histórico de tabagismo e fumo diário, alcoolismo; residência urbana ou rural; número de indivíduos vivendo no mesmo domicílio, número de pessoas por dormitório; status socioeconômico (definido pelo fato da moradia ter piso de cerâmica, cimento, tijolo ou madeira e paredes de cimento, tijolo, pedra ou madeira, dispor de instalações sanitárias e sistema de esgoto encanado ou fossa séptica; despesa total domiciliar per capita em relação ao mês anteriore ter seguro de saúde). Na análise do plano individual, em países de baixa renda, após o ajuste para o status de seguro de saúde e renda per capita, os indivíduos eram mais propensos a relatar sintomas de TB ativa, se também relataram diagnóstico prévio de DM tipo 2. No plano populacional, entre os anos 1990 e início de 2000, a prevalência e a incidência de TB foram mais propensas a aumentar nos países em que a prevalência de DM aumentou. Os autores destacam como países de particular preocupação, dado o seu tamanho, carga significativa de TB e importante aumento na prevalência de DM, o Brasil, a China, a Índia, o Peru e a Rússia (Goldhaber-Fiebert et. al., 2011).

Estudo de coorte prospectivo, realizado em Taiwan, em 2001, foi realizado para estimar o risco de TB entre pessoas com DM, através de medidas sóciodemográficas e comportamentais. As variáveis incluídas como fatores de risco para a TB foram: sexo, idade, aglomeração, tabagismo, renda familiar, estado civil, escolaridade, abuso de álcool, residência em comunidade indígena, recebimento de subsídio governamental, emprego, doença pulmonar, IMC, hipertensão e doenças cardíacas. Sujeitos com DM apresentavam maior idade, baixa renda familiar, recebiam subsídios do governo, maior prevalência de desempregados, estavam casados ou em união, tinham menor escolaridade, IMC mais elevado, hipertensão, doença cardíaca e doença pulmonar. Quanto aos fatores de risco compartilhados entre os sujeitos com DM e aqueles cm TB encontrou-se: idade avançada, desemprego e baixa 
escolaridade. A risco na análise univariada foi quase duas vezes maior que na análise multivariada. Sobre esses resultados, os autores refletem quanto ao papel complexo que o IMC desempenha na etiologia da suscetibilidade à TB. A pesquisa demonstra que o DM aumenta o risco para a TB (Baker et al. 2012).

Moualeu et al. (2012) investigou o impacto do DM sobre a dinâmica de transmissão da TB na comunidade, considerando seus determinantes individuais e sociais, através da criação de um modelo matemático. O principal objetivo do estudo foi prever tendências futuras na incidência de TB e quantificar a associação entre DM e TB na comunidade. $O$ contexto considerado foi o de diminuição, nas últimas décadas, da incidência de TB em países de alta renda, mas alta incidência em países que têm altas taxas de infecção com o HIV, alta prevalência de desnutrição e condições de vida em locais superlotados, ou pobre infraestrutura para o controle da TB; além do aumento na prevalência de DM no nível mundial, impulsionado pela obesidade. A posição do autor é de que o DM afeta negativamente o controle da TB e enquanto esse controle for tomado como uma intervenção apenas biomédica, com quimioprofilaxia e tratamento por si só, pode não ser bem sucedido. Afirma que cuidar de pacientes com TB envolve mais do que apenas oferecer o tratamento anti-TB, e se apoio adicional apropriado não é fornecido (a partir da detecção ou do diagnóstico) ao cumprimento e à conclusão do regime de tratamento, uma taxa de cura de $88 \%$, como promovida pelo programa DOTS, provavelmente não seria alcançada. Ressalta a necessidade urgente de estratégias de intervenção voltadas para o paciente e não para a doença, tais como aconselhamento e campanhas educativas, a fim de reduzir a propagação da TB bem como a prevenção primária e controle da DM, através da atenção às dietas não saudáveis, sedentarismo e obesidade infantil e no adulto (Moualeu et. al., 2012). 
Análise descritiva dos Resultados $\mid \mathbf{7 8}$ 


\section{RESULTADOS E DISCUSSÃO}

\subsection{Os determinantes sociais e a coexistência TB-DM}

Esta revisão foi capaz de demonstrar a progressiva importância atribuída à associação entre uma doença infecciosa, como a tuberculose, e uma doença crônica não-transmissível, como o diabetes mellitus, nas pesquisas científicas, ao logo das últimas décadas.

Apesar de, como já colocado, ser conhecida há muitos anos, tal associação ganha representatividade com o aumento disparado na incidência do diabetes mellitus tipo 2 e da obesidade a partir de meados da década de 1990. Resultado da transição de estilos de vida rumo a uma maior ingestão de calorias, em alimentos de fácil preparo e/ou consumo, e menor atividade física.

A maior densidade de produção científica acerca da associação é percebida no final da década de 90 e início dos anos 2000. Uma análise temporal permite observarmos a priorização de uma abordagem biomédica para tratar da associação TB-DM até o final do ano 2000. Nota-se que os primeiros estudos classificados com enfoque social ocorrem a partir de 2011, com a pesquisa epidemiológica-social de Goldhaber-Fiebert et al. (2011) e o estudo farmacológico-social de Gnanasan et al. (2011). As publicações anteriores foram classificadas com enfoque de apresentação clínica (4), epidemiológico com abordagem clássica (8), imunológico (2) e farmacológico (1). As próximas publicações classificadas com enfoque epidemiológico social ocorreram no ano de 2012 com o modelo epidemiológico de Moualeua et al. (2012), estudo de Sullivan e Amor (2012) e estudos chineses de Lin et al. (2012) e Wang et al. (2012).

Em decorrência das discussões sobre Epidemiologia Crítica e medicina social, a ênfase nos determinantes sociais de saúde é amplamente difundida na Conferência de Alma-Ata, no final dos anos 70 e nas atividades inspiradas no lema "Saúde para todos no ano 2000", e gradual e lentamente introduzida na década seguinte em meio a um sistema ainda privatista e de assistência médica individual. Na década de 90, tal ênfase ganha força com o debate sobre as Metas do Milênio e a criação, em 2005, 
da Comissão sobre Determinantes Sociais da Saúde da OMS, (Buss, Pellegrine Filho, 2007). Percebe-se que a introdução dos determinantes sociais de saúde na discussão dos estudos sobre a associação TB-DM tem um avanço tardio. Esta observação é relevante ao considerarmos que a discussão acerca da determinação social da tuberculose deu-se já no início da década de 90.

Considerar a determinação social da associação TB-DM significa pensa-la sendo usualmente devido a fatores como condições de vida e trabalho, estilo de vida, fatores sociais, status econômico, exposição ocupacional, fatores genéticos e ecológicos, fatores culturais, étnicos/raciais, psicológicos e comportamentais que influenciam a ocorrência de problemas de saúde e que contribuem para a incidência da associação TB-DM dos indivíduos e de grupos populacionais (Buss, Pellegrini Filho, 2007; Davies, Grange, 2001).

À excessão dos estudos ditos como sociais, o que se observou nas publicações incluídas neste estudos foi o predomínio de utilização de variáveis sociodemográficas para representar a amostra de indivíduos. Tanto nos estudos de apresentação clínica quanto naqueles de enfoque epidemiológico, variáveis como sexo, idade, presença de comorbidades, em especial o HIV, escolaridade, raça e etnia foram predominantemente consideradas. Para Buss e Pellegrini Filho (2007), esta análise restrita a fatores sociodemográficos classifica os indivíduos em grupos de acordo com certas características (sexo, idade, escolaridade, renda, raça ou etnia). Após estruturar os grupos populacionais, o pesquisador converte os dados desta população específica em percentuais de epidemiologia clássica, calculandoos aritmeticamente a partir das características individuais (Buss, Pellegrini Filho, 2007).

Os estudos classificados como epidemiológicos de abordagem clássica mantém a tendência de utilização de variáveis sociodemográficas, porém destacam-se por consider além destas, os fatores sociais clássicos para a tuberculose, como tabagismo, alcoolismo, uso de drogas, situação de encarceramento, ausência de seguridade social, baixa escolaridade, situação de superpopulação; ou aqueles relacionados à causalidade do diabetes 
mellitus, como estilo de vida sedentário, índice de massa corporal (IMC), colesteral.

Apesar de reconhecerem que tais fatores sociais têm impacto na causalidade de enfermidades como a tuberculose e o diabetes mellitus, a maior parte destas pesquisas não apresentaram em seus resultados ou em sua discussão uma correlação entre a presença ou ausência destes fatores sociais e a incidência de co-ocorrência TB-DM, ou seja, os resultados para estas varíaveis são apresentados de forma individualizada e descontextualizada. Uma excessão é o estudo de Pérez-Guzmán et al. (2003) que ao analisar o resultado obtido pela variável sexo, justifica a predominância de pacientes do sexo masculino no grupo TB é pela maior atividade social exercida pelos homens, o que os predispõe a risco aumentado de contato a tuberculose. Condições socioeconômicas e culturais são postuladas nesta pesquisa como fatores que causam menor acesso aos serviços de saúde pelas mulheres, resultando em subdiagnósticos e subnotificações.

O que se observou portanto nos estudos com os enfoques de apresentação clínica e de epidemiologia clássica foi a multifatorialização da associação entre tuberculose e o diabetes mellitus. Ao contrário desta prática, o que se espera nas pesquisas de duas enfermidades com altas cargas de fatores sociais incidindo sobre sua causalidade, é a análise da causalidade através das principais categorias analíticas: reprodução social, classe social, produção econômica, cultura, etnia e gênero, entre outros. Para Iriart et al. (2002), é a partir destas categorias que as especificidades individuais, como sexo, idade, escolaridade, renda ou raça, encontram sua determinação explicativa. Por exemplo, se não se explicitam as categorias econômicas, sociais, políticos e ideológicas específicas que, em uma determinada sociedade e momento histórico, definem ser uma mulher ou um homem em relação ao problema estudado, estão ignorando os determinantes que subjacem a classificação por sexo (Iriart et al., 2002).

Como exemplo da utilização dos determinantes sociais como variável de estudo tem-se o estudo epidemiológico de Gholdaber-Fiebert et al. (2011), que realizou análise em países agrupados por região geográfica para avaliar como o relacionamento, bem como mediadoras influências de 
determinantes sociais variou entre as regiões. O modelo incluiu co-variáveis que tenham sido previamente associados com TB: sexo, idade categorizada em intervalos de 10 anos , índice de massa corporal (IMC) classificado como; escolaridade em anos; tabagismo e o número de anos que uma pessoa tem sido um fumante diário, beber pelo menos uma dose por dia; residência urbana ou rural; número de indivíduos vivendo na casa, número de pessoas por quarto; status sócio-econômico definido pelo fato de a casa tinha pisos feitos de cerâmica, cimento , tijolo ou madeira e paredes feitas de cimento, tijolo, pedra ou madeira, se a casa tinha instalações sanitárias liberadas a um sistema de esgoto encanado ou fossa séptica, a despesa total do agregado familiar percapita no mês anterior, expresso em ano 2.003 dólares internacionais, calculadas com paridade de poder aquisitivo e ter seguro de saúde (Gholdaber-Fiebert et al.; 2011).

Tanto as variáveis sociodemográficas presentes neste estudo, quanto os DSS foram analisados de forma interativa, desta forma, foram explorados os efeitos de status sócio-econômico relativo sobre a relação entre a tuberculose e a diabetes, bem como as interações entre diabetes e as medidas de despesa relativas. Além disso, avaliou-se as interações entre sexo, idade, tabagismo e consumo de álcool e as medidas de despesa relativa (Gholdaber-Fiebert et al.; 2011).

Observa-se portanto uma distinção entre os determinantes de saúde dos indivíduos e os de grupos e populações. Para Buss e Pellegrine Filho (2007) não basta somar os determinantes de saúde identificados em estudos com indivíduos para conhecer os determinantes de saúde no nível da sociedade. Para Iriart et al. (2002) o trabalho da epidemiologia social considera a população e as instituições sociais como totalidades cujas características transcendem os indivíduos que compõem, definindo os problemas e desenvolvendo suas pesquisas por meio de unidades sociais e individuais de análise, mas com um quadro teórico e metodológico coletivo (Iriart et al., 2002). Fatores de risco individuais, como colesterol, hábito de fumar, hipertensão arterial e outros são capazes de explicar apenas uma pequena parte da diferença de situação de saúde entre diferentes grupos populacionais, porém as especificidades individuais e de grupo são 
analisados no contexto social que os determina (Buss, Pellegrine Filho, 2007; Iriart et al., 2002).

A ruptura entre os fatores clínicos e imunológicos e aqueles sociais e sociodemográficos foi observada em diversos estudos. Restrepo et al. (2007) descrevem a tuberculose como doença da pobreza ou de imunossupressão. Para Davies e Grange (2001), além dos fatores genéticos e ambientais que contribuem para a resistência e susceptibilidade à tuberculose, deve-se considerar os fatores sócio-econômicos responsáveis pelas grandes diferenças na incidência de tuberculose nos países. Embora as diferenças inatas na resistência possam ocorrer, estes devem ser considerados à luz de numerosos estilo de vida não-hereditária e fatores sociais (Davies, Grange, 2001).

As variáveis raça e etnia também estavam presentes nos estudos primários considerados nesta pesquisa. Estudos de Dyck et al. (2007) que faz distinção entre populações aborógenes no Canadá e de Walker et al. (2010) que faz distinção entre indivíduos asiáticos, negros e brancos, representam pesquisas que utilizaram as variáveis raça e etnia para verificar as diferenças de apresentação clínica ou epidemiológica da associação TBDM. Apesar das reivindicações de que populações e grupos raciais variam em sua resistência à tuberculose, para Davies e Grange (2002) ainda é muito difícil separar os fatores determinados geneticamente daqueles ambientais. Ainda segundo estes autores, o risco de tuberculose em todos os grupos raciais e étnicos está relacionada à baixa renda, a pobreza, a necessidade de assistência pública, desemprego, falta de educação e, mais fortemente, com superlotação, ao invez de isoladamente relacionadas às origens étnicas dos pacientes, apesar da grande maioria das pessoas nos grupos de minorias étnicas viverem em áreas pobres (Davies, Grange, 2001).

Além da utilização de variáveis multifatoriais outra tendência observada nos estudos primários foi o predomínio de pesquisas com enfoque biomédico, principalmente nas pesquisas classificadas com enfoque imunológico e nas de apresentação clínica. Na primeira categoria observa-se uma centralidade nos aspectos biológicos da associação TB-DM. Estes centram-se na investigação de aspectos microbiológicos ou imunológicos da 
associação, sempre desconsiderado qualquer influência de fatores sociais sobre estes aspectos. Outro objetivo bastante presente nesta categorias é o de desenvolver formas de diagnóstico para a associação, representadas pelos estudos de Mustafa et al. (2008), Tan et al. (2010), Walsh et al. (2011) e Zhang et al. (2011), e desta forma, desconsoderam que este diagnóstico deve estar contextualizado às condições de vida e saúde das populações, ao acesso aos serviços de saúde, entre outros fatores sociais.

As estudos primários de apresentação clínica centram-se em pesquisas sobre as manifestações clínicas, radilógicas e bacteriológicas da associação TB-DM, e assim como a categoria anterior, mantém uma discussão predominantemente biomédica desta associação.

Já pesquisas categorizadas como enfoque farmacêutico centraram-se na apresentação ou efetividade dos medicamentos ou na efetividade do tratamento de tuberculose em pacientes com diabetes mellitus. A destes estudos primários realizou esta análise sem considerar todo o complexo processo que envolve a adesão ao tratamento de ambas enfermidades. Esta complexidade é explicada por Queiroz et al. (2012, p. 370), que considera “a adesão ao tratamento como dimensão que extrapola os aspectos clínicos e biológicos, avançando da multifatorialização do processo saúde-doença para a sua determinação social”. Esta inclusão dos determinantes sociais de saúde na pesquisa de adesão ao tratamento da associação TB-DM foi realizada apenas no estudo de Gananasan et al. (2011), categorizado como farmacológico-social, onde considerou-se a gestão da TB como altamente desafiadora quando um paciente se apresenta com DM como comorbidade. Para os autores, este desafio se coloca inicialmente na quantidade de medicamentos que este indivíduo em tratamento de DM e TB deverá tomar e o impacto disto sobre a adesão ao tratamento. Tratou-se de pesquisa qualitativa para avaliar a assistência farmacêutica precisa dos pacientes com TB e DM, explorando as crenças dos pacientes sobre a medicação e as preocupações. As experiências dos profissionais de saúde na gestão de pacientes com TB e DM também foram investigadas. Os resultados da investigação qualitativa destacaram que uma solução abrangente de gestão de assistência farmacêutica deve incorporar a educação e aconselhamento 
do paciente, acompanhamento de reações adversas, revisão de medicação e cuidado centrado nas necessidades do paciente.

Em estudo categorizado como epidemiológico-social, Sullivan e Amor (2012) também concentram sua atenção na gestão do tratamento da tuberculose e do diabetes mellitus. Os autores investigam a co-gestão do tratamento TB-DM, sugerindo se esta deva se tornar mais integrada, similar aos recentes esforços para vincular a gestão da TB e HIV. O fazem considerando que a TB é decorrente de diversos fatores sociais e econômicos, como a pobreza ou desnutrição, bem como outras doenças infecciosas, como o HIV; e que a prevalência de obesidade e diabetes devem aumentar dramaticamente nas áreas pobres em recursos, onde TB prospera.

Sullivan e Amor (2012) propõem que todos os pacientes com TB sejam sistematicamente rastreados para a diabetes, e que todos os pacientes com diabetes sejam rastreados para a TB, quando sintomática. Como medidas de tratamento, propõem a ampliação dos programas de TB locais para incluir o tratamento da diabetes, sendo necessário o treinamento dos agentes comunitários de saúde no tratamento do diabetes básico, tais como testes de glicose no sangue e gestão de medicamentos, bem como a consulta de enfermeiros e médicos treinados em gestão de diabetes. Além da continuidade do cuidados de pacientes que já concluíram o tratamento de TB, retornando para exames regulares de tuberculose após a conclusão do tratamento da TB para garantir melhor acompanhamento e detecção rápida de possíveis recaídas. Os autores sugerem também que os programas de controle da TB devam desenvolver materiais educativos a serem distribuídos em centros de tratamento do diabetes, para informar os pacientes diabéticos do seu risco de desenvolver TB ativa (Sullivan, Amor, 2012).

Desenho de estudo bastante presentes entre as pesquisas de enfoque epidemiológico, os estudos epidemiológicos, como estudos coorte, modelos epidemiológicos, entre outros, mantiveram, em sua maioria, uma abordagem epidemiológica clássica e objetivaram identificar a incidência e/ou prevalência da associação TB-DM. As análises estatísticas com ou sem 
regressão logística, foram observadas e os resultados foram apresentados em sua maioria de forma quantitativa ou estatística. Autores como Breilh, defendem as tendências metodológicas atuais para abordagem multimetodológico que "triangula" métodos complementares de análise do nível individual e social, onde mesmo nos inquéritos iniciais, combinam-se métodos e técnicas de coleta de dados quantitativos e análise multivariada, com métodos qualitativos Iriart et. al (2002). Um exemplo deste método combinado é o estudo de Moualeu et al. (2012), que através de criação de modelo epidemiológico com análise qualitativa, em estudo primário de enfoque epidemiológico social, demonstrou que o DM está associado a resultados negativos de saúde específicos e promove o desenvolvimento de TB. Além disso, demonstrou que na presença de tratamento, o controle da tuberculose é mais eficaz em comunidades com não diabéticos do que nas comunidades com diabéticos. Assim, DM pode reduzir a eficácia do tratamento da TB e melhora a transmissão da TB e progressão da doença (Moualeu et al., 2012).

A discussão realizada por Moualeu et al. (2012) é de que o DM afeta negativamente o controle da TB enquanto esse controle for tomado como uma intervenção puramente biomédica. Basear o tratamento apenas em quimioprofilaxia e tratamento pode não ser bem-sucedido em populações com alta incidência de DM. Para os autores, cuidar de pacientes com tuberculose envolve mais do que apenas dar o tratamento anti-TB, e se apoio adicional (a partir de detecção ou diagnóstico) ao cumprimento e conclusão do regime de tratamento apropriado não fosse fornecido, uma taxa de cura de $88 \%$ promovida pelo programa DOTS provavelmente não seria alcançado (Moualeu et al., 2012). As estratégias de intervenção propostas pelo autores englobam aconselhamento e campanhas educativas; prevenção primária da DM através da atenção às dietas não saudáveis, sedentarismo e obesidade infantil e adulto devem ser incluídas nas estratégias de prevenção gerais para doenças não transmissíveis, como a tuberculose.

É possível observar que as propostas de gerenciamento do tratamento TB-DM destes três últimos estudos primários classificados com 
enfoque social que transcendem os aspectos biomédicos da associação e consideram a integração de estratégias de prevenção e de cuidados de doença transmissíveis e não transmissíveis, voltando-se para o paciente e não para a doença e considerando seus determinantes sociais.

Observou-se portanto, nos estudos apresentados um predomínio de pesquisas com enfoque biomédico ou pautado na epidemiologia clássica. A associação TB-DM é vista nestes casos como comorbidade estática, sendo desconsiderado seu caráter dinâmico e o efeito do contexto social na causalidade destas enfermidades. Vê-se, portanto a necessidade de um olhar sobre a associação TB-DM com lentes que considerem os determinantes sociais de saúde, entendendo o conceito de saúde e doença como processo dialético e não como uma categoria dicotômica (Iriart et al., 2002).

Entende-se que para a implantação de estratégias de gestão da associação entre a tuberculose e o diabetes mellitus deva-se entender o perfil epidemiológico dos grupos sociais nas sociedade onde há alta incidência da coexistência destas enfermidades (Iriart et al., 2002). Esta co-gestão requer uma análise multinível para entender por que e como social, como a reprodução social, a produção econômica, a cultura, a marginalização e as condições de participação política, se organizam historicamente em distintos modos de vida característicos de distintos grupos e determinar as estratégias de acesso às condições favoráveis ou de proteção ou condições desfavoráveis ou destrutivas, estabelecendo a dinâmica do processo saúde e doença para associação TB-DM (Iriart et al., 2002).

\subsection{Análise espacial da associação TB-DM}

A distribuição espacial das publicações incluídas no estudo foi heterogênea, compreendendo todos os continentes a exceção da Oceania.

Nenhuma pesquisa no Brasil foi encontrada, apesar deste estar entre os 22 países com maior incidência de tuberculose no mundo, ocupando a $17^{\circ}$ posição em 2012 , e estar na $4^{\circ}$ posição no ranking mundial de países com maior incidência de diabetes mellitus, com 11,9 milhões de indivíduos no ano de 2013 (IDF, 2013; WHO, 2013), além dos inúmeros 
determinantes sociais presentes no país que predispõem a co-ocorrência de TB e DM.

Das 23 localidades onde realizaram-se pesquisas sobre a associação entre tuberculose e diabetes mellitus a grande maioria ocorreu em países em desenvolvimento ou subdesenvolvidos (Figura 2).

Figura 4 - Resultados de quantificação de publicações por país de pesquisa.

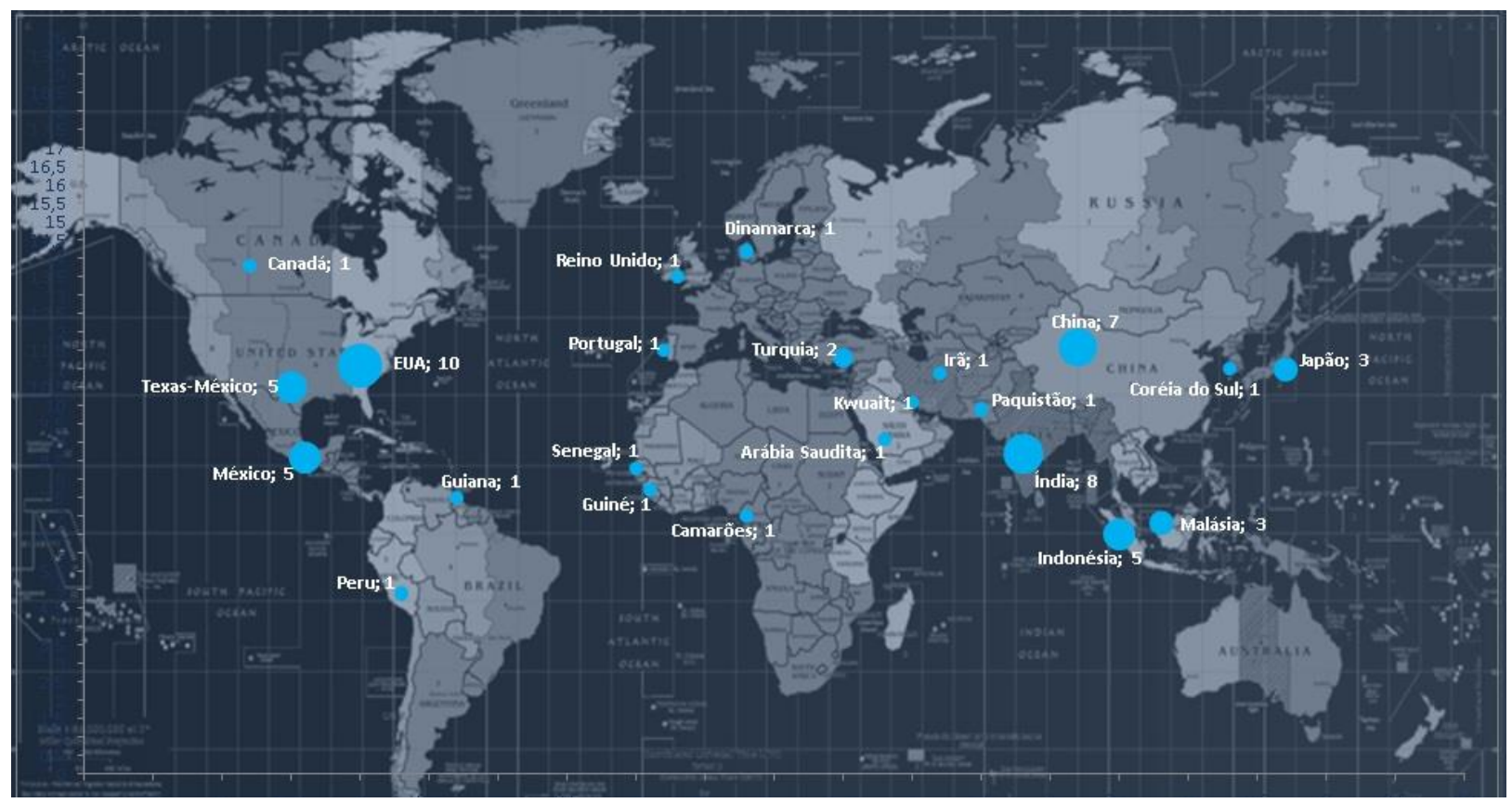

A liderança em publicações e como local de estudo foi dos EUA. A tendência predominante encontrada nos estudos realizadas em países desenvolvidos foi a realização de pesquisas em populações ou regiões socialmente vulneráveis. $\mathrm{Na}$ situação específica dos EUA, 33,3\% das pesquisas foi realizada no Texas, na região fronteiriça com o México. Este é um dos mais pobres estados americanos e apresenta alta prevalência de tuberculose e aumento progressivo na incidência de diabetes mellitus. No caso de estudo realizado no Canadá, a população em questão foi de Saskatchwan, população indígena com alta prevalência de tuberculose. Os estudos no Japão compreenderam pesquisas com enfoque imunológico, sendo os ensaios clínicos em ratos de Sugawara, Yamada e Mizuno (2004) e de Yamashiro et al. (2005), e o estudo de Wang et al. (2009) realizado no Hospital Municipal de Kaohsiung Hsiao-Kang, que serve como um centro 
de referência terciária e de cuidados primários no sul de Taiwan, que possui as maiores taxas de notificação de casos de TB e de mortalidade por TB do Japão (Liao et al., 2012). O estudo no Reino Unido ocorreu com dados populacionais do Observatório Público de Yorkshire and Humber e a análise foi baseada em grupos populacionais étnicos: asiáticos, negros e brancos.

Nos países de renda alta tem-se as 15 pesquisas realizadas nos EUA, sendo que três ocorreram no Texas e 5 na fronteira do Texas com o México, e as 3 pesquisas realizadas no Japão. A lista de publicações por países é seguida por países de renda média alta, como China, com 7 pesquisas, México com 5, Malásia com 3 e Turquia com 2; países de renda média e baixa, como a Índia, com 8 pesquisas e Indonésia com 5.

Dos 23 países onde foram realizados estudos sobre a associação TBDM, 4 encontram-se entre os 22 países com maior incidência de TB no mundo, estando eles no topo da lista de incidência por 100.000 habitantes em 2012, segundo WHO (2013), são eles: Índia $\left(1^{\circ}\right)$, China $\left(2^{\circ}\right)$, Indonésia $\left(4^{\circ}\right)$ e Paquistão $\left(5^{\circ}\right)$ (WHO, 2013). Os achados corroboram com os dados de que mais de $50 \%$ dos casos mundiais de tuberculose são encontrados no sudeste da Ásia e do Pacífico Ocidental (Liao et al., 2012). Nestas regiões observa-se aumento crescente da incidência de diabetes mellitus, além de

Quanto à incidência de Diabetes observa-se uma coincidência nos resultados de estimativas de pessoas com Diabetes em 2013, quando comparamos os 10 primeiros países no ranking de incidência da doença em milhões de pessoas. A China ( $1^{\circ}, 98,4$ milhões) lidera o ranking, seguida da Índia ( $2^{\circ}, 65,1$ milhões) e EUA ( $3^{\circ}, 24,4$ milhões). O México aparece em $6^{\circ}$ lugar (8,7 milhões), a Indonésia em $7^{\circ}$ (8,5 milhões) e o Japão em $10^{\circ}$ lugar (7,2 milhões) (International Diabetes Federation, 2013). Como se pode observar ao analisarmos os números e segundo o International Diabetes Federation (2013), a maioria das pessoas com diabetes vivem nas regiões economicamente menos desenvolvidas do mundo. Enquanto mais de $80 \%$ das pessoas com diabetes vivem em países de renda baixa e média apenas $20 \%$ dos gastos de saúde globais sobre diabetes foram gastos nesses países, refletindo enormes disparidades. 
Davies e Grange (2001) relatam que as tendências de mudanças observadas até o presente momento na incidência de tuberculose no mundo permitem a observação de que aparentemente as diferentes populações ao redor do mundo estão em estágios diferentes da pandemia de tuberculose. Estes autores acreditam que depois de 200 anos de história de tuberculose, a população branca do Oeste Europeu, pode estar estar no final ou próximo ao final da epidemia desta doença infecciosa. Em contraste, as populações de nações em desenvolvimento, como China e Índia estão somente na metade do caminho com uma incidência anual "natural" de tuberculose de 100 a 200 por 100000 habitantes (Davies, Grange, 2001). Esta mudança na tendência incidência da tuberculose pode muito bem ser extendida para a discussão acerca da associação TB-DM. A própria coexistência de tuberculose e diabetes mellitus representa um fator de modificação da apresentação destas enfermidades nos territórios, pois permitem a possibilidade de reascenção de TB em países onde as incidências já declinaram no decorrer dos anos. A epidemiologia crítica estuda o conceito saúde-doença no contexto social, considerando-se os efeitos das mudanças nas condições sociais ao longo do tempo Iriart et. al (2002).

Em estudo epidemiológico de base populacional realizado por Goldhaber-Fiebert et al. (2011), indivíduos em países de baixa renda, onde a maioria da carga de TB do mundo está localizado, eram mais propensos a relatar sintomas de tuberculose ativa, se eles também relataram diagnóstico prévio de DM2. Ao nível da população, entre os anos 1990 e início de 2000, a prevalência e a incidência de TB eram mais propensos a aumentar nos países em que a prevalência de diabetes aumentou, condicionado no anobase, ao PIB per capita. Países de particular preocupação, dado o seu tamanho, encargos substanciais TB e grandes aumentos previstos na prevalência de diabetes incluem o Brasil, China, Índia, Peru e da Federação Russa (Goldhaber-Fiebert et al. 2011).

O formato de caracterização dos locais e países de ocorrência das pesquisas deu-se, para a maior parte dos estudos, como subdistritos e distritos da cidade de acordo com os parâmetros clássicos sociodemográficas, associando estas informações com dados 
epidemiológicos sobre a prevalência e incidência da doença. Para Breilh (2010), o " diagnóstico " da saúde de uma cidade, não pode ser feito por dados lineares cartesianos e esquemas formais de nível empírico, e só com base em estatísticas e camadas geoespaciais de efeitos ou, indicadores mensuráveis observáveis , mas deve integrar todos determinar as relações de uma forma que para interpretar a gênese de tais efeitos observáveis (Breilh, 2010).

Alguns estudos compararam a prevalência da associação de acordo com as variáveis rural e urbano, mas sem realizar a discussão acerca do significado desta distinção para estas comorbidades. Esta discussão quanto ao espaço geográfico de ocorrência da associação TB-DM bem como o espaço onde os pesquisadores decidem pesquisa-la é justificada por Breilh (2010) ao refletir que os problemas de saúde superam as restrições da teoria clássica do espaço urbano e as concepções reducionistas da saúde e do meio ambiente, para abordar a necessidade coletiva (Breilh, 2010). Este mesmo autor cita o conceito de Lefebvre (1969), que considera que este espaço urbano não pode ser considerado como um locus passivo das relações sociais, mas sim, hospeda a visão dialética do espaço como oposições contraditórias e cruzados, com papel operacional e instrumental como conhecimento no modo de produção existente (Breilh, 2010).

A incidência na associação TB-DM podem ser atribuíveis a muitas diferenças ambientais entre populações urbanas e rurais.

Outra tendência observada nos estudos foi a realização de grande maioria em ambiente hospitalar. Hospitais de referência para doenças respitarórias, clínicas ambulatoriais ou centros de referência de tratamento de TB foram os ambientes mais comuns para coleta de dados, bem como a utilização de dados registros hospitalares. Dados retirados de amostras populacionais, como bases de dados populacionais para TB ou DM também foram comuns, principalmente para estudos epidemiológicos. Dos 13 estudos com enfoque de apresentação clínica, 10 (76,92\%) ocorreram com pacientes hospitalizados ou com dados de registros hospitalares. Estudos de Rawat, Sindhwani e Biswas (2011) considerou pacientes internados em ambiente hospitalar, mas também pacientes ambulatoriais que não 
permaneciam em estado de internamento, e Alisjabhama et al. (2007) realizaram estudo com pacientes de 3 clínicas ambulatoriais. Os 26 estudos com enfoque epidemiológico ocorrem em ambiente hospitalar, em clínicas de referência para TB e com dados de bases populacionais. Este achado representa uma restrição nas pesquisas à utilização de dados sociodemográficos e fatores de risco coletados no ambiente hospitalar ou ambulatorial, representados pelos questionamentos de enfoque predominantemente biomédicos.

Ao considerar a que saúde humana e os ecossistemas são objetos que incluem processos biológicos socialmente determinados, Breilh (2010) ressalte-se que na realidade epidemiológica da cidade, não há objeto puro nem sujeito puro, mas um movimento entre sujeitos e objetos são objetivados produção de sujeitos. Ou seja, não há nenhuma área urbana de saúde como lugar estático, continente e passivos, mas um movimento complexo e criativo espaço (Breilh, 2010).

Tem-se portanto que tanto os espações urbanos como a forma de evolução dos mesmos, refletidos nas condições de vida e trabalho, hábitos alimentares e padrões de movimento, representam fatores determinantes nas condições de saúde das populações e têm grande influência na apresentação de enfermaidades a exemplo da Tuberculose e do Diabetes Mellitus. 


\section{CONSIDERAÇÕES FINAIS}

Esta pesquisa permitiu uma análise sobre o olhar dos pesquisadores quanto à associação entre a Tuberculose e o Diabetes Mellitus. Reiterando a hipótese de estudo, observou-se predomínio de um enfoque biomédico pautado na multifatorialização da causalidade da associação TB-DM.

Apesar da TB e da DM serem enfermidades em que se denota importante componente social, a maior parte dos estudos analisados não leva em conta a Determinação Social do processo Saúde-Doença. Observouse a tendência dos pesquisadores em avaliar o impacto do DM no gerenciamento clínico e programático da $\mathrm{TB}$, com foco na conversão de cultura de escarro, desfecho de tratamento, recorrência de TB e interações farmacocinéticas entre os medicamentos de DM e TB.

Apesar de realizados em países com forte desigualdade social e desigualdades em saúde, onde a incidência de TB permanece alta e a do DM se mantém crescente, a maior parte dos estudos indagou a associação TBDM sem considerar a forte determinação social posta na causalidade destas doenças, bem como os DSS como condicionantes para a coexistência destas enfermidades. Ao entendermos os DDS como grandes responsáveis pelas iniquidades em saúde, sabemos que somente uma ação sobre eles pode resultar em melhoria da saúde.

Pode-se notar que apesar das crescentes discussões acerca da associação entre TB e diabetes, a implantação de medidas para o gerenciamento destas comorbidades ainda é negligenciada. O Relatório Global da World Health Organization (WHO, 2013) para o ano de 2013, cita o diabetes mellitus como uns dos diversos fatores que aumentam o risco para TB ativa (WHO, 2013, p. 33, 93). Não há neste relatório informações sobre o impacto do Diabetes Mellius nas taxas de incidência e prevalência da Tuberculose, e a coexistência da associação TB-DM não é relatada.

Posto isso entende-se a necessidade de maiores pesquisas que considerem o rastreio para identificação da associação TB-DM, bem como a co-gestão do tratamento, e principalmente que tais medidas considerem os DSS como variáveis a serem investigadas, permitindo a implantação de 
praticas adequadas para retardar o crescimento do DM e reduzir a vulnerabilidade das populações à infecção por TB. 


\section{REFERÊNCIAS}

Alisjahbana B, van Crevel R, Sahiratmadja E, den Heijer M, Maya A, Istriana E, Danusantoso H, Ottenhoff TH, Nelwan RH, van der Meer JW. Diabetes mellitus is strongly associated with tuberculosis in Indonesia. Int $\mathbf{J}$ Tuberc Lung Dis. 2006 Jun;10(6):696-700.

Alisjahbana B, Sahiratmadja E, Nelwan EJ, Purwa AM, Ahmad Y, Ottenhoff THM, et al. The effect of type 2 diabetes mellitus on the presentation and treatment response of pulmonary tuberculosis. Clin Infect Dis. 2007 August 15; 45(4): 428-435. Published online 2007 July 5.

Al-Jahdali H, Al-Zahrani K, Amene P, Memish Z, Al-Shimemeri A, Moamary M, Alduhaim A. Clinical aspects of miliary tuberculosis in Saudi adults. Int J Tuberc Lung Dis. 2000 March; 4(3): 252-255.

Alladin B, Mack S, Singh A, Singh C, Smith B, Cummings E, et al. Tuberculosis and diabetes in Guyana. Int J Infect Dis. 2011

Dec;15(12):e818-21. Epub 2011 Sep 9.

American Diabetes Association. Diagnosis and classification of diabetes mellitus. Diabetes Care. vol. 27. Supl. 1. Jan. 2004.

Arcêncio RA, Arakawa T, Oliveira MF, Cardozo-Gonzales RI, Scatena LM, Ruffino-Netto A, et al . Barreiras econômicas na acessibilidade ao tratamento da tuberculose em Ribeirão Preto - São Paulo. Rev. esc. enferm. USP [serial on the Internet]. 2011 Oct [cited 2012 Nov 07] ; 45(5): 11211127.

Arce-Mendoza A, Rodriguez-de Ita J, Salinas-Carmona MC, Rosas-Taraco AG. Expression of CD64, CD206, and RAGE in adherent cells of diabetic patients infected with Mycobacterium tuberculosis. Arch Med Res. 2008 Apr;39(3):306-11. doi: 10.1016/j.arcmed.2007.11.013.

Arredondo A, Zuñiga A, Parada I. Health care costs and financial consequences of epidemiological changes in chronic diseases in Latin America: evidence from Mexico. Public Health. 2005;119:711-20.

Bacakoğlu F, Başoğlu OK, Cok G, Sayiner A, Ateş M. Pulmonary tuberculosis in patients with diabetes mellitus. Respiration. 2001; 68(6): 595-600.

Bailey SL, Grant P. 'The tubercular diabetic': the impact of diabetes mellitus on tuberculosis and its threat to global tuberculosis control. Clin Med. 2011 Aug;11(4):344-7. 
Baker MA, Harries AD, Jeon CY, Hart JE, Kapur A, Lonnr Oth K, et al. The impact of diabetes on tuberculosis treatment outcomes: a systematic review. BMC Medicine 2011, 9:81.

Baker MA, Lin HH, Chang HY, Murray MB. The risk of tuberculosis disease among persons with diabetes mellitus: a prospective cohort study. Clin Infect Dis. 2012 Mar;54(6):818-25. doi: 10.1093/cid/cir939. Epub 2012 Jan 11.

Balasubramanian R, Ramanathan U, Thyagarajan K, Ramachandran R, Rajaram K, Bhaskar D, et al. Evaluation of an intermittent six-month regimen in new pulmonary tuberculosis patients with diabetes mellitus.. Indian J Tuberc. 2007 October; 54(4): 168-176.

Baldé NM, Camara A, Camara LM, Diallo MM, Kaké A, Bah-Sow OY. Associated tuberculosis and diabetes in Conakry, Guinea: prevalence and clinical characteristics. Int J Tuberc Lung Dis. 2006 Sep;10(9):1036-40.

Banerjee D, Bhattacharyya R, Kaul D, Sharma P. Diabetes and tuberculosis: analysis of a paradox. Adv Clin Chem. 2011;53:139-53. Review.

Barata RB. Epidemiologia social. Rev. bras. epidemiol., São Paulo, v. 8, n. 1, Mar. 2005.

Bashar M, Alcabes P, Rom WN, Condos R. Increased incidence of multidrug-resistant tuberculosis in diabetic patients on the Bellevue Chest Service, 1987 to 1997. Chest. 2001 November; 120(5): 1514-1519.

Breilh J. La epidemiología crítica: una nueva forma de mirar la salud en el espacio urbano. Salud colectiva [online]. 2010, vol.6, n.1, pp. 83-101 .

Buss, Paulo Marchiori, \& Pellegrini Filho, Alberto. (2007). A saúde e seus determinantes sociais. Physis: Revista de Saúde Coletiva, 17(1), 77-93.

Campos GWS, Minayo MCS, Akerman M, Drumond Júnior M, Carvalho, YM. Tratado de saúde coletiva. Rio de Janeiro, Hucitec;Fiocruz, 2006. p.5392. (Saúde em debate, 170).

Carr DB; Utzschneider KM; Hull RL et al. Intra-abdominal fat is a major determinant of the National Cholesterol Education Program Adult Treatment Panel III criteria for the metabolic syndrome.

Carreira S, Costeira J, Gomes C, André JM, Diogo N. Impact of diabetes on the presenting features of tuberculosis in hospitalized patients. Rev Port Pneumol. 2012 Sep-Oct;18(5):239-43. doi: 10.1016/j.rppneu.2012.04.001. Epub 2012 May 19. English, Portuguese.

Castro, CBA et al. Avaliação de um escore clínico para rastreamento de suspeitos de tuberculose pulmonar. Rev. Saúde Pública [online]. 2011, 
vol.45, n.6, pp. 1110-1116. Epub Sep 23, 2011. ISSN 0034-8910. Disponível em: <http://dx.doi.org/10.1590/S0034-89102011005000071> Acesso em: mar 2012

CDC, Centers for Disease Control and Prevention. Tuberculosis (TB). Data and Statistics [site]. USA. 2012.

Davies P, Grange J. Factors affecting susceptibility and resistance to tuberculosis. Thorax. 2001 September; 56(Suppl 2): ii23-ii29.

Dixon B. Diabetes and tuberculosis: an unhealthy partnership. Lancet Infect Dis. 2007 July; 7(7): 444. doi: 10.1016/S1473-3099(07)70144-5

Dooley KE, Chaisson RE: Tuberculosis and diabetes mellitus: convergence of two epidemics. Lancet Infect Dis 2009, 9:737-746

Dooley KE, Tang T, Golub JE, Dorman SE, Cronin W. Impact of diabetes mellitus on treatment outcomes of patients with active tuberculosis. Am J Trop Med Hyg. 2009 Apr;80(4):634-9.

Dyck RF, Klomp H, Marciniuk DD, Tan L, Stang MR, Ward HA, et al. The relationship between diabetes and tuberculosis in Saskatchewan: comparison of registered Indians and other Saskatchewan people. Can J Public Health. 2007 Jan-Feb; 98(1): 55-59.

Dye C, Bourdin Trunz B, Lönnroth K, Roglic G, Williams BG (2011) Nutrition, Diabetes and Tuberculosis in the Epidemiological Transition. PLoS ONE 6(6): e21161. doi:10.1371/journal.pone.0021161

Fantuzzi G. Tuberculosis and the inflammatory processes of obesity in human evolution. JAMA. 2009 Oct 28;302(16):1754; author reply 1754-5.

Faurholt-Jepsen D, Range N, Praygod G, Jeremiah K, Faurholt-Jepsen M, Aabye MG, Changalucha J, Christensen DL, Pipper CB, Krarup H, Witte $\mathrm{DR}$, Andersen AB, Friis $\mathrm{H}$. Diabetes is a risk factor for pulmonary tuberculosis: a case-control study from Mwanza, Tanzania. PLoS One. 2011;6(8):e24215. doi: 10.1371/journal.pone.0024215. Epub 2011 Aug 30.

Fisher-Hoch SP. Diabetes and tuberculosis: a twenty-first century plague? Int J Tuberc Lung Dis. 2011 Nov;15(11):1422. doi: 10.5588/ijtld.11.0606. No abstract available

Gnanasan S, Ting KN, Wong KT, Mohd Ali S, Muttalif AR, Anderson C. Convergence of tuberculosis and diabetes mellitus: time to individualise pharmaceutical care. Int J Clin Pharm. 2011 Feb;33(1):44-52. Epub 2011 Jan 14.

Goldhaber-Fiebert JD, Jeon CY, Cohen T, Murray MB. Diabetes mellitus and tuberculosis in countries with high tuberculosis burdens: individual 
risks and social determinants. Int J Epidemiol. 2011 Apr;40(2):417-28. Epub 2011 Jan 20.

Gomez DI, Twahirwa M, Schlesinger LS, Restrepo BI. Tuberculosis (Edinb). 2013 Mar;93(2):192-7. doi: 10.1016/j.tube.2012.10.003. Epub 2012 Nov 3.Reduced Mycobacterium tuberculosis association with monocytes from diabetes patients that have poor glucose control.

Gonzalez-Curiel I, Castañeda-Delgado J, Lopez-Lopez N, Araujo Z, Hernandez-Pando R, Gandara-Jasso B, et AL. Differential expression of antimicrobial peptides in active and latent tuberculosis and its relationship with diabetes mellitus. Hum Immunol. 2011 Aug;72(8):656-62. Epub 2011 Apr 15.

Gupta S, Shenoy VP, Bairy I, Srinivasa H, Mukhopadhyay C. Diabetes mellitus and HIV as co-morbidities in tuberculosis patients of rural south India.J Infect Public Health. 2011 Aug;4(3):140-4. Epub 2011 Jun 14.

Handel AE, Ramagopalan SV. Tuberculosis and diabetes mellitus: is vitamin D the missing link? The Lancet Infectious Diseases - 1 September 2010 ( Vol. 10, Issue 9, Page 596 ) DOI: 10.1016/S1473-3099(10)70185-7

Harries AD, Billo N, Kapur A. Links between diabetes mellitus and tuberculosis: should we integrate screening and care? Trans R Soc Trop Med Hyg. 2009 January; 103(1): 1-2. Published online 2008 September 21. doi: $10.1016 /$ j.trstmh.2008.08.008

Harries AD, Lin Y, Satyanarayana S, Lönnroth K, Li L, Wilson N, et AL. The looming epidemic of diabetes-associated tuberculosis: learning lessons from HIV-associated tuberculosis. Int J Tuberc Lung Dis. 2011 Nov;15(11):1436-44, i. Epub 2011 Sep 6.

International Diabetes Federation. IDF Diabetes Atlas. Sixth edition. 2013.

Iriart C, Waitzkin H, Breilh J, Estrada A, Merhy EE. Medicina social latinoamericana: aportes y desafios. Rev. panam. salud pública $=$ Pan am. j. public health;12(2):128-136, ago. 2002.

Jabbar A, Hussain SF, Khan AA. Clinical characteristics of pulmonary tuberculosis in adult Pakistani patients with co-existing diabetes mellitus. East Mediterr Health J. 2006 Sep;12(5):522-7.

Jeon C, Murray M. Diabetes mellitus increases the risk of active tuberculosis: a systematic review of 13 observational studies. PLoS Med. 2008;5(7):e152.

Jeon CY, Harries AD, Baker MA, Hart JE, Kapur A, Lönnroth K, et al. Bidirectional screening for tuberculosis and diabetes: a systematic review. 
Trop Med Int Health. 2010 Nov;15(11):1300-14. doi: 10.1111/j.13653156.2010.02632.x. Epub 2010 Sep 24. Review.

Karlsson EA; Beck, MA. The burden of obesity on infectious disease. Experimental Biology and Medicine 2010; 235: 1412-1424. DOI: 10.1258/ebm.2010.010227.

Kota SK, Jammula S, Kota SK, Tripathy PR, Panda S, Modi KD. Effect of vitamin D supplementation in type 2 diabetes patients with pulmonary tuberculosis. Diabetes Metab Syndr. 2011 Apr-Jun;5(2):85-9. doi: 10.1016/j.dsx.2012.02.021. Epub 2012 Mar 15.

Leegaard A, Riis A, Kornum JB, Prahl JB, Thomsen VØ, Sørensen HT, Horsburgh CR, Thomsen RW. Diabetes, glycemic control, and risk of tuberculosis: a population-based case-control study. Diabetes Care. 2011 Dec;34(12):2530-5. doi: 10.2337/dc11-0902. Epub 2011 Oct 4.

Leung CC, Lam TH, Chan WM, Yew WW, Ho KS, Leung G. Lower risk of tuberculosis in obesity. Arch Intern Med. 2007 Jun 25;167(12):1297-304.

Leung CC, Lam TH, Chan WM, Yew WW, Ho KS, Leung GM, Law WS, Tam CM, Chan CK, Chang KC. Diabetic control and risk of tuberculosis: a cohort study. Am J Epidemiol. 2008 Jun 15;167(12):1486-94. doi: 10.1093/aje/kwn075. Epub 2008 Apr 8.

Lin Y, Li L, Mi F, Du J, Dong Y, Li Z, Qi W, Zhao X, Cui Y, Hou F, Zachariah R, Kapur A, Lönnroth K, Harries AD. Screening patients with Diabetes Mellitus for Tuberculosis in China. Trop Med Int Health. 2012 Oct;17(10):1302-8. doi: 10.1111/j.1365-3156.2012.03069.x. Epub 2012 Jul 25.

Maâlej S, Belhaoui N, Bourguiba M, Mahouachi R, Chtourou A, Taktak S, et al. La tuberculose pulmonaire provoque un déséquilibre du diabète Etude rétrospective de 60 malades en Tunisie. Presse Med. 2009 January; 38(1): 20-24. Published online 2008 September 3. doi: 10.1016/j.lpm.2008.05.011

Magee MJ, Blumberg HM, Narayan KM Commentary: Co-occurrence of tuberculosis and diabetes: new paradigm of epidemiological transition. Int $\mathbf{J}$ Epidemiol. 2011 Apr;40(2):428-31. Epub 2011 Jan 20.

Malfatti CRM, Assinção AN. Hipertensão arterial e diabetes na Estratégia de Saúde da Família: uma análise da frequência de acompanhamento pelas equipes de Saúde da Família. Ciênc. saúde coletiva [online]. 2011, vol.16, suppl.1, pp. 1383-1388. ISSN 1413-8123.

Marinho MGS, Cesse EAP, Bezerra AFB, Sousa IMC de, Fontbonne A, Carvalho EF de. Análise de custos da assistência à saúde aos portadores de diabetes melito e hipertensão arterial em uma unidade de saúde pública de 
referência em Recife - Brasil. Arq Bras Endocrinol Metab [serial on the Internet]. 2011 Aug [cited 2012 Nov 07] ; 55(6): 406-411.

Marks SM. Diabetes and tuberculosis, US National Health Interview Survey, 2000-2005. Int J Tuberc Lung Dis. 2011 Jul;15(7):982-4.

Martens, GW Meltem Cevik Arikan, Jinhee Lee, Fucheng Ren, Dale Greiner, Hardy Kornfeld Am J Respir Cell Mol Biol. 2007 November; 37(5): 518-524. Published online 2007 June 21. doi: 10.1165/rcmb.20060478OC PMCID: PMC2048677

Matos LN, Giorelli GV, Saado A; Dias CB. Prevalence of prediabetes in patients with metabolic risk. São Paulo Med. J. [online]. 2011, vol.129, n.5, pp. 300-308. ISSN 1516-3180.

Matsuzawa Y, Funahashi T, Kihara S, Shimomura I. Adiponectin and Metabolic Syndrome. Arteriosclerosis, Thrombosis and Vascular Biology 2004;24:29

Maurice J. WHO framework targets tuberculosis-diabetes link. Lancet. 2011 Oct 1;378(9798):1209-10.

Moraes AS, Freitas ICM, Gimeno SGA, Mondini L. Prevalência de diabetes mellitus e identificação de fatores associados em adultos residentes em área urbana de Ribeirão Preto, São Paulo, Brasil, 2006: Projeto OBEDIARP. Cad. Saúde Pública [online]. 2010, vol.26, n.5, pp. 929-941. ISSN 0102$311 X$.

Moualeu DP, Bowong S, Tewa JJ, Emvudu Y. Analysis of the impact of Diabetes on the dynamical transmission of Tuberculosis. Mathematical Modelling of Natural Phenomena, 7 (03), pp 117-146.

doi:10.1051/mmnp/20127309.

Moutinho, ILD. Tuberculose: aspectos imunológicos na infecção e na doença. Rev Med Minas Gerais 2011; 21(1): 42-48.

Mustafa AS, El-Shamy AM, Madi NM, Amoudy HA, Al-Attiyah R. Cellmediated immune responses to complex and single mycobacterial antigens in tuberculosis patients with diabetes. Med Princ Pract. 2008; 17(4): 325330. Published online 2008 June 3. doi: 10.1159/000129614

Nijland HM, Ruslami R, Stalenhoef JE, Nelwan EJ, Alisjahbana B, Nelwan RH, van der Ven AJ, Danusantoso H, Aarnoutse RE, van Crevel R. Exposure to rifampicin is strongly reduced in patients with tuberculosis and type 2 diabetes. Clin Infect Dis. 2006 Oct 1;43(7):848-54. Epub 2006 Aug 22. 
Nissapatorn V, Kuppusamy I, Jamaiah I, Fong MY, Rohela M, Anuar AK. Tuberculosis in diabetic patients: a clinical perspective. Southeast Asian J Trop Med Public Health. 2005;36 Suppl 4:213-20

Ottmani SE, Murray MB, Jeon CY, Baker MA, Kapur A, Lönnroth K, Harries AD. Consultation meeting on tuberculosis and diabetes mellitus: meeting summary and recommendations Int J Tuberc Lung Dis. 2010 Dec;14(12):1513-7..

Park SW, Shin JW, Kim JY, Park IW, Choi BW, Choi JC, et al. The effect of diabetic control status on the clinical features of pulmonary tuberculosis. Eur J Clin Microbiol Infect Dis. 2012 Jul;31(7):1305-10. Epub 2011 Oct 25

Patel AK, Rami KC, Ghanchi FD. Radiological presentation of patients of pulmonary tuberculosis with diabetes mellitus. Lung India. 2011 Jan-Mar; 28(1): 70 .

Pereira MG. Artigos Científicos: como redigir, publicar e avaliar / Maurício Gomes Pereira. - Rio de Janeiro: Guanabara Koogan, 2011. p. 383.

Pérez A, Brown HS 3rd, Restrepo BI. Association between tuberculosis and diabetes in the Mexican border and non-border regions of Texas. Am J Trop Med Hyg. 2006 Apr;74(4):604-11

Pérez-Guzman C, Torres-Cruz A, Villarreal-Velarde H, Salazar-Lezama MA, Vargas MH. Atypical radiological images of pulmonary tuberculosis in 192 diabetic patients: a comparative study. Int J Tuberc Lung Dis. 2001 May; 5(5): 455-461.

Pérez-Guzman C, Torres-Cruz A, Villarreal-Velarde H, Vargas MH. Progressive age-related changes in pulmonary tuberculosis images and the effect of diabetes. Am J Respir Crit Care Med. 2000 November; 162(5): 1738-1740. doi: 10.1164/ajrccm.162.5.2001040

Pérez-Guzmán C, Vargas MH, Torres-Cruz A, Pérez-Padilla JR, Furuya ME, Villarreal-Velarde H. Diabetes modifies the male:female ratio in pulmonary tuberculosis. Int J Tuberc Lung Dis. 2003 Apr;7(4):354-8.

Pérez-Navarro LM, Fuentes-Domínguez F, Morales-Romero J, ZentenoCuevas R. Factors associated to pulmonary tuberculosis in patients with diabetes mellitus from Veracruz, México. Gac Med Mex. 2011 MayJun;147(3):219-25.

Ponce-De-Leon A, Garcia-Garcia Md Mde L, Garcia-Sancho MC, GomezPerez FJ, Valdespino-Gomez JL, Olaiz-Fernandez G, Rojas R, FerreyraReyes L, Cano-Arellano B, Bobadilla M, Small PM, Sifuentes-Osornio J. Tuberculosis and diabetes in southern Mexico. Diabetes Care. 2004 Jul;27(7):1584-90. 
Ponte CMM, Gurgel MHC, Ponte GA, Ramos AVA, Montenegro Júnior RM. Distúrbios metabólicos em doenças infecciosas emergentes e negligenciadas. Arq Bras Endocrinol Metab [online]. 2010, vol.54, n.9, pp. 785-792. ISSN 0004-2730.

Qu HQ, Rentfro AR, Lu Y, Nair S, Hanis CL, McCormick JB, Fisher-Hoch SP. Host susceptibility to tuberculosis: insights from a longitudinal study of gene expression in diabetes. Int J Tuberc Lung Dis. 2012;16(3):370-2. doi: 10.5588/ijtld.11.0536. Epub 2012 Jan 5.

Rawat J, Sindhwani G, Biswas D. Effect of age on presentation with diabetes: Comparison of nondiabetic patients with new smear-positive pulmonary tuberculosis patients. Lung India. $2011 \mathrm{Jul}$;28(3):187-90.

Rekha VVB, Balasubramanian R, Swaminathan S, Ramachandran R, Rahman F, Sundaram V, et al. Sputum conversion at the end of intensive phase of Category-1 regimen in the treatment of pulmonary tuberculosis patients with diabetes mellitus or HIV infection: An analysis of risk factors. Indian J Med Res. 2007 November; 126(5): 452-458.

Requena-Méndez A, Davies G, Ardrey A, Jave O, López-Romero SL, Ward SA, Moore DA. Pharmacokinetics of rifampin in Peruvian tuberculosis patients with and without comorbid diabetes or HIV. Antimicrob Agents Chemother. 2012 May;56(5):2357-63. doi: 10.1128/AAC.06059-11. Epub 2012 Feb 13.

Restrepo BI. Convergence of the tuberculosis and diabetes epidemics: renewal of old acquaintances. Clin Infect Dis. Author manuscript; available in PMC 2010 July 8. Published in final edited form as: Clin Infect Dis. 2007 August 15; 45(4): 436-438. Published online 2007 July 5. doi: 10.1086/519939 PMCID: PMC2900315

Restrepo BI, Fisher-Hoch SP, Crespo JG, Whitney E, Perez A, Smith B, McCormick JB; Nuevo Santander Tuberculosis Trackers. Type 2 diabetes and tuberculosis in a dynamic bi-national border population. Epidemiol Infect. 2007 Apr;135(3):483-91. Epub 2006 Jul 25.

Restrepo BI, Fisher-Hoch SP, Smith B, Jeon S, Rahbar MH, McCormick JB; Nuevo Santander Tuberculosis Trackers. Mycobacterial clearance from sputum is delayed during the first phase of treatment in patients with diabetes. Am J Trop Med Hyg. 2008 Oct;79(4):541-4.

Restrepo BI, Fisher-Hoch SP, Pino PA, Salinas A, Rahbar MH, Mora F, et al. Tuberculosis in Poorly Controlled Type 2 Diabetes: Altered Cytokine Expression in Peripheral White Blood Cells Clin Infect Dis. Author manuscript; available in PMC 2010 July 8. Published in final edited form as: Clin Infect Dis. 2008 September 1; 47(5): 634-641. doi: 10.1086/590565 PMCID: PMC2900313 
Restrepo BI, Camerlin AJ, Rahbar MH, Wang WW, Restrepo MA, Zarate I, et al. Cross-sectional assessment reveals high diabetes prevalence among newly-diagnosed tuberculosis cases. Bulletin of the World Health Organization 2011;89:352-359. doi: 10.2471/BLT.10.085738

Roghieh G, Golshah E, Rahim RS, Hami G, Aida M. Diabetes mellitus and pulmonary tuberculosis, association or co-incidence? SOURCEPakistan Journal of Medical Sciences;Jul2011, Vol. 27 Issue 4, p819

Roth J. Evolutionary speculation about tuberculosis and the metabolic and inflammatory processes of obesity. JAMA. 2009 Jun 24;301(24):2586-8. No abstract available.

Rosen G. Da polícia médica à medicina social. Rio de Janeiro, Graal, 1980.

Ruffino Netto A. Doenças emergentes ou reemer-gentes? Medicina (Ribeirão Preto) 1997; 30:405.

Ruslami R., Nijland HMJ, Adhiarta IGN, Kariadi Sri HKS, Alisjahbana B, Aarnoutse RE, et al. Pharmacokinetics of antituberculosis drugs in pulmonary tuberculosis patients with type 2 diabetes. Antimicrob. Agents Chemother. 54:1068-1074. 2010.

Ruslami R, Aarnoutse RE, Alisjahbana B, van der Ven AJ, van Crevel R. Implications of the global increase of diabetes for tuberculosis control and patient care. Trop Med Int Health. 2010 Nov;15(11):1289-99. doi: 10.1111/j.1365-3156.2010.02625.x. Review.

Sen T, Joshi SR, Udwadia ZF. Tuberculosis and diabetes mellitus: merging epidemics.. J Assoc Physicians India. 2009 May;57:399-404. Review.

Sidibé ELH. Pulmonary tuberculosis and diabetes: Aspects of its epidemiology, pathophysiology, and symptoms. Cahiers d'études et de recherches francophones / Santé. Volume 17, Number 1, 29-32, JanvierFévrier-Mars 2007, Synthèse

Singla R, Khan N, Al-Sharif N, Ai-Sayegh MO, Shaikh MA, Osman MM. Influence of diabetes on manifestations and treatment outcome of pulmonary TB patients. Int J Tuberc Lung Dis. 2006 Jan;10(1):74-9.

Stalenhoef JE, Alisjahbana B, Nelwan EJ, Ven-Jongekrijg J van der, Ottenhoff THM, Meer JWM van der. The role of interferon-gamma in the increased tuberculosis risk in type 2 diabetes mellitus. Eur J Clin Microbiol Infect Dis. 2008. February; 27(2): 97-103. Published online 2007 October 26. doi: 10.1007/s10096-007-0395-0

Stevenson CR, Forouhi NG, Roglic G, Willians BG, Lauer JA, Due C. Diabetes and tuberculosis: the impact of the diabetes epidemic on tuberculosis incidence. BMC Public Health 2007, 7:234. 
Stevenson CR, Critchley JA, Forouhi NG, Roglic G, Williams BG, Dye C. Diabetes and the risk of tuberculosis: a neglected threat to public health? Chronic Illness;Sep2007, Vol. 3 Issue 3, p228

Sugawara I, Yamada H, Mizuno S. Pulmonary tuberculosis in spontaneously diabetic goto kakizaki rats.Tohoku J Exp Med. 2004 Oct;204(2):135-45.

Suleiman SAS, Ishaq Aweis DM, Mohamed AJ, Razakmuttalif A, Moussa MA. Role of diabetes in the prognosis and therapeutic outcome of tuberculosis. Int J Endocrinol. 2012;2012:645362. doi:

10.1155/2012/645362. Epub 2012 Apr 18.

Sullivan T, Ben Amor Y. The co-management of tuberculosis and diabetes: challenges and opportunities in the developing world. PLoS Med.

2012;9(7):e1001269. doi: 10.1371/journal.pmed.1001269. Epub 2012 Jul 24. Review.

Sun Q, Zhang Q, Xiao H, Cui H, Su B. Significance of the frequency of CD4+CD25+CD127- T-cells in patients with pulmonary tuberculosis and diabetes mellitus. Respirology. 2012 Jul;17(5):876-82. doi: 10.1111/j.14401843.2012.02184.x.

Tan CK, Lai CC, Chen HW, Liao CH, Chou CH, Huang YT, Yang WS, Yu CJ, Hsueh PR. Enzyme-linked immunospot assay for interferon-gamma to support the diagnosis of tuberculosis in diabetic patients. Scand J Infect Dis. 2010 Oct;42(10):752-6. doi: 10.3109/00365548.2010.490237.

Tatar D, Senol G, Alptekin S, Karakurum C, Aydin M, Coskunol I. Tuberculosis in diabetics: features in an endemic area.. Jpn J Infect Dis. 2009 Nov;62(6):423-7.

Teixeira CRS, Becker TAC, Citro R, Zanetti ML, Landin CAP. Validação de intervenções de enfermagem em pessoas com diabetes mellitus. Rev. esc. enferm. USP [online]. 2011, vol.45, n.1, pp. 173-179. ISSN 0080-6234.

Teixeira HC; Abramo C; Munk ME. Diagnóstico imunológico da tuberculose: problemas e estratégias para o sucesso. J. bras. pneumol. [online]. 2007, vol.33, n.3, pp. 323-334.

Touré NO, Kane YD, Diatta A, Diop SBa, Niang S, Ndiaye EM, Thiam K, MBaye FBR, Badiane M, Hane AA. Tuberculose et diabète.

Elsevier.Volume 24, Issue 7, September 2007, Pages 869-875

Vallerskog T, Martens GW, Kornfeld H. Diabetic mice display a delayed adaptive immune response to Mycobacterium tuberculosis. J Immunol. 2010 Jun 1;184(11):6275-82. doi: 10.4049/jimmunol.1000304. Epub 2010 Apr 26. 
Vernasque, Juliana Ribeiro da Silva. Determinantes sociais da saúde: os olhares dos profissionais da atenção básica do município de Marília-SP [dissertação]. São Paulo: Universidade de São Paulo, Faculdade de Medicina; 2010

Viswanathan V, Kumpatla S, Aravindalochanan V, Rajan R, Chinnasamy C, Srinivasan R, Selvam JM, Kapur A. Prevalence of Diabetes and Pre-

Diabetes and Associated Risk Factors among Tuberculosis Patients in India. Published: Jul 26, 2012DOI: 10.1371/journal.pone.0041367

Zhang Q, Xiao H, Sugawara I. Tuberculosis complicated by diabetes mellitus at shanghai pulmonary hospital, china.

Jpn J Infect Dis. 2009 Sep;62(5):390-1.

Zhang Q, Xiao HP, Cui HY, Sugawara I. Significant increase in naturalkiller T cells in patients with tuberculosis complicated by type 2 diabetes mellitus. J Int Med Res. 2011;39(1):105-11.

Walker C, Unwin N. Thorax. Estimates of the impact of diabetes on the incidence of pulmonary tuberculosis in different ethnic groups in England.. 2010 Jul;65(7):578-81. Epub 2010 Apr 26.

Wang CS, Yang CJ, Chen HC, Chuang SH, Chong IW, Hwang JJ, Huang MS. Impact of type 2 diabetes on manifestations and treatment outcome of pulmonary tuberculosis. Epidemiol Infect. 2009 February; 137(2): 203-210. Published online 2008 June 18. doi: 10.1017/S0950268808000782

Wang Q, Han X, Ma A, Wang Y, Bygbjerg IC, Li G, Sun Y, Zhou X. Screening and intervention of diabetes mellitus in patients with pulmonary tuberculosis in poverty zones in China: rationale and study design. Diabetes Res Clin Pract. 2012 Jun;96(3):385-91. doi: 10.1016/j.diabres.2011.11.012. Epub 2011 Dec 5.

Weng SF, Hsu CH, Lirn ML, Huang CL. Extrapulmonary tuberculosis: a study comparing diabetic and nondiabetic patients.. Exp Clin Endocrinol Diabetes. 2009 Jun;117(6):305-7. Epub 2009 Feb 18.

WHO, World Health Organization. Global Health Observatory Data Repository. World Health Statistics 2011. Tuberculosis. Cases. [site].

WHO, World Health Organization. Global tuberculosis report 2013.1.Tuberculosis - epidemiology. 2.Tuberculosis, Pulmonary prevention and control. 3.Tuberculosis - economics. 4.Tuberculosis, Multidrug-Resistant. 5.Annual reports. I.World Health Organization. ISBN 9789241564656

Young F, Critchley J, Unwin N. Diabetes \& tuberculosis: a dangerous liaison \& no white tiger. Indian J Med Res. 2009 Jul;130(1):1-4. No abstract available. 
Young F, Critchley JA, Johnstone LK, Unwin NC. A review of comorbidity between infectious and chronic disease in Sub Saharan Africa: TB and diabetes mellitus, HIV and metabolic syndrome, and the impact of globalization.. Global Health. 2009 Sep 14;5:9.

Young F, Wotton CJ, Critchley JA, Unwin NC, Goldacre MJ. Increased risk of tuberculosis disease in people with diabetes mellitus: record-linkage study in a UK population. J Epidemiol Community Health. 2012 Jun;66(6):519-23. Epub 2010 Nov 2 
Apêndice A - Apresentação dos resultados da busca

\begin{tabular}{|c|c|c|c|c|c|}
\hline & Ano & Título/ Autor/ Procedência & $\begin{array}{l}\text { Publicação/ } \\
\text { Revista/Idioma }\end{array}$ & $\begin{array}{l}\text { Local/ Delineamento/ } \\
\quad \text { Enfoque }\end{array}$ & Resumo \\
\hline \multirow[t]{3}{*}{1} & \multirow[t]{3}{*}{2001} & Pulmonary tuberculosis in patients with diabetes mellitus. & PubMed (MEDLINE) & Turquia & \multirow{3}{*}{ 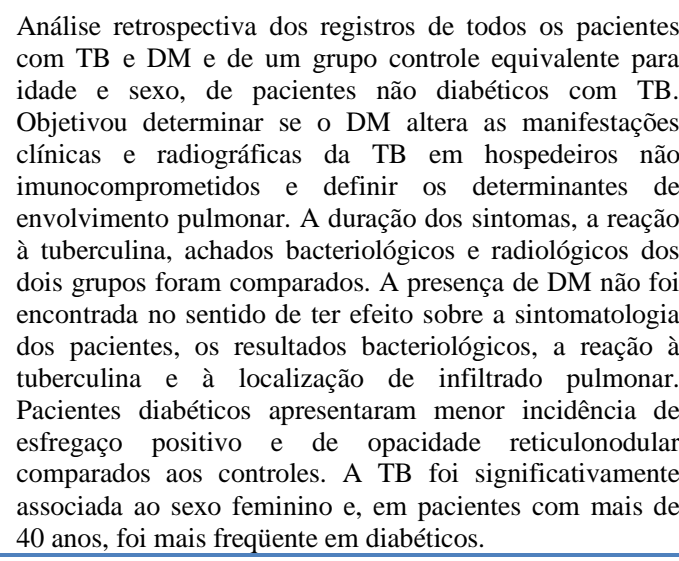 } \\
\hline & & Bacakoğlu F, Başoğlu OK, Cok G, Sayiner A, Ateş M. & Respiration. & Caso-controle retrospectivo & \\
\hline & & Turquia & Inglês & Apresentação clínica & \\
\hline \multirow[t]{3}{*}{2} & \multirow[t]{3}{*}{2001} & $\begin{array}{l}\text { Atypical radiological images of pulmonary tuberculosis in } 192 \text { diabetic } \\
\text { patients: a comparative study. }\end{array}$ & $\begin{array}{l}\text { PubMed (MEDLINE) } \\
\text { Web of Science }\end{array}$ & Cidade do México, México & \multirow{3}{*}{ 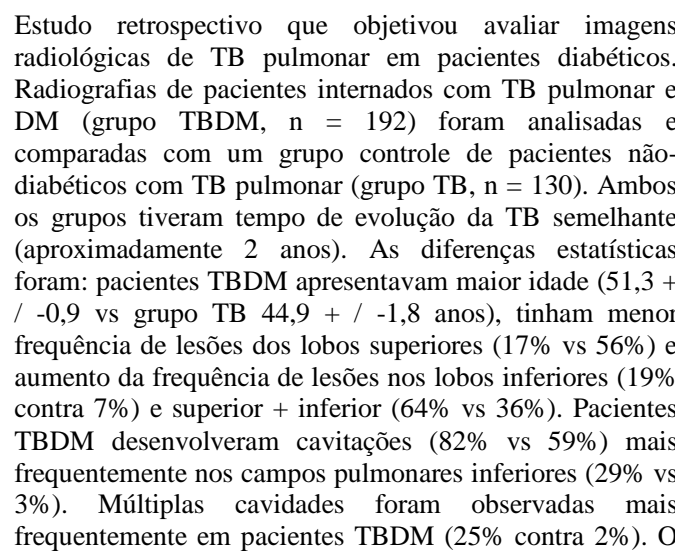 } \\
\hline & & $\begin{array}{l}\text { Pérez-Guzman C, Torres-Cruz A, Villarreal-Velarde H, Salazar- } \\
\text { Lezama MA, Vargas MH. }\end{array}$ & $\begin{array}{l}\text { Int } \mathrm{J} \text { Tuberc Lung } \\
\text { Dis. }\end{array}$ & $\begin{array}{l}\text { Estudo caso-controle } \\
\text { retrospectivo }\end{array}$ & \\
\hline & & México & Inglês & Apresentação clínica & \\
\hline
\end{tabular}




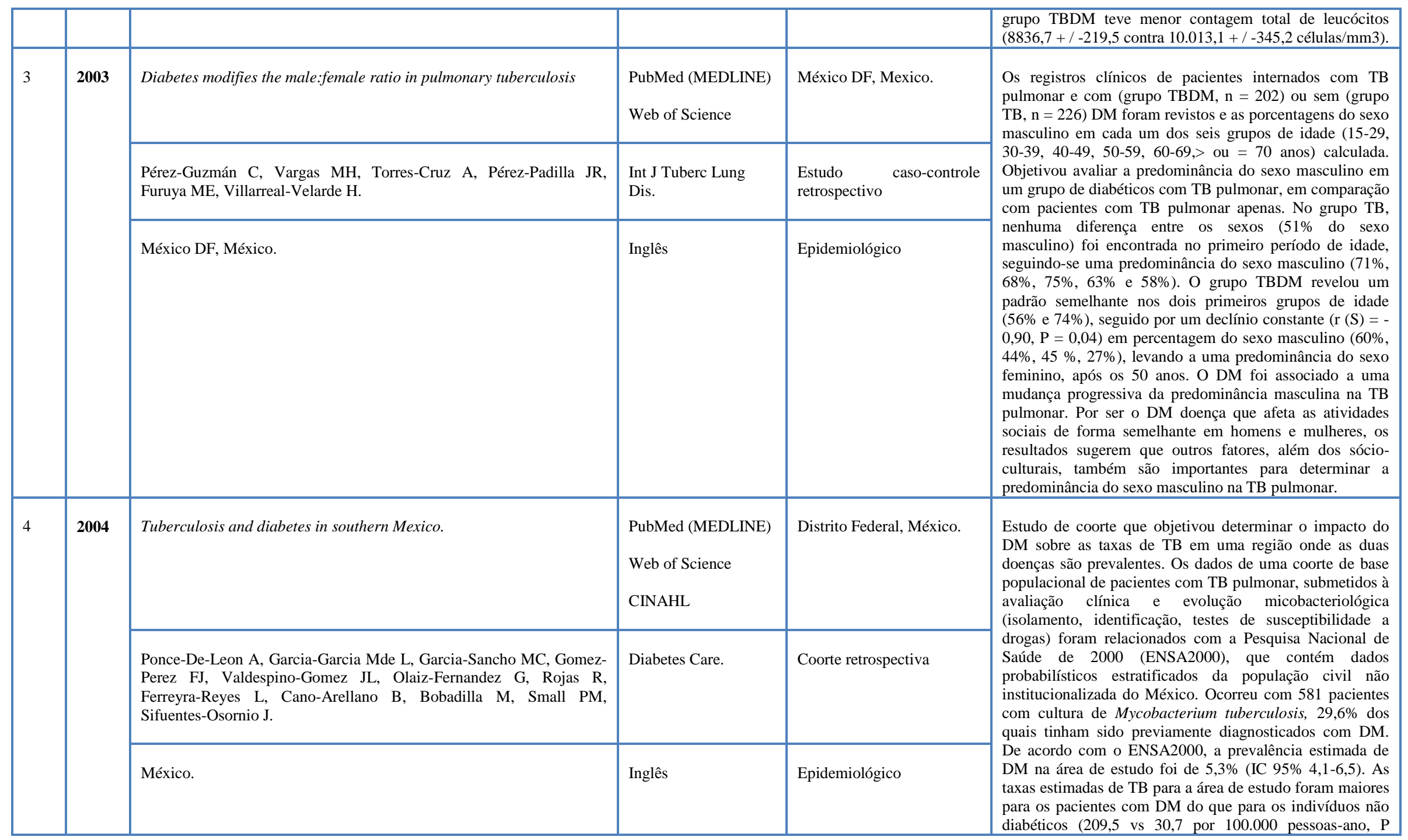




\begin{tabular}{|c|c|c|c|c|c|}
\hline & & & & & $\begin{array}{l}<0,0001) \text {. Neste cenário, a taxa de TB aumentou } 6,8 \text { vezes } \\
\text { (IC } 95 \% 5,7-8,2, \mathrm{P}<0,0001 \text { ) em pacientes com DM devido } \\
\text { a aumento tanto na infecção reativada quanto na } \\
\text { recentemente transmitida. }\end{array}$ \\
\hline \multirow[t]{3}{*}{5} & 2004 & Pulmonary tuberculosis in spontaneously diabetic goto kakizaki rats. & $\begin{array}{l}\text { PubMed (MEDLINE) } \\
\text { Web of Science }\end{array}$ & Tóquio, Japão & \multirow{3}{*}{$\begin{array}{l}\text { Estudo realizado para verificar se os ratos diabéticos GK / } \\
\text { Jcl são mais suscetíveis à infecção por Mycobacterium } \\
\text { tuberculosis do que os ratos não-diabéticos. Ratos } \\
\text { diabéticos GK / Jcl aerially foram infectados com } M \text {. } \\
\text { tuberculosis e sua capacidade de controlar o crescimento } \\
\text { de micobactérias, formação de granulomas, secreção de } \\
\text { citocinas pelos macrófagos alveolares e óxido nítrico (NO) } \\
\text { foi avaliada. Os ratos desenvolveram grandes granulomas, } \\
\text { mas não lesões necróticas em seus pulmões, fígado ou } \\
\text { baço. Isto é consistente com um aumento significativo no } \\
\text { número de unidades formadoras de colônias de } M \text {. } \\
\text { tuberculosis nos pulmões (p <0,01). Os níveis de expressão } \\
\text { INF-gama, TNF-alfa e IL-12 ARNm foram menores nos } \\
\text { ratos diabéticos GK / Jcl do que os dos controles ratos } \\
\text { Wistar. Não foi observada diferença significativa entre } \\
\text { fagocitose dos bacilos pelos macrófagos alveolares de } \\
\text { GK/Jcl ou ratos Wistar. Esses dados mostram que existe } \\
\text { uma estreita associação entre a TB experimental e a DM } \\
\text { em animais, e que os macrófagos alveolares de ratos } \\
\text { diabéticos GK/Jcl não são totalmente ativados por infecção } \\
\text { por M. tuberculosis. }\end{array}$} \\
\hline & & Sugawara I, Yamada H, Mizuno S. & Tohoku J Exp Med. & Ensaio clínico & \\
\hline & & Tóquio, Japão & Inglês & Imunológico & \\
\hline \multirow[t]{3}{*}{6} & \multirow[t]{3}{*}{2005} & Tuberculosis in diabetic patients: a clinical perspective. & PubMed (MEDLINE) & Malásia & \multirow{3}{*}{$\begin{array}{l}\text { Estudo descritivo e retrospectivo sobre a situação clínica da } \\
\text { TB em pacientes diabéticos, com } 1.651 \text { pacientes } \\
\text { recrutados. A idade média dos pacientes com TBDM fo } \\
\text { significativamente maior do que em relação aos pacientes } \\
\text { não diabéticos (p <0,05). Os pacientes com TBDM tinham } \\
\text { maior proporção de homens do que o outro grupo. A } \\
\text { proporção significativa de TB pareceu aumentar } \\
\text { progressivamente com a idade, em doentes diabéticos em } \\
\text { comparação com os não-diabéticos (p }<0,05 \text { ). No entanto, } \\
\text { eles mostraram semelhanças em termos de sexo, raça } \\
\text { estado civil, endereço atual e ocupação. A percentagem } \\
\text { mais elevada de TB pulmonar }(91,4 \%) \text { foi mostrada no } \\
\text { grupo TBDM. Ambos os grupos não apresentaram } \\
\text { diferenças nos achados radiológicos, com opacidade ou } \\
\text { cavidade do envolvimento do lobo superior, sendo } 89 \% \text { e }\end{array}$} \\
\hline & & $\begin{array}{l}\text { Nissapatorn V, Kuppusamy I, Jamaiah I, Fong MY, Rohela M, Anuar } \\
\text { AK. }\end{array}$ & $\begin{array}{l}\text { Southeast Asian J } \\
\text { Trop Med Public } \\
\text { Health. }\end{array}$ & Estudo coorte retrospectivo & \\
\hline & & Malásia & Inglês & Epidemiológico & \\
\hline
\end{tabular}




\begin{tabular}{|c|c|c|c|c|c|}
\hline & & & & & $\begin{array}{l}91 \% \text { nos grupos TBDM e não diabéticos, respectivamente } \\
\text { Pacientes com TBDM tiveram mais sucesso do tratamento } \\
(33,3 \%) \text {, especialmente o tipo de TB pulmonar de longa } \\
\text { duração ( } 9 \text { meses). Outros resultados demonstraram que } \\
\text { uma proporção menor do grupo com TBDM foi } \\
\text { inadimplente em seu tratamento }(19,8 \%) \text { e apresentavan } \\
\text { resistência à terapia anti-tuberculose }(1,4 \%) \text {, em relação } \\
\text { aos não-diabéticos. }\end{array}$ \\
\hline \multirow[t]{3}{*}{7} & \multirow[t]{3}{*}{2005} & $\begin{array}{l}\text { Lower expression of Th1-related cytokines and inducible nitric oxide } \\
\text { synthase in mice with streptozotocin-induced diabetes mellitus infected } \\
\text { with Mycobacterium tuberculosis }\end{array}$ & $\begin{array}{l}\text { PubMed (MEDLINE) } \\
\text { Web of Science }\end{array}$ & Japão & \multirow{3}{*}{$\begin{array}{l}\text { O estudo objetivou investigar o mecanismo subjacente à } \\
\text { associação entre DM e TB, através de um modelo de ratos } \\
\text { murinos. Os ratos com DM induzida por estreptozotocina } \\
\text { foram propensos à infecção por Mycobacterium } \\
\text { tuberculosis, tal como indicado pelo aumento do número } \\
\text { de bactérias vivas no pulmão, fígado e baço. Em ratos } \\
\text { diabéticos, os níveis de IL-12 e IFN- } \gamma \text { no pulmão, no } \\
\text { fígado e no baço foram inferiores aos dos controle no dia } \\
14 \text { após a infecção, ao passo que o oposto era verdade para } \\
\text { os níveis de IL-4 no pulmão e no fígado. O padrão de } \\
\text { expressão de síntese induzida por óxido nítrico (iNOS), nos } \\
\text { dois tipos de ratos, era para IL-12 e IFN- } \gamma \text {. Além disso, as } \\
\text { células de exsudato peritoneal, obtidas a partir de ratos } \\
\text { diabéticos produziram quantidades mais baixas de IL-12 } \\
\text { de NO do que as dos controles, quando estimuladas in vitro } \\
\text { com BCG de } M \text {. bovis. As células do baço de ratos } \\
\text { diabéticos infectados com } M \text {. tuberculosis produziram } \\
\text { quantidade significativamente menor de IFN- } \gamma \text { após re- } \\
\text { estimulação com derivados da proteína purificada (PPD) } \\
\text { do que aqueles a partir de ratos não diabéticos infectados. } \\
\text { A adição de níveis elevados de glucose (33 mM) à culturas } \\
\text { de células de baço de PPD-reestimuladas reduziu a síntese } \\
\text { de IFN- } \gamma \text { apenas em ratos diabéticos, e não em ratos não } \\
\text { diabéticos. O controle dos níveis de glicose no sangue por } \\
\text { terapia com insulina resultou em melhora da proteção do } \\
\text { hospedeiro e síntese de citocinas Th1-relacionadas. }\end{array}$} \\
\hline & & $\begin{array}{l}\text { Yamashiro S, Kawakami K, Uezu K, Kinjo T, Miyagi K, Nakamura K, } \\
\text { Saito A. }\end{array}$ & Clin Exp Immunol. & Ensaio clínico & \\
\hline & & Japão & Inglês & Imunológico & \\
\hline \multirow[t]{2}{*}{8} & \multirow[t]{2}{*}{2006} & Diabetes mellitus is strongly associated with tuberculosis in Indonesia. & $\begin{array}{l}\text { PubMed (MEDLINE) } \\
\text { Web of Science }\end{array}$ & Jakarta, Indonésia & \multirow{2}{*}{$\begin{array}{l}\text { Estudo caso-controle comparando a prevalência de DM } \\
\text { (glicemia de jejum> } 126 \mathrm{mg} / \mathrm{dl} \text { ) entre os pacientes recém- } \\
\text { diagnosticados com TB pulmonar e controles parelhados } \\
\text { retirados da vizinhança. Objetivou examinar se e em que } \\
\text { medida o DM está associado a risco aumentado para TB } \\
\text { em um ambiente urbano, na Indonésia. Pacientes e }\end{array}$} \\
\hline & & Alisjahbana B, van Crevel R, Sahiratmadja E, den Heijer M, Maya A, & Int J Tuberc Lung & Caso-controle & \\
\hline
\end{tabular}




\begin{tabular}{|c|c|c|c|c|c|}
\hline & & Istriana E, Danusantoso H, Ottenhoff TH, Nelwan RH, van der Meer & Dis. & & \multirow{2}{*}{$\begin{array}{l}\text { controles tinham idade semelhante (mediana } 30 \text { anos) e } \\
\text { semelhante distribuição por sexo (52\% do sexo masculino), } \\
\text { mas a desnutrição era mais comum entre pacientes com TB } \\
\text { (mediana do IMC } 17,7 \text { vs } 21,5 \mathrm{~kg} / \mathrm{m} 2) \text {. Infeçãão pelo HIV } \\
\text { foi incomum (1,5\% dos pacientes). DM esteve presente em } \\
60 \text { dos } 454 \text { pacientes com TB }(13,2 \%) \text { e em } 18 \text { dos } 556 \\
(3,2 \%) \text { indivíduos controle (OR }=4,7 \text {, IC } 95 \% 2,7-8,1) \text {. O } \\
\text { ajuste para possíveis fatores de confusão não reduziu as } \\
\text { estimativas de risco. Após o tratamento anti-TB, a } \\
\text { hiperglicemia foi revertida em uma minoria }(3,7 \%) \text { dos } \\
\text { pacientes com TB. }\end{array}$} \\
\hline & & Bandung, Indonesia. & $\begin{array}{l}\text { Idioma de publicação: } \\
\text { inglês }\end{array}$ & Epidemiológico & \\
\hline \multirow[t]{3}{*}{9} & \multirow[t]{3}{*}{2006} & $\begin{array}{l}\text { Associated tuberculosis and diabetes in Conakry, Guinea: prevalence } \\
\text { and clinical characteristics. }\end{array}$ & $\begin{array}{l}\text { PubMed (MEDLINE) } \\
\text { Web of Science }\end{array}$ & Conakry, Guiné & \multirow{3}{*}{$\begin{array}{l}\text { Estudo realizado em centros anti-tuberculose com o } \\
\text { objetivo de determinar a prevalência de DM em pacientes } \\
\text { com TB, identificar os fatores de risco associados, e } \\
\text { descrever os sinais clínicos da associação de TB e DM. Um } \\
\text { total de } 388 \text { pacientes com TB, selecionados por } \\
\text { amostragem aleatória simples, a partir do registro de casos } \\
\text { diagnosticados em Conakry foram examinados, além de } \\
\text { administrado um teste de glicemia capilar para detectar } \\
\text { DM. Foram identificados } 13 \text { casos de DM, com taxa de } \\
\text { prevalência de } 3,35 \% \text { (IC } 95 \% \text { 1,35-5,35). Quatro }(31 \%) \\
\text { não haviam sido diagnosticados antes do inquérito. O } \\
\text { diagnóstico de diabetes precedia o de TB por uma média de } \\
5 \text { anos (1-9 anos). As características clínicas da TB } \\
\text { (exposição frequente à infecção, local e proporção de casos } \\
\text { novos e retratamento) não diferiram de um grupo para } \\
\text { outro. O aumento da idade }(\mathrm{P}<0,0001) \text {, obesidade (P } \\
<0,005) \text {, sedentarismo (P <0,0004), e história prévia de } \\
\text { diabetes na família }(\mathrm{P}=0,04) \text { ou obesidade (P }=0,04) \\
\text { foram significativamente associados com DM. }\end{array}$} \\
\hline & & $\begin{array}{l}\text { Baldé NM, Camara A, Camara LM, Diallo MM, Kaké A, Bah-Sow } \\
\text { OY. }\end{array}$ & $\begin{array}{l}\text { Int J Tuberc Lung } \\
\text { Dis. }\end{array}$ & Estudo coorte & \\
\hline & & Conakry, Guiné & $\begin{array}{l}\text { Idioma de publicação: } \\
\text { inglês }\end{array}$ & Epidemiológico & \\
\hline \multirow[t]{3}{*}{10} & \multirow[t]{3}{*}{2006} & $\begin{array}{l}\text { Clinical characteristics of pulmonary tuberculosis in adult Pakistani } \\
\text { patients with co-existing diabetes mellitus. }\end{array}$ & $\begin{array}{l}\text { PubMed (MEDLINE) } \\
\text { CINAHL }\end{array}$ & Karachi, Paquistão & \multirow{3}{*}{$\begin{array}{l}\text { Estudo retrospectivo dos registros de todos os pacientes } \\
\text { com TB pulmonar e DM internados por um período de } 5 \\
\text { anos em um hospital em Karachi, Paquistão. Objetivou } \\
\text { determinar se o DM altera as manifestações clínicas e } \\
\text { radiológicas da TB pulmonar em pacientes paquistaneses e } \\
\text { comparar a prevalência da TB em pacientes hospitalizados. } \\
\text { Entre } 42.358 \text { pacientes, o número total com tuberculose e } \\
\text { diabetes (TBDM) foi de 173. A prevalência da TB em } \\
\text { pacientes diabéticos é } 10 \text { vezes maior do que em pacientes } \\
\text { não-diabéticos, sendo que a prevalência aumentou com a }\end{array}$} \\
\hline & & Jabbar A, Hussain SF, Khan AA. & $\begin{array}{l}\text { East Mediterr Health } \\
\text { J. }\end{array}$ & Coorte retrospectiva & \\
\hline & & Karachi, Pakistan & Inglês, francês. & Apresentação clínica & \\
\hline
\end{tabular}




\begin{tabular}{|c|c|c|c|c|c|}
\hline & & & & & $\begin{array}{l}\text { duração do DM. O campo pulmonar inferior foi mais } \\
\text { frequientemente envolvido, seguido pelo superior e médio. } \\
\text { O envolvimento bilateral foi observado em } 50 \% \text { dos } \\
\text { pacientes e efusão pleural associada foi encontrada em um } \\
\text { terço dos pacientes. Lesões cavitantes foram observadas } \\
\text { em } 32 \% \text { dos homens e } 15 \% \text { das mulheres. }\end{array}$ \\
\hline \multirow[t]{3}{*}{11} & \multirow[t]{3}{*}{2006} & $\begin{array}{l}\text { Exposure to rifampicin is strongly reduced in patients with tuberculosis } \\
\text { and type } 2 \text { diabetes. }\end{array}$ & $\begin{array}{l}\text { PubMed (MEDLINE) } \\
\text { Web of Science }\end{array}$ & Indonésia & \multirow{3}{*}{$\begin{array}{l}17 \text { pacientes adultos da Indonésia com TB-DM e } 17 \\
\text { pacientes controles, pareados para sexo e idade, com TB } \\
\text { sem DM foram incluídos no estudo.Todos os pacientes } \\
\text { receberam } 450 \mathrm{mg} \text { de rifampicina }(10 \mathrm{mg} / \mathrm{kg}) \text { e } 600 \mathrm{mg} \text { de } \\
\text { isoniazida, } 3 \text { vezes por semana. As concentraçós } \\
\text { plasmáticas do estado estacionário de rifampicina e seu } \\
\text { metabólito desacetylrifampicin foram avaliados nos tempos } \\
0,2,4 \text { e } 6 \text { horas após a ingestão do fármaco. A média } \\
\text { geométrica da exposição à rifampicina (AUC }(0-6 \mathrm{~h})) \text { foi } \\
\text { de } 12,3 \mathrm{mg} \text { xh / } \mathrm{L} \text { (intervalo de confiança de } 95 \% \text { [IC] } 8,0 \\
24,2) \text { em pacientes com TB e DM, e } 25,9 \mathrm{mg} \text { xh } / \mathrm{L}(95 \% \\
\mathrm{IC}, 21,4-40,2) \text { em pacientes com apenas TB }(\mathrm{P}=0,003) \\
\text { Foram encontradas diferenças similares para } \\
\text { concentração máxima de rifampicina. A análise de } \\
\text { regressão linear revelou que o aumento de peso corporal }(\mathrm{P} \\
<0,001) \text {, a presença de DM }(\mathrm{P}=0,06) \text {, e a concentração de } \\
\text { glicose no plasma }(\mathrm{P}=0,016) \text { foram correlacionados com a a } \\
\text { exposição à rifampicina. A exposição (AUC }(0-6 \mathrm{~h})) \text { para } \\
\text { rifampicina foi } 53 \% \text { menor em pacientes da Indonésia com } \\
\text { TB-DM, em comparação com pacientes com TB. Pacientes } \\
\text { com TB e DM que têm um maior peso corporal podem } \\
\text { precisar de uma dose mais elevada de rifampicina. }\end{array}$} \\
\hline & & $\begin{array}{l}\text { Nijland HM, Ruslami R, Stalenhoef JE, Nelwan EJ, Alisjahbana B, } \\
\text { Nelwan RH, van der Ven AJ, Danusantoso H, Aarnoutse RE, van } \\
\text { Crevel R. }\end{array}$ & Clin Infect Dis. & $\begin{array}{l}\text { Estudo prospectivo } \\
\text { farmacocinético }\end{array}$ & \\
\hline & & Holanda & Inglês & Farmacológico & \\
\hline \multirow[t]{3}{*}{12} & \multirow[t]{3}{*}{2006} & $\begin{array}{l}\text { Association between tuberculosis and diabetes in the Mexican border } \\
\text { and non-border regions of Texas. }\end{array}$ & $\begin{array}{l}\text { PubMed (MEDLINE) } \\
\text { Web of Science }\end{array}$ & Texas, EUA & \multirow{3}{*}{$\begin{array}{l}\text { A associação entre a TB e os fatores de risco subjacentes } \\
\text { foi avaliada em pacientes hospitalizados do Texas, em } 15 \\
\text { municípios ao longo da fronteira com o México e nos } \\
\text { restantes municípios não fronteiriços. Foram identificados } \\
\text { casos de alta para TB }(\mathrm{N}=4.915) \text {. Casos de trombose } \\
\text { venosa profunda, embolia pulmonar, e condições de } \\
\text { apendicite aguda foram identificados como controles }(\mathrm{N} \\
70.808 \text { ). Os fatores de risco associados à TB foram } \\
\text { identificados por meio de regressão logística. Considerou- } \\
\text { se também como variáveis: seguro médico, escolaridade, } \\
\text { local de moradia. Pacientes com DM tinham quase duas } \\
\text { vezes mais probabilidade de ter TB após o ajuste por sexo, }\end{array}$} \\
\hline & & Pérez A, Brown HS 3rd, Restrepo BI. & Am J Trop Med Hyg. & Caso-controle & \\
\hline & & Texas - EUA & Inglês & Epidemiológico & \\
\hline
\end{tabular}




\begin{tabular}{|c|c|c|c|c|c|}
\hline & & & & & $\begin{array}{l}\text { idade e raça/etnia. A associação foi mais forte para a } \\
\text { população na região de fronteira do Texas, onde há maiores } \\
\text { taxas de incidência de TB (odds ratio [OR] (adj) }=1,82 \text {, IC } \\
95 \%=1,57-2,12) \text {, em comparação com municípios não } \\
\text { fronteiriços (OR (adj) }=1,51 \text {, IC 95\% } 95=1,36-1,67) \text {. }\end{array}$ \\
\hline \multirow[t]{3}{*}{13} & \multirow[t]{3}{*}{2006} & $\begin{array}{l}\text { Influence of diabetes on manifestations and treatment outcome of } \\
\text { pulmonary TB patients. }\end{array}$ & Web of Science & Arábia Saudita & \multirow{3}{*}{$\begin{array}{l}\text { Objetiva compreender a influência do DM sobre os } \\
\text { aspectos clínicos e bacteriológicos e o resultado do } \\
\text { tratamento de pacientes com TB pulmonar (PTB). } \\
\text { Registros de } 692 \text { PTB com baciloscopia positiva, } \\
\text { internados em um hospital, foram analisados } \\
\text { retrospectivamente. As características de } 187 \text { pacientes } \\
\text { com DM (grupo PTB-DM) foram comparadas às de } 505 \\
\text { pacientes sem DM (grupo PTB). No grupo PTB-DM, } \\
65,2 \% \text { dos pacientes tiveram numerosos bacilos ácido-- } \\
\text { resistentes (AFB) no exame de escarro em comparação } \\
\text { com } 54,1 \% \text { no grupo controle }(\mathrm{P}=0,008) \text {. Entre os novos } \\
\text { casos, os pacientes PTB-DM tiveram menor prevalência de } \\
\text { resistência a qualquer droga anti-TB }(6,4 \% \text { vs } 16,0 \%, \mathrm{P}= \\
0,007) \text { e alcançou maiores taxas de conversão de escarro ao } \\
\text { final de } 3 \text { meses de tratamento }(98,9 \% \text { vs. 94,7\%, } \mathrm{P}= \\
0,013) \text {. PTB-DM tem carga bacilar de pré-tratamento } \\
\text { maior, menor prevalência de resistência às drogas anti-TB } \\
\text { e atingem ligeiramente maior conversão de escarro até o } \\
\text { final de } 3 \text { meses de tratamento, em comparação com } \\
\text { pacientes não-diabéticos. }\end{array}$} \\
\hline & & $\begin{array}{l}\text { Singla R, Khan N, Al-Sharif N, Ai-Sayegh MO, Shaikh MA, Osman } \\
\text { MM. }\end{array}$ & $\begin{array}{l}\text { Int J Tuberc Lung } \\
\text { Dis. }\end{array}$ & Estudo caso-controle & \\
\hline & & New Dheli - India & Inglês & Apresentação clínica & \\
\hline \multirow[t]{2}{*}{14} & \multirow[t]{2}{*}{2007} & $\begin{array}{l}\text { The relationship between diabetes and tuberculosis in Saskatchewan: } \\
\text { comparison of registered Indians and other Saskatchewan people }\end{array}$ & $\begin{array}{l}\text { PubMed (MEDLINE) } \\
\text { Web of Science } \\
\text { CINAHL }\end{array}$ & Saskatchewan, Canadá & \multirow{2}{*}{$\begin{array}{l}\text { Objetivou determinar se existe relação entre DM e TB em } \\
\text { Saskatchewan e determinar se há diferença no grau de } \\
\text { associação entre aborígines e não-aborígines. Utilizando } \\
\text { bancos de dados de saúde de Saskatchewan, a incidência de } \\
\text { TB foi comparada entre quatro subpopulações: índios } \\
\text { registrados (RI), com e sem DM, e outras pessoas de } \\
\text { Saskatchewan (OSKP) com e sem DM. As mulheres } \\
\text { diabéticas com idade entre 20-59 anos apresentaram maior } \\
\text { média das taxas de incidência anual de TB do que mulheres } \\
\text { não-diabéticas, mas as taxas no interior da população de } \\
\text { TB em mulheres diabéticas e não-diabéticas foram }\end{array}$} \\
\hline & & $\begin{array}{l}\text { Dyck RF, Klomp H, Marciniuk DD, Tan L, Satng MR, Ward HA, } \\
\text { Hoeppner VH. }\end{array}$ & $\begin{array}{l}\text { Canadian Journal of } \\
\text { Public Health }\end{array}$ & $\begin{array}{ll}\text { Estudo } \\
\text { descritivo }\end{array}$ epidemiológico & \\
\hline
\end{tabular}




\begin{tabular}{|c|c|c|c|c|c|}
\hline & & Saskatchewan, Canadá & Inglês & Epidemiológico & $\begin{array}{l}\text { significantes apenas para a idade entre } 50-59 \text { ( } 2,7 \text { [IC } 1,28 \text {, } \\
5,72] \text { em RI e } 3,9 \text { [IC } 1,58,9,67] \text { na OSKP). Nenhum } \\
\text { subgrupo de pacientes diabéticos teve taxas } \\
\text { significativamente mais altas de TB. O único grupo de } \\
\text { homens diabéticos, que teve a maior taxa de tuberculose, } \\
\text { foi o de homens RI mais homens OSKP entre } 50-59 \text { anos. } \\
\text { Em geral, o diabetes precedia a TB em 87/111 indivíduos } \\
\text { com ambas as doenças (p }<0,0001) \text {. }\end{array}$ \\
\hline \multirow[t]{3}{*}{15} & \multirow[t]{3}{*}{2007} & $\begin{array}{l}\text { Type } 2 \text { diabetes and tuberculosis in a dynamic bi-national border } \\
\text { population. }\end{array}$ & $\begin{array}{l}\text { PubMed (MEDLINE) } \\
\text { Web of Science }\end{array}$ & México / Texas (EUA) & \multirow{3}{*}{$\begin{array}{l}\text { Estudo retrospectivo que objetivou analisar a associação } \\
\text { entre o DM e a TB na fronteira Texas-México, em uma } \\
\text { população de pacientes com TB em sua maioria não- } \\
\text { hospitalizados. Seis anos de dados foram analisados } \\
\text { retrospectivamente, de todos os pacientes com TB (n = } \\
5049 \text { ) no sul do Texas e nordeste do México, encontrando- } \\
\text { se DM auto-relatada por } 27,8 \% \text { dos pacientes TB texanos } \\
17,8 \% \text { dos pacientes TB mexicanos, superando } \\
\text { significativamente as taxas nacionais de DM auto-referido } \\
\text { para ambos os países. Comorbidade DM excedeu } \\
\text { substancialmente a de HIV/AIDS. Pacientes com TB e DM } \\
\text { apresentavam maior idade, mais propensos a ter hemoptise, } \\
\text { cavitações pulmonares, ter mancha positiva no diagnóstico, } \\
\text { e permanecer positivo no final do primeiro (Texas) ou o } \\
\text { segundo mês (México) de tratamento. }\end{array}$} \\
\hline & & $\begin{array}{l}\text { Restrepo BI, Fisher-Hoch SP, Crespo JG, Whitney E, Perez A, Smith } \\
\text { B, McCormick JB; Nuevo Santander Tuberculosis Trackers. }\end{array}$ & Epidemiol Infect. & Estudo coorte retrospectivo & \\
\hline & & Texas - EUA & Inglês & Epidemiológico - Social & \\
\hline \multirow[t]{2}{*}{16} & \multirow[t]{2}{*}{2007} & Tuberculosis susceptibility of diabetic mice & $\begin{array}{l}\text { PubMed (MEDLINE) } \\
\text { Web of Science }\end{array}$ & $\begin{array}{l}\text { Worcester, Massachusetts - } \\
\text { EUA }\end{array}$ & \multirow{2}{*}{$\begin{array}{l}\text { A associação entre DM e TB foi modelada, infectando-se } \\
\text { ratos com DM aguda ( }<1 \text { mês) ou crônica ( }>3 \text { meses), com } \\
\text { uma dose baixa de aerossol de Mycobacterium tuberculosis } \\
\text { (Mtb) Erdman. O DM foi induzido pelo tratamento com } \\
\text { estreptozotocina (STZ) em ratos C57BL / 6, enquanto a } \\
\text { outra estirpe de ratos e outro modelo de DM foram } \\
\text { utilizados para confirmar as observaçães. Pulmôes de ratos } \\
\text { com DM aguda e euglicêmicos tiveram cargas bacterianas, } \\
\text { perfis de expressão de citocinas e histopatologia } \\
\text { semelhantes. Em contraste, os ratos com DM crônica } \\
\text { tiveram }>1 \text { log maior carga bacteriana e mais inflamação } \\
\text { no pulmão em comparação com ratos euglicêmicos. A } \\
\text { expressão da imunidade adaptativa foi retardada em ratos }\end{array}$} \\
\hline & & Martens GW, Arikan CM, Fucheng GL, Greiner D, Kornfeld, H. & $\begin{array}{l}\text { American Journal of } \\
\text { Respiratory Cell and } \\
\text { Molecular Biology }\end{array}$ & Estudo experimental & \\
\hline
\end{tabular}




\begin{tabular}{|c|c|c|c|c|c|}
\hline & & Massachusetts, EUA & Inglês & Imunológico & $\begin{array}{l}\text { DM crônicos, mostrada pela produção precoce reduzida de } \\
\text { IFN-g no pulmão e pela menor presença de antígeno Mtb } \\
\text { (ESAT-6)-células T responsivas, em comparação com ratos } \\
\text { euglicêmicos no primeiro mês de infecção. No entanto, } \\
\text { após } 2 \text { meses com TB, os níveis de citocinas pró- } \\
\text { inflamatórias foram maiores em ratos DM crônicos do que } \\
\text { nos euglicêmicos. A infecção pelo Mtb em ratos tratados } \\
\text { com STZ fornece um modelo útil para estudar os efeitos da } \\
\text { hiperglicemia na imunidade. Os dados indicam que o início } \\
\text { da imunidade adaptativa é prejudicado pela hiperglicemia } \\
\text { crônica, resultando em maior carga de estado estacionário } \\
\text { de Mtb no pulmão. }\end{array}$ \\
\hline \multirow[t]{3}{*}{17} & \multirow[t]{3}{*}{2007} & $\begin{array}{l}\text { The effect of type } 2 \text { diabetes mellitus on the presentation and treatment } \\
\text { response of pulmonary tuberculosis }\end{array}$ & $\begin{array}{l}\text { PubMed (MEDLINE) } \\
\text { Web of Science }\end{array}$ & $\begin{array}{l}\text { Jakarta e } \quad \text { Bandung, } \\
\text { Indonésia }\end{array}$ & \multirow{3}{*}{$\begin{array}{l}\text { Na Indonésia, } 737 \text { pacientes com TB pulmonar foram } \\
\text { identificados com DM e acompanhados prospectivamente } \\
\text { durante o tratamento da TB. O DM foi diagnosticado em } \\
14,8 \% \text { dos pacientes com TB e foi associado à idade e } \\
\text { maior peso corporal. Na apresentação, os pacientes } \\
\text { diabéticos com TB apresentaram maior quantidade de } \\
\text { sintomas, mas não havia evidências de TB mais grave. } \\
\text { Após } 2 \text { meses, os resultados do exame microscópico da } \\
\text { expectoração foi mais frequentemente positivo em doentes } \\
\text { diabéticos }(18,1 \% \text { vs } 10,0 \% \text { ). Após } 6 \text { meses, } 22,2 \% \text { das } \\
\text { amostras de escarro em cultura de pacientes diabéticos } \\
\text { foram positivas para Mycobacterium tuberculosis (odds } \\
\text { ratio ajustada, } 7,65 ; \text { Pp.004). }\end{array}$} \\
\hline & & $\begin{array}{l}\text { Alisjahbana B, Sahiratmadja E, Nelwan EJ, Purwa L, Yana Ahmad } \\
\text { AM, Ottenhoff OHM, Nelwan RHH, Parwati I, Meer JWM van der, } \\
\text { Crevel, R van. }\end{array}$ & $\begin{array}{l}\text { Clinical Infectious } \\
\text { Diseases }\end{array}$ & Coorte prospectiva & \\
\hline & & Bandung, Indonésia & Inglês & Apresentação clínica & \\
\hline \multirow[t]{3}{*}{18} & \multirow[t]{3}{*}{2007} & $\begin{array}{l}\text { Diabetes and tuberculosis: the impact of the diabetes epidemic on } \\
\text { tuberculosis incidence }\end{array}$ & PubMed (MEDLINE) & Índia & \multirow{3}{*}{$\begin{array}{l}\text { Foi construído um modelo epidemiológico com dados } \\
\text { sobre a incidência da TB, a prevalência do DM, estrutura } \\
\text { da população, e o risco relativo da TB associada ao DM. O } \\
\text { estudo objetivou avaliar o potencial impacto do DM como } \\
\text { fator de risco para a TB pulmonar, usando a Índia como } \\
\text { exemplo. Avaliou-se a contribuição do DM para } \\
\text { incidência da TB e a diferença entre a incidência da } \\
\text { tuberculose em áreas urbanas e rurais. Na Índia, em } 2000 \\
\text { havia uma estimativa de } 20,7 \text { milhões de adultos com DM } \\
\text { e } 900.000 \text { casos incidentes de adultos de TB pulmonar } \\
\text { Cálculos sugerem que o DM é responsável por } 14,8 \% \\
\text { (intervalo de incerteza de } 7,1 \% \text { para } 23,8 \% \text { da TB } \\
\text { pulmonar e } 20,2 \% \text { (8,3\% para } 41,9 \% \text { de TB com } \\
\text { baciloscopia positiva (ou seja, infecciosa). Estima-se que a } \\
\text { prevalência de DM, maior em áreas urbanas, está associada }\end{array}$} \\
\hline & & $\begin{array}{l}\text { Stevenson CR; Forouhi, NG; Roglic, G; Williams, BG; } \\
\text { Lauer, JA; Dye, C; Unwin, N. }\end{array}$ & BMC Public Health & Coorte retrospectiva & \\
\hline & & Cambridge, RU & $\begin{array}{l}\text { Idioma de publicação: } \\
\text { inglês }\end{array}$ & Epidemiológico & \\
\hline
\end{tabular}




\begin{tabular}{|c|c|c|c|c|c|}
\hline & & & & & $\begin{array}{l}\text { à incidência de } \mathrm{TB} \text { de } 15,2 \% \text { maior com baciloscopia } \\
\text { positiva em áreas urbanas que em áreas rurais - mais de } 1 / 5 \\
\text { da diferença do total estimado. }\end{array}$ \\
\hline \multirow[t]{3}{*}{19} & \multirow[t]{3}{*}{2007} & Tuberculose et diabètes. & PubMed (MEDLINE) & Dakar, Sénegal & \multirow{3}{*}{$\begin{array}{l}\text { Estudo retrospectivo caso controle comparando-se as } \\
\text { apresentações radiológicas de TB em } 100 \text { pacientes } \\
\text { diabéticos, sendo os pacientes pareados por idade e sexo, } \\
\text { com pacientes que apresentavam apenas TB pulmonar. O } \\
\text { DM estava presente em 4,7\% dos } 2116 \text { pacientes } \\
\text { internados por TB pulmonar durante o período de estudo, } \\
\text { sendo mais comum em homens }(60 \%) \text {, com idade média de } \\
51 \text { anos }(73 \%) \text { O DM2 era o mais comum }(82 \%) \text {. Quanto } \\
\text { à apresentação radiológica, a associação de diferentes tipos } \\
\text { de lesões classicamente descritas na TB foi encontrada em } \\
\text { proporções quase idênticas em ambos os grupos de } \\
\text { pacientes e lesão parenquimatosa foi o tipo mais frequente, } \\
\text { tanto em pacientes com DM (n }=86) \text { quanto nos controles } \\
\text { (n = 88). A tendência para a cavitação foi } \\
\text { significativamente menor nos diabéticos (72\%) do que nos } \\
\text { controles }(88 \%) \text {, p = 0,04. Imagens radiológicas, quando } \\
\text { bilaterais, tinham localização mais para a esquerda em } \\
\text { pacientes diabéticos (27\% contra } 15 \% \text { no grupo controle). } \\
\text { Houve tendência para lesões basais mais frequentemente } \\
\text { em diabéticos }(15 \%) \text { do que nos controles }(3 \%)(p=0,06) \text {. }\end{array}$} \\
\hline & & $\begin{array}{l}\text { N.O. Touré, NO; Kane, YD; Diatta A; Diop, SA; Niang, A; Ndiaye, } \\
\text { EM; Thiam, M; MBaye, FBR; Badiane, M; Hane, AA. }\end{array}$ & Rev Mal Respr & $\begin{array}{l}\text { Estudo de caso controle } \\
\text { retrospectivo }\end{array}$ & \\
\hline & & Dakar, Senegal & Francês & Apresentação clínica & \\
\hline \multirow[t]{3}{*}{20} & \multirow[t]{3}{*}{2007} & $\begin{array}{l}\text { Evaluation of an intermittent six-month regimen in new pulmonary } \\
\text { tuberculosis patients with diabetes mellitus. }\end{array}$ & PubMed (MEDLINE) & Chennai - Índia & \multirow{3}{*}{$\begin{array}{l}\text { O estudo objetivou avaliar as taxas de cura e recaída } \\
\text { durante acompanhamento de } 3 \text { anos, entre pacientes com } \\
\text { TB com baciloscopia positiva e DM2, tratados com regime } \\
\text { CAT-I (2E3H3R3Z3/4R3H3). Estudo coorte prospectivo, } \\
\text { observacional, empreendido para avaliar a adequação do } \\
\text { regime CAT-I em pacientes DM2 com esfregaços } \\
\text { positivos. Foram realizadas estimativa da linha de base } \\
\text { cardíaca, renal, testes de função hepática e glicosilada-de } \\
\text { HbA1c. Exames clínicos de escarro (baciloscopia e cultura) } \\
\text { e monitorização do estado diabético foram realizados a } \\
\text { cada mês até completar } 24 \text { meses. Dos } 100 \text { pacientes } \\
\text { internados, } 7 \text { foram excluídos por várias razões de análise. } \\
\text { De } 93 \text { pacientes, } 87 \text { (94\%) tiveram resposta favorável no } \\
\text { final do tratamento. Durante o período de de } \\
\text { acompanhamento, } 6 \text { pacientes morreram e houve uma } \\
\text { perda. Dos restantes, quatro recaídas. O regime CAT-I, }\end{array}$} \\
\hline & & $\begin{array}{l}\text { Balasubramanian R, Ramanathan U, Thyagarajan K, Ramachandran R, } \\
\text { Rajaram K, Bhaskar K, Shantharam Hariharan RS, Narayanan PR. }\end{array}$ & $\begin{array}{ll}\text { Indian } & \text { Journal } \\
\text { Tuberculosis }\end{array}$ & $\begin{array}{l}\text { Estudo prospectivo coorte } \\
\text { observacional }\end{array}$ & \\
\hline & & Chennai, Tamil Nadu - Índia & Inglês & Farmacológico & \\
\hline
\end{tabular}




\begin{tabular}{|c|c|c|c|c|c|}
\hline & & & & & $\begin{array}{l}\text { recomendado para todos os novos pacientes com } \\
\text { baciloscopia positiva no programa de TB indiano, foi } \\
\text { considerado eficaz no tratamento de pacientes TBDM. }\end{array}$ \\
\hline \multirow[t]{3}{*}{21} & \multirow[t]{3}{*}{2007} & $\begin{array}{l}\text { Sputum conversion at the end of intensive phase of Category-1 regimen } \\
\text { in the treatment of pulmonary tuberculosis patients with diabetes } \\
\text { mellitus or HIV infection: An analysis of risk factors. }\end{array}$ & $\begin{array}{l}\text { PubMed (MEDLINE) } \\
\text { Web of Science }\end{array}$ & Chennai, Madurai - Índia & \multirow{3}{*}{$\begin{array}{l}\text { Análise retrospectiva realizada para comparar as taxas de } \\
\text { conversão do escarro (baciloscopia cultura), no final da } \\
\text { fase intensiva (IP) do regime de CAT-1 entre os pacientes } \\
\text { admitidos em ensaios clínicos controlados: TB } \\
\text { isoladamente (PTB) ou com DM } 2 \text { (DM-TB) ou infecção } \\
\text { pelo HIV (HIV-TB), e identificar os fatores de risco que } \\
\text { influenciam a conversão de escarro. Os pacientes com DM } \\
\text { foram tratados com hipoglicemiantes orais ou insulina (sc). } \\
\text { A população de estudo incluiu } 98,92 \text { e } 88 \text { pacientes no } \\
\text { PTB, DM-TB e HIV-TB. No final da fase IP, a conversão } \\
\text { de esfregaço (58, } 61 \text {, e } 62 \% \text { e conversão da cultura ( } 86,88 \\
\text { e } 92 \% \text { f foram semelhantes nos três grupos, } \\
\text { respectivamente. As variáveis associadas com a falta de } \\
\text { baciloscopia ou conversão da cultura foram: idade maior } \\
\text { que } 45 \text { anos, maior mancha pré-tratamento e classificação } \\
\text { de cultura e extensão do envolvimento radiológico. }\end{array}$} \\
\hline & & $\begin{array}{l}\text { Rekha VV, Balasubramanian R, Swaminathan S, Rahman RRF, } \\
\text { Sundaram V, Thyagarajan K, Selvakumar N, Adhilakshmi Sheik } \\
\text { Iliayas AR, Narayanan PR. }\end{array}$ & $\begin{array}{l}\text { Indian Journal Med } \\
\text { Res }\end{array}$ & $\begin{array}{l}\text { Análise retrospectiva de } \\
\text { três estudos }\end{array}$ & \\
\hline & & Chennai, Índia & Inglês & Farmacológico & \\
\hline \multirow[t]{3}{*}{22} & \multirow[t]{3}{*}{2008} & $\begin{array}{l}\text { Cell-mediated immune responses to complex and single mycobacterial } \\
\text { antigens in tuberculosis patients with diabetes. }\end{array}$ & PubMed (MEDLINE) & Kwuait & \multirow{3}{*}{$\begin{array}{l}\text { O estudo objetivou avaliar a resposta imune mediada por } \\
\text { células (CMI) em pacientes com TB e DM e não diabéticos } \\
\text { (TB) e indivíduos saudáveis, em resposta aos antígenos de } \\
\text { Mycobacterium tuberculosis complexos, fracionados e } \\
\text { únicos. Células mononucleares sanguíneas periféricas } \\
\text { (PBMC) foram obtidas de pacientes com TB pulmonar e } \\
\text { DM2 }(\mathrm{n}=7) \text {, TB pulmonar sem DM }(\mathrm{n}=10) \text { e indivíduos } \\
\text { saudáveis sem TB e DM }(\mathrm{n}=10) \text {. Os pacientes com TB } \\
\text { diabéticos e não-diabéticos reagiram com frequência para } \\
\text { secreção de antígeno de baixo peso molecular ESAT6 de } \\
\text { M. tuberculosis, indicando que este antígeno pode ser útil } \\
\text { no diagnóstico de TB em ambos os grupos. }\end{array}$} \\
\hline & & Mustafa, AS; El-Shamy, AM; Madi, NM; Amoudy, HA; Al-Attiyah, R. & Med Princ Pract & Ensaio clínico & \\
\hline & & Kwuait & Inglês & Imunológico & \\
\hline \multirow[t]{2}{*}{23} & \multirow[t]{2}{*}{2008} & Diabetic control and risk of tuberculosis: a cohort study. & $\begin{array}{l}\text { PubMed (MEDLINE) } \\
\text { CINHAL }\end{array}$ & China & \multirow{2}{*}{$\begin{array}{l}\text { Uma coorte de } 42.116 \text { pacientes foram acompanhados } \\
\text { prospectivamente por meio do registro de TB em todo o } \\
\text { território. Os efeitos da DM e controle do DM em risco de } \\
\text { TB foram avaliados com o ajuste para variáveis de base } \\
\text { sócio-demográficos e outros. Diabetes mellitus foi }\end{array}$} \\
\hline & & & & & \\
\hline
\end{tabular}




\begin{tabular}{|c|c|c|c|c|c|}
\hline & & $\begin{array}{l}\text { Leung CC, Lam TH, Chan WM, Yew WW, Ho KS, Leung GM, Law } \\
\text { WS, Tam CM, Chan CK, Chang KC. }\end{array}$ & Am J Epidemiol. & Coorte prospectiva & \multirow{2}{*}{$\begin{array}{l}\text { associado com um aumento modesto no risco de TB ativa, } \\
\text { confirmada por cultura, e TB pulmonar (com ou sem } \\
\text { envolvimento extrapulmonar), mas não TB extrapulmonar } \\
\text { (com ou sem envolvimento pulmonar). }\end{array}$} \\
\hline & & China & Inglês & Epidemiológico & \\
\hline \multirow[t]{3}{*}{24} & \multirow[t]{3}{*}{2008} & $\begin{array}{l}\text { Tuberculosis in poorly controlled type } 2 \text { diabetes: altered cytokine } \\
\text { expression in peripheral white blood cells. }\end{array}$ & $\begin{array}{l}\text { PubMed (MEDLINE) } \\
\text { Web of Science }\end{array}$ & Texas - EUA, México. & \multirow{3}{*}{$\begin{array}{l}\text { Com a hipótese de que a hiperglicemia crônica leva à } \\
\text { imunossupressão que facilita a progressão para TB ativa, o } \\
\text { estudo objetivou avaliar esta possibilidade, determinando } \\
\text { se os pacientes com TB e DM (especialmente aqueles com } \\
\text { hiperglicemia crônica), em comparação com pacientes com } \\
\text { TB que não tinham DM, apresentaram respostas alteradas } \\
\text { de citocinas para um antígeno da micobactéria. Amostras } \\
\text { de sangue total de pacientes com TB e DM e de pacientes } \\
\text { com TB que não tinham DM foi estimulada in vitro com } \\
\text { derivado protéico purificado de Mycobacterium } \\
\text { tuberculosis. Em seguida, determinou-se se houve } \\
\text { associação entre os níveis de citocinas inata e adaptativa, } \\
\text { secretadas em resposta ao antígeno e status, DM ou DM } \\
\text { com hiperglicemia crônica (medido pelo nível de } \\
\text { hemoglobina glicosilada), após o controle de possíveis } \\
\text { fatores de confusão. }\end{array}$} \\
\hline & & $\begin{array}{l}\text { Restrepo, BI; Fisher-Hoch, SP; Pino, PA; Salinas, A; Rahbar, MH; } \\
\text { Mora, F; Cortes-Penfield, N; McCormick, JB. }\end{array}$ & Clin Infect Dis. & Estudo experimental & \\
\hline & & Texas, EUA & Inglês & Imunológico & \\
\hline \multirow[t]{3}{*}{25} & \multirow[t]{3}{*}{2008} & $\begin{array}{l}\text { Mycobacterial clearance from sputum is delayed during the first phase } \\
\text { of treatment in patients with diabetes. }\end{array}$ & PubMed (MEDLINE) & Texas, México & \multirow{3}{*}{$\begin{array}{l}\text { Foram analisados dados retrospectivos, a partir de } 2.878 \\
\text { pacientes com TB na fronteira Texas/México. Em geral, } \\
161 / 2878 \text { (5,6\%) pacientes apresentavam TB MDR } \\
\text { (resistência à rifampicina e isoniazida): no Texas } 49 / 1442 \\
(3,4 \%) \text { e no México } 112 / 1436(7,8 \%) \text {. No Texas, TBMDR } \\
\text { foi significativamente associada ao DM tipo } 2 \text { (OR 2.1, } \\
95 \% \text { CI 1,1-4,2), quando ajustado para idade, sexo, drogas } \\
\text { e abuso de álcool, infecção por HIV e episódio anterior de } \\
\text { TB; e, no México (OR 1,80, } 95 \% \text { CI 1,1-2,9), quando } \\
\text { ajustado para idade e sexo. Pacientes com DM2, em ambos } \\
\text { os países, eram mais propensos a ser compatíveis com a } \\
\text { terapia DOTS (Texas: OR 2.4, 95\% CI } 1,1-5,4 \text { ) do que } \\
\text { pacientes sem DM2. No Texas, todos os } 3 \text { dos pacientes } \\
\text { com DM2 com MDR-TB eram resistentes, em sua primeira } \\
\text { cultura, no momento do diagnóstico. }\end{array}$} \\
\hline & & $\begin{array}{l}\text { Restrepo BI, Fisher-Hoch SP, Smith B, Jeon S, Rahbar MH, } \\
\text { McCormick JB; Nuevo Santander Tuberculosis Trackers. }\end{array}$ & Am J Trop Med Hyg. & Estudo coorte & \\
\hline & & Texas - EUA & Inglês & Farmacológico & \\
\hline 26 & 2008 & $\begin{array}{l}\text { The role of interferon-gamma in the increased tuberculosis risk in type } \\
2 \text { diabetes mellitus. }\end{array}$ & PubMed (MEDLINE) & Indonésia & $\begin{array}{l}\text { Hipótese de que a suscetibilidade de pacientes diabéticos à } \\
\text { infecção por micobactérias é devida a defeito na resposta }\end{array}$ \\
\hline
\end{tabular}




\begin{tabular}{|c|c|c|c|c|c|}
\hline & & & Web of Science & & \multirow{3}{*}{$\begin{array}{l}\text { da citocina Th1. Quatro grupos de indivíduos foram } \\
\text { analisados na Indonésia: } 23 \text { pacientes com TB, } 34 \\
\text { pacientes com TB e DM, } 32 \text { pacientes com DM apenas e } \\
36 \text { controles saudáveis. Produção ex-vivo de interferon } \\
\text { gama (IFN), fator de necrose tumoral-alfa e interleucina } \\
\text { (IL)-1beta, 6, 10,-12 e - } 4 \text { foram medidas após estimulação } \\
\text { com o Mycobacterium tuberculosis e lipopolissacarídeo e } \\
\text { fito-hemaglutinina de Escherichia coli. Em doentes com } \\
\text { TB ativa foram detectados níveis baixos de IFNgama e } \\
\text { aumento da produção de outras citocinas pró-inflamatórias } \\
\text { e IL-4, ambos na presença e na ausência de DM. Os } \\
\text { doentes com DM sem TB, no entanto, mostraram produção } \\
\text { de IFNgama não específica fortemente reduzida, o que é } \\
\text { essencial para a inibição do crescimento inicial de } M \text {. } \\
\text { tuberculosis. }\end{array}$} \\
\hline & & $\begin{array}{l}\text { Stalenhoef JE, Alisjahbana B, Nelwan EJ, van der Ven-Jongekrijg J, } \\
\text { Ottenhoff TH, van der Meer JW, Nelwan RH, Netea MG, van Crevel } \\
\text { R. }\end{array}$ & $\begin{array}{l}\text { Eur J Clin Microbiol } \\
\text { Infect Dis. }\end{array}$ & Ensaio clínico & \\
\hline & & Holanda & Inglês & Imunológico & \\
\hline \multirow[t]{3}{*}{27} & 2008 & $\begin{array}{l}\text { Expression of CD64, CD206, and RAGE in adherent cells of diabetic } \\
\text { patients infected with Mycobacterium tuberculosis. }\end{array}$ & $\begin{array}{l}\text { PubMed (MEDLINE) } \\
\text { Web of Science }\end{array}$ & México & \multirow{3}{*}{$\begin{array}{l}\text { Quatro grupos de } 15 \text { pacientes com DM tipo } 2 \text {, TB } \\
\text { pulmonar (PTB ), DM tipo } 2 \text { e TB pulmonar (DM2 - PTB) } \\
\text {, e controle ( GC) foram estudados. O sangue foi colhido e } \\
\text { as células mononucleares (MNC) isoladas e cultivadas para } \\
\text { se obter as células aderentes ( CA ) e em seguida } \\
\text { estimuladas com lípidos } M \text {. tuberculosis H37Rv . A } \\
\text { expressão de CD64, CD206 e RAGE foi medida por } \\
\text { citometria de fluxo .Nos grupos sem estímulo, PTB e DM2 } \\
\text { - PTB expressa maior intensidade média de fluorescência } \\
\text { (MFI ) de CD64 e CD206 em relação ao GC. DM2-PTB } \\
\text { mostraram uma diminuição na expressão em relação ao } \\
\text { PTB . Após a estimulação de lipídeos nenhuma diferença } \\
\text { significativa entre os grupos ocorreu. Quando DM2 - PTB } \\
\text { foi comparado ao PTB, uma diminuição significativa na } \\
\text { expressão ocorreu. }\end{array}$} \\
\hline & & $\begin{array}{l}\text { Arce-Mendoza A, Rodriguez-de Ita J, Salinas-Carmona MC, Rosas- } \\
\text { Taraco AG. }\end{array}$ & Arch Med Res. & Caso-controle & \\
\hline & & Monterrey, México & $\begin{array}{l}\text { Idioma de publicação: } \\
\text { inglês }\end{array}$ & Imunológico & \\
\hline 28 & 2009 & $\begin{array}{l}\text { Impact of diabetes mellitus on treatment outcomes of patients with } \\
\text { active tuberculosis. }\end{array}$ & $\begin{array}{l}\text { PubMed (MEDLINE) } \\
\text { Web of Science }\end{array}$ & Maryland - EUA & $\begin{array}{l}\text { Estudo de coorte retrospectivo de pacientes com TB ativa } \\
\text { confirmada por cultura para determinar o impacto do DM } \\
\text { no desfecho do tratamento da TB. De } 297 \text { pacientes com } \\
\text { TB, } 42(14 \%) \text { apresentavam DM. Pacientes com DM }\end{array}$ \\
\hline
\end{tabular}




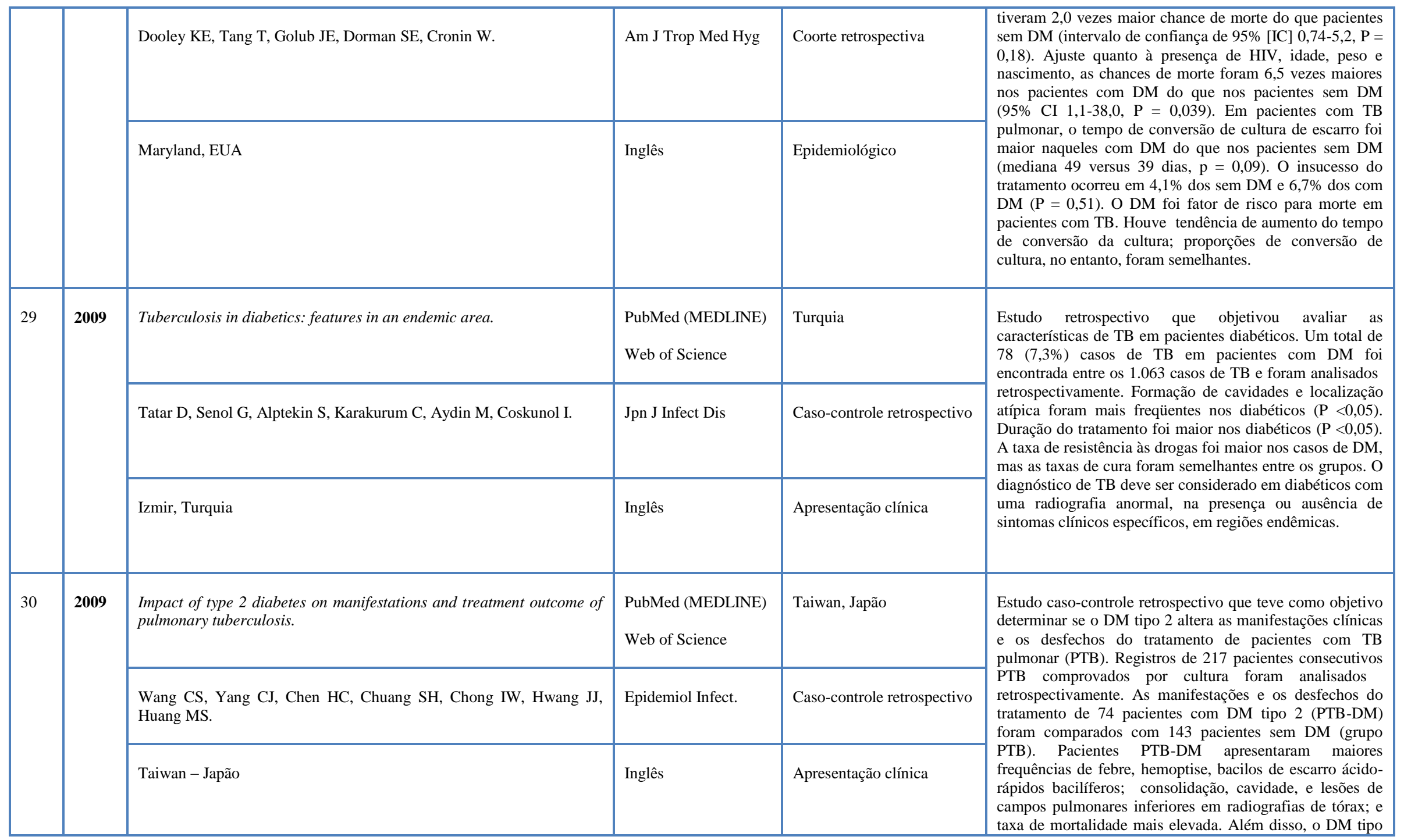




\begin{tabular}{|c|c|c|c|c|c|}
\hline & & & & & $\begin{array}{l}\text { 2, em pacientes com idade maior ou igual a } 65 \text { anos, e } \\
\text { doença radiográfico extensa, foram fatores } \\
\text { independentemente associados com um resultado } \\
\text { desfavorável. Este estudo confirmou que as manifestações } \\
\text { clínicas e radiografias de tórax de pacientes PTB } \\
\text { associados com DM tipo } 2 \text { afastam significativamente da } \\
\text { apresentação típica. }\end{array}$ \\
\hline \multirow[t]{3}{*}{31} & \multirow[t]{3}{*}{2010} & $\begin{array}{l}\text { Estimates of the impact of diabetes on the incidence of pulmonary } \\
\text { tuberculosis in different ethnic groups in England. }\end{array}$ & PubMed (MEDLINE) & Reino Unido & \multirow{3}{*}{ 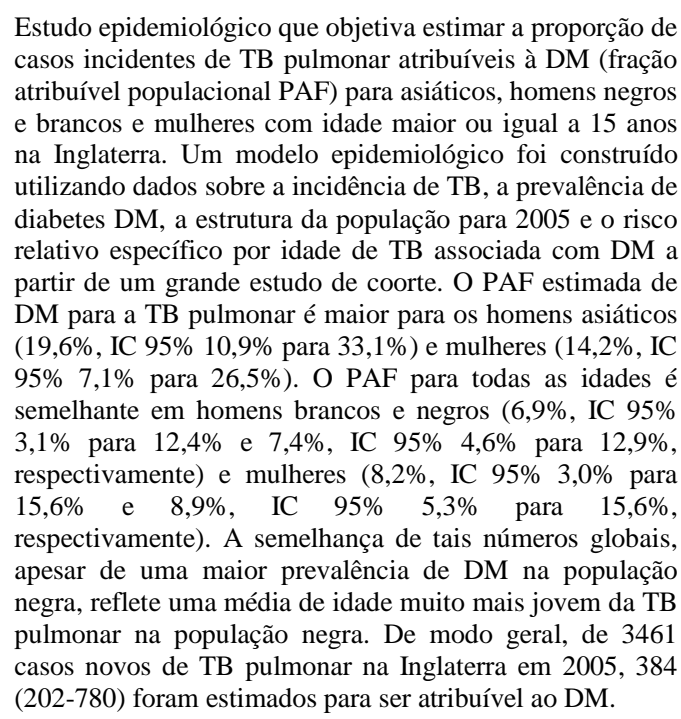 } \\
\hline & & Walker C, Unwin N. & Thorax. & Estudo epidemiológico & \\
\hline & & Newcastle, Reino Unido & Inglês & Epidemiológico & \\
\hline \multirow[t]{3}{*}{32} & \multirow[t]{3}{*}{2010} & $\begin{array}{l}\text { Pharmacokinetics of antituberculosis drugs in pulmonary tuberculosis } \\
\text { patients with type } 2 \text { diabetes. }\end{array}$ & PubMed (MEDLINE) & Bamdung, Indonésia & \multirow{3}{*}{$\begin{array}{l}\text { Ensaio clínico que objetivou examinar a influência do DM } \\
\text { sobre a farmacocinética dos medicamentos anti-TB na fase } \\
\text { intensiva do tratamento da TB, e avaliou-se o efeito do } \\
\text { controle glicêmico. Para isso, } 18 \text { pacientes diabéticos e } 18 \\
\text { controles pareados para gênero e peso corporal com TB e } \\
\text { não-DM foram incluídos. Amostragem da farmacocinética } \\
\text { intensiva foi realizado para a rifampicina, pirazinamida e } \\
\text { etambutol em estado estacionário. A biodisponibilidade de } \\
\text { rifampicina foi determinada por comparação da exposição } \\
\text { à rifampicina após a administração oral versus intravenosa. } \\
\text { Avaliacõos farmacocinéticas foram repetidas em } 10\end{array}$} \\
\hline & & $\begin{array}{l}\text { Ruslami R, Nijland HM, Adhiarta IG, Kariadi SH, Alisjahbana B, } \\
\text { Aarnoutse RE, van Crevel R. }\end{array}$ & $\begin{array}{l}\text { Antimicrob Agents } \\
\text { Chemother. }\end{array}$ & Ensaio clínico & \\
\hline & & Indonésia & Inglês & Farmacológico & \\
\hline
\end{tabular}




\begin{tabular}{|c|c|c|c|c|c|}
\hline & & & & & $\begin{array}{l}\text { pacientes com TB e DM após o controle glicêmico. Não } \\
\text { houve diferenças nas áreas sob as curvas de concentração- } \\
\text { tempo da droga no plasma de } 0 \text { a } 24 \mathrm{~h} \text { pós-dose (AUC ( } 0 \text { - } \\
\text { 24). Para a rifampicina, a biodisponibilidade oral e o } \\
\text { metabolismo foram semelhantes em pacientes DM e não- } \\
\text { DM. Os parâmetros farmacocinéticos de drogas anti-TB } \\
\text { não foram correlacionados com os níveis de glicose no } \\
\text { sangue ou o controle da glicose. }\end{array}$ \\
\hline \multirow[t]{3}{*}{33} & \multirow[t]{3}{*}{2010} & $\begin{array}{l}\text { Enzyme-linked immunospot assay for interferon-gamma to support the } \\
\text { diagnosis of tuberculosis in diabetic patients. }\end{array}$ & PubMed (MEDLINE) & Taiwan, China & \multirow{3}{*}{$\begin{array}{l}\text { Estudo experimental que objetivou avaliar o apoio a } \\
\text { diagnóstico da TB através de uma nova ferramenta } \\
\text { imunológica, um immunospot (ELISPOT) enzyme-linkea } \\
\text { de interferon- } \gamma \text {, em pacientes DM. De março de } 2007 \text { a } \\
\text { janeiro de 2008, pacientes COM DM de um hospital } \\
\text { terciário com suspeita de TB pulmonar foram incluídos. } \\
\text { Dados sobre as características clínicas dos pacientes } \\
\text { resultados de laboratório convencionais foram recolhidos e } \\
\text { amostras de sangue foram obtidas pelo ensaio ELISPOT (T } \\
\text { SPOT-TB; Oxford Immunotec Ltd, Oxford, Reino Unido). } \\
\text { Um total de } 84 \text { pacientes com suspeita de TB pulmonar } \\
\text { foram recrutados. Cinquenta e um (60,7\%) dos pacientes } \\
\text { foram considerados com TB pulmonar, incluindo } 42 \text { (50\%) } \\
\text { com TB confirmada e } 9 \text { (10,7\%) com TB provável. O total } \\
\text { (TB confirmados e prováveis) de sensibilidade, } \\
\text { especificidade, valor preditivo positivo e valor preditivo } \\
\text { negativo do ensaio ELISPOT foram } 84,3 \% \text {, } 66,7 \%, 79,6 \% \\
\text { e } 73,3 \% \text {, respectivamente. O valor preditivo negativo do } \\
\text { ensaio ELISPOT foi significativamente maior em pacientes } \\
\text { com controle glicêmico adequado ( } 90 \% \text { vs } 56,3 \% \text { ). } \\
\text { Concluiu-se que o ELISPOT pode fornecer suporte útil no } \\
\text { diagnóstico da TB pulmonar em pacientes diabéticos, } \\
\text { especialmente aqueles com controle glicêmico adequado. }\end{array}$} \\
\hline & & $\begin{array}{l}\text { Tan CK, Lai CC, Chen HW, Liao CH, Chou CH, Huang YT, Yang } \\
\text { WS, Yu CJ, Hsueh PR. }\end{array}$ & Scand J Infect Dis. & Estudo experimental & \\
\hline & & China, Taiwan & Inglês & Imunológico & \\
\hline \multirow[t]{3}{*}{34} & \multirow[t]{3}{*}{2010} & $\begin{array}{l}\text { Diabetic mice display a delayed adaptive immune response to } \\
\text { Mycobacterium tuberculosis. }\end{array}$ & PubMed (MEDLINE) & Massachusetts, EUA & \multirow{3}{*}{$\begin{array}{l}\text { O estudo apresentou a hipótese de que o DM provoca um } \\
\text { atraso na imunidade adaptativa nos gânglios linfáticos que } \\
\text { drenam o pulmão (linfonodos), após baixa dose de } \\
\text { aerossóis com Mycobacterium tuberculosis virulenta. Fo } \\
\text { demonstrado que as células T produtoras de IFN-gama } \\
\text { específicas para } M \text {. tuberculosis surgem mais tarde nas } \\
\text { linfonodos de ratos diabéticos do que nos controles, com } \\
\text { um atraso proporcionado no recrutamento destas células } \\
\text { para o pulmão e de estimulacão de respostas IFN-gama- }\end{array}$} \\
\hline & & Vallerskog T, Martens GW, Kornfeld H & J Immunol. & Ensaio Clínico & \\
\hline & & EUA & Inglês & Farmacológico & \\
\hline
\end{tabular}




\begin{tabular}{|c|c|c|c|c|c|}
\hline & & & & & $\begin{array}{l}\text { dependentes. Disseminação de } M \text {. tuberculosis do pulmão } \\
\text { para linfonodos também foi atrasada em ratos diabéticos, } \\
\text { embora não tenha havido defeito no tráfico de células } \\
\text { dendríticas do pulmão para os linfonodos após a } \\
\text { estimulação com LPS. Agregados de leucócitos } \\
\text { pulmonares nos sítios iniciais de infecção por } M \text {. } \\
\text { tuberculosis desenvolveram-se com maior atraso do que } \\
\text { em pessoas com DM em ratos não diabéticos, } \\
\text { possivelmente relacionados com a redução dos níveis de } \\
\text { leucócitos, incluindo fatores quimioatrantes CCL2 CCL5 } \\
\text { e em pontos de tempo mais cedo após a infecção. }\end{array}$ \\
\hline \multirow[t]{3}{*}{35} & \multirow[t]{3}{*}{2011} & $\begin{array}{l}\text { Diabetes mellitus and tuberculosis in countries with high tuberculosis } \\
\text { burdens: individual risks and social determinants. }\end{array}$ & $\begin{array}{l}\text { PubMed (MEDLINE) } \\
\text { Web of Science }\end{array}$ & Stanford - EUA & \multirow{3}{*}{ 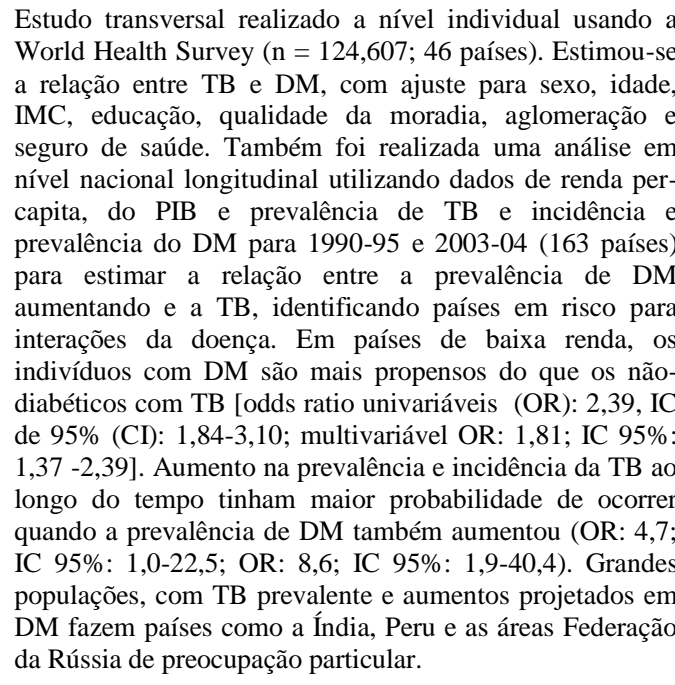 } \\
\hline & & Goldhaber-Fiebert JD, Jeon CY, Cohen T, Murray MB. & Int J Epidemiol. & $\begin{array}{l}\text { Estudo transversal de nível } \\
\text { individual }\end{array}$ & \\
\hline & & Califórnia, EUA & Inglês & Epidemiológico - social & \\
\hline \multirow[t]{2}{*}{36} & \multirow[t]{2}{*}{2011} & $\begin{array}{l}\text { Commentary: Co-occurrence of tuberculosis and diabetes: new } \\
\text { paradigm of epidemiological transition. }\end{array}$ & $\begin{array}{l}\text { PubMed (MEDLINE) } \\
\text { Web of Science }\end{array}$ & EUA & \multirow{2}{*}{$\begin{array}{l}\text { A autora ressalta que a convergência das pandemias de TB } \\
\text { e DM exemplifica uma transição epidemiológica, onde as } \\
\text { doenças crônicas comumente ocorrem simultaneamente } \\
\text { com as doenças infecciosas, e não simplesmente em uma } \\
\text { mesma população, mas no mesmo indivíduo. Este estado } \\
\text { simultâneo de doenças infecciosas comuns prevalentes } \\
\text { (TB) com ocorrências de doenças não transmissíveis e cada }\end{array}$} \\
\hline & & Magee MJ, Blumberg HM, Narayan KM. & Int J Epidemiol. & Artigo de opinião & \\
\hline
\end{tabular}




\begin{tabular}{|c|c|c|c|c|c|}
\hline & & EUA & Inglês & Epidemiológico & $\begin{array}{l}\text { vez mais prevalentes (MS) aponta para a necessidade de } \\
\text { um quadro conceitual modificado para a teoria da transição } \\
\text { epidemiológica. Deve-se reconhecer o impacto da } \\
\text { globalização sobre o rápido aumento das doenças crônicas } \\
\text { não-transmissíveis, e gerar soluções inovadoras que } \\
\text { integram abordagens para a prevenção e controle de ambas } \\
\text { as doenças não-transmissíveis e infecciosas. }\end{array}$ \\
\hline \multirow[t]{3}{*}{37} & \multirow[t]{3}{*}{2011} & $\begin{array}{l}\text { Differential expression of antimicrobial peptides in active and latent } \\
\text { tuberculosis and its relationship with diabetes mellitus. }\end{array}$ & $\begin{array}{l}\text { PubMed (MEDLINE) } \\
\text { Web of Science }\end{array}$ & México & \multirow{3}{*}{$\begin{array}{l}\text { Foi analisada a expressão de CAMP, DEFA1, DEFB4 } \\
\text { DEFB103A em } 60 \text { pacientes, de ambos os sexos, com TB } \\
\text { latente e TB progressiva com e sem comorbidade com DM } \\
\text { tipo 2. A expressão do gene peptídio antimicrobiano } \\
\text { aumentou durante TB progressiva, o que poderia ser usado } \\
\text { como um biomarcador para reativação. Em contraste, } \\
\text { pacientes com DM2 demonstraram menor expressão do } \\
\text { gene antimicrobiana, sugerindo que a falta da sua produção } \\
\text { adequada nestes pacientes contribuir para aumentar o risco } \\
\text { de reativação da TB. }\end{array}$} \\
\hline & & $\begin{array}{l}\text { Gonzalez-Curiel I, Castañeda-Delgado J, Lopez-Lopez N, Araujo Z, } \\
\text { Hernandez-Pando R, Gandara-Jasso B, Macias-Segura N, Enciso- } \\
\text { Moreno A, Rivas-Santiago B. }\end{array}$ & Hum Immunol. & Caso-controle & \\
\hline & & México & Inglês & Imunológico & \\
\hline \multirow[t]{3}{*}{38} & \multirow[t]{3}{*}{2011} & $\begin{array}{l}\text { Cross-sectional assessment reveals high diabetes prevalence among } \\
\text { newly-diagnosed tuberculosis cases. }\end{array}$ & $\begin{array}{l}\text { PubMed (MEDLINE) } \\
\text { Web of Science }\end{array}$ & $\begin{array}{l}\text { Texas - EUA; Matamoros - } \\
\text { México }\end{array}$ & \multirow{3}{*}{$\begin{array}{l}\text { Estudo prospectivo para estimar a contribuição da DM } \\
\text { clinicamente confirmados para as taxas de TB em } \\
\text { comunidades onde as duas doenças são prevalentes, como } \\
\text { uma maneira de descobrir as oportunidades para prevenir a } \\
\text { TB entre os diabéticos. Os indivíduos, com TB com idade } \\
\text { entre } 20 \text { anos ou mais em clínicas de TB na região da } \\
\text { fronteira Texas-México, foram testados para DM. O risco } \\
\text { de TB atribuível à DM foi estimado a partir de estatísticas } \\
\text { na população adulta correspondente. Prevalência de DM } \\
\text { entre os pacientes com TB foi de } 39 \% \text { no Texas e } 36 \% \text { no } \\
\text { México. Diabetes contribuiu } 25 \% \text { dos casos de TB } \\
\text { estudados, ao passo que [HIV] contribuíram com } 5 \% \text { ou } \\
\text { menos. Os homens eram menos freqüentemente } \\
\text { conscientes de que tinha DM em comparação com as } \\
\text { mulheres }(p=0,03) \text {. }\end{array}$} \\
\hline & & $\begin{array}{l}\text { Restrepo BI, Camerlin AJ, Rahbar MH, Wang WW, Restrepo MA, } \\
\text { Zarate I. }\end{array}$ & $\begin{array}{l}\text { Bull World Heath } \\
\text { Organ }\end{array}$ & Estudo transversal & \\
\hline & & Texas, EUA & Inglês & Epidemiológico & \\
\hline 39 & 2011 & $\begin{array}{l}\text { Significant increase in natural-killer } T \text { cells in patients with } \\
\text { tuberculosis complicated by type } 2 \text { diabetes mellitus. }\end{array}$ & $\begin{array}{l}\text { PubMed (MEDLINE) } \\
\text { Web of Science }\end{array}$ & Shanghai - China & $\begin{array}{l}\text { Estudo caso-controle que examinou a freqüência de } \mathrm{V} \alpha 24 \\
(+) / \mathrm{V} \beta 11(+) \text { de células T natural-killer (NKT) do sangue } \\
\text { periférico e lavado broncoalveolar na TB pulmonar em } \\
\text { pacientes com ou sem DM. O grau clínico de TB foi }\end{array}$ \\
\hline
\end{tabular}




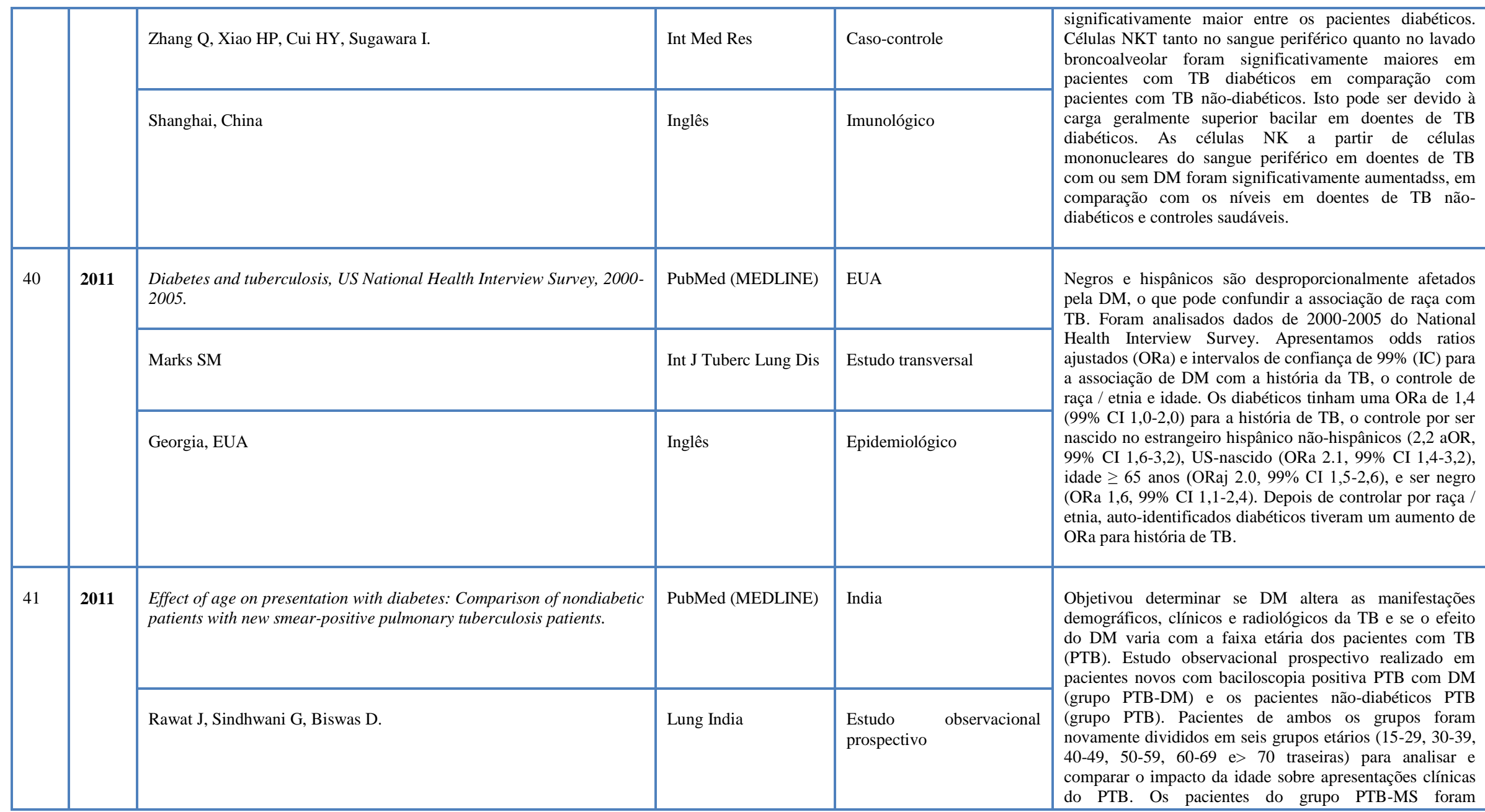




\begin{tabular}{|c|c|c|c|c|c|}
\hline & & Uttarakhand, India & Inglês & Apresentação clínica & $\begin{array}{l}\text { significativamente mais velhos }(53,34 \pm 14,06 \text { anos) em } \\
\text { comparação com suas contrapartes não-diabéticos (PTB } \\
\text { grupo) }(44,35 \pm 18,14 \text { anos) }(\mathrm{P}<0,001) \text {. O primeiro grupo } \\
\text { também apresentou uma menor proporção homem: mulher, } \\
\text { embora a diferença não foi estatisticamente significativa } \\
(1.16: 1 \text { vs } 2.05: 1, \mathrm{P}=0,101) \text {. Positividade tuberculina foi } \\
\text { significativamente maior no grupo } \mathrm{PTB} \text {, em comparação } \\
\text { com os pacientes no grupo PTB-DM ( } \mathrm{P}<0,004) \text {. A } \\
\text { proporção de doentes com menor envolvimento do pulmão } \\
(\mathrm{P}=0,003) \text { e cavitações }(\mathrm{P}=0,005) \text { foi também maior no } \\
\text { primeiro grupo em comparação com este último. }\end{array}$ \\
\hline \multirow[t]{3}{*}{42} & \multirow[t]{3}{*}{2011} & Tuberculosis and diabetes in Guyana. & $\begin{array}{l}\text { PubMed (MEDLINE) } \\
\text { Web of Science }\end{array}$ & Guiana & \multirow{3}{*}{$\begin{array}{l}\text { O estudo objetivou determinar a prevalência de DM entre } \\
\text { pacientes com TB atendidos em três clínicas de TB na } \\
\text { Guiana. Questionário estruturado foi usado para coletar } \\
\text { dados sobre os fatores demográficos, clínicos e risco. } \\
\text { Testagem de glicose no sangue foi feita usando o } \\
\text { glicosímetro OneTouch (LifeScan, Inc., 2002). Cem } \\
\text { pacientes com TB foram recrutados, 90 tiveram TB } \\
\text { pulmonar e } 10 \text { tinham doençaa extrapulmonar. Quatorze } \\
\text { pacientes foram classificados como diabéticos: } 12 \text { haviam } \\
\text { sido previamente diagnosticado como diabético por um } \\
\text { médico e dois tiveram alta concentração de glicose no } \\
\text { sangue no momento da inscrição. Todos os } 14 \text { pacientes } \\
\text { diabéticos apresentaram TB pulmonar. Trinta e um } \\
\text { pacientes eram HIV-positivos e } 28 \text { deles tiveram TB } \\
\text { pulmonar, enquanto que três tiveram TB extrapulmonar. } \\
\text { Nenhum dos diabéticos foram infectadas com o HIV. Os } \\
\text { pacientes TB-diabéticos tendiam a ser mais velhos do que } \\
\text { os não-diabéticos (idade mediana } 44 \text { vs } 36,5 \text { anos), e eram } \\
\text { mais propensos a terem um elevado (aleatório) nível de } \\
\text { açúcar no sangue }(p=0,02 \text { ). Clinicamente, o DM não } \\
\text { influenciou a apresentação da TB. }\end{array}$} \\
\hline & & $\begin{array}{l}\text { Alladin B, Mack S, Singh A, Singh C, Smith B, Cummings E, } \\
\text { Hershfield E, Mohanlall J, Ramotar K, La Fleur C. }\end{array}$ & Int J Infect Dis & Estudo transversal & \\
\hline & & Guiana & Inglês & Epidemiológico & \\
\hline \multirow[t]{2}{*}{43} & \multirow[t]{2}{*}{2011} & WHO framework targets tuberculosis-diabetes link & $\begin{array}{l}\text { PubMed (MEDLINE) } \\
\text { CINAHL }\end{array}$ & - & \multirow{2}{*}{$\begin{array}{l}\text { O artigo discute a elaboração do guia "Cuidados e Controle } \\
\text { da Tuberculose e Diabetes", pela OMS. Tal guia foi } \\
\text { elaborado diante da união da frente anti-TB e anti-DM e } \\
\text { sua criaçãa objetivou aumentar, em um nível individual o } \\
\text { número de pessoas que recebem diagnóstico preciso e } \\
\text { tratamento adequado para as duas doenças. E em um nível } \\
\text { de saúde pública, esperamos que ele ajude a reduzir a }\end{array}$} \\
\hline & & Maurice J. & The Lancet. & Artigo de opinião & \\
\hline
\end{tabular}




\begin{tabular}{|c|c|c|c|c|c|}
\hline & & - & Inglês & Epidemiológico & $\begin{array}{l}\text { incidência das duas doenças. Ao nível da saúde pública, a } \\
\text { epidemia de DM pode ser uma razão pela qual os esforços } \\
\text { para reduzir a incidência global de TB está tendo pouco } \\
\text { efeito, apesar de as taxas de detecção de casos e alta taxa } \\
\text { de cura. Detectou-se uma média global de cerca de } 65 \% \text { do } \\
\text { número estimado de novos casos de TB com uma taxa de } \\
\text { cura de } 86 \% \text {. Com esses percentuais, a incidência de TB } \\
\text { deveria estar reduzida em } 5-10 \% \text { por ano de acordo com a } \\
\text { modelagem matemática. }\end{array}$ \\
\hline \multirow[t]{3}{*}{44} & \multirow[t]{3}{*}{2011} & $\begin{array}{l}\text { The effect of diabetic control status on the clinical features of } \\
\text { pulmonary } \\
\text { Tuberculosis }\end{array}$ & PubMed (MEDLINE) & Coréía do Sul & \multirow{3}{*}{$\begin{array}{l}\text { Obetivou determinar se o status de controle do DM } \\
\text { influencia manifestações clínicas e radiográficas e } \\
\text { respostas ao tratamento em pacientes com TB. Os } \\
\text { prontuários de } 492 \text { pacientes que iniciaram medicação anti- } \\
\text { TB foram revisadas retrospectivamente. DM foi } \\
\text { diagnosticado em } 124 \text { pacientes }(25,2 \%) \text {. Destes, } 74 \\
(59,7 \% \text { ) eram não-controlados }(H b A 1 c \geq 7,0) \text {, } 25(20,2 \%) \\
\text { eram controlados }(H b A 1 c<7,0) \text {, e os níveis de HbAlc, não } \\
\text { foram avaliados os } 25 \text { restantes }(20,2 \%) \text {. Não houve } \\
\text { diferenças nos sintomas clínicos entre diabéticos e não- } \\
\text { diabéticos, independentemente do status de controle do } \\
\text { DM. Também não houve diferenças de achados } \\
\text { radiográficos ou resultados AFB entre diabéticos } \\
\text { controlados e não-diabéticos. No entanto, os diabéticos não } \\
\text { controlados apresentavam lesões mais cavitárias (p = } \\
0,008 \text { ) e maiores taxas de bacilíferos (p <0,001) em } \\
\text { comparação com os não-diabéticos. Após o ajuste para } \\
\text { idade, cavidades e manchas antes do início do tratamento, } \\
\text { o DM descontrolado era um fator de risco significativo } \\
\text { para uma cultura de escarro positiva em } 2 \text { meses (odds } \\
\text { ratio, } 4,316,95 \% \text { CI, } 1,306-14,267, p=0,017) \text {. }\end{array}$} \\
\hline & & Park SW, Shin JW, Kim JY, Park IW, Choi BW, Choi JC, Kim YS. & $\begin{array}{l}\text { Eur J Clin Microbiol } \\
\text { Dis. }\end{array}$ & Estudo retrospectivo & \\
\hline & & Coréia & Inglês & Apresentação clínica & \\
\hline \multirow[t]{3}{*}{45} & \multirow[t]{3}{*}{2011} & $\begin{array}{l}\text { Convergence of tuberculosis and diabetes mellitus: time to } \\
\text { individualise pharmaceutical care. }\end{array}$ & $\begin{array}{l}\text { PubMed (MEDLINE) } \\
\text { Web of Science }\end{array}$ & Malásia & \multirow{3}{*}{$\begin{array}{l}\text { Objetivou avaliar a viabilidade da prestação de um serviço } \\
\text { de atenção farmacêutica para pacientes com TB e DM. } \\
\text { Realizado em um hospital terciário na região norte da } \\
\text { península da Malásia. Os principais defechos pesquisados } \\
\text { foram os problemas de atenção farmacêutica. A } \\
\text { prevalência de DM entre os pacientes recém- } \\
\text { diagnosticados com TB foi de } 15 \%(53 / 352) \text {. As idades } \\
\text { variaram entre } 29 \text { e } 73 \text { anos (média de } 52 \pm 10 \text { anos). A } \\
\text { relação masculino:feminino foi de } 1,7: 1 \text {. Questões de } \\
\text { cuidados farmacêuticos identificados pelos farmacêuticos }\end{array}$} \\
\hline & & $\begin{array}{l}\text { Gnanasan S, Ting KN, Wong KT, Mohd Ali S, Muttalif AR, Anderson } \\
\text { C. }\end{array}$ & Int J Clin Pharm. & Método ativo de pesquisa & \\
\hline & & Reino Unido & Inglês & Farmacológico - Social & \\
\hline
\end{tabular}




\begin{tabular}{|c|c|c|c|c|c|}
\hline & & & & & $\begin{array}{l}\text { foram não adesão ao tratamento, DM não controlada, } \\
\text { reações adversas a medicamentos e problemas individuais } \\
\text { relacionados com medicamentos. Os farmacêuticos foram } \\
\text { capazes de intervir e resolver alguns dos problemas de } \\
\text { cuidados farmacêuticos. A conclusão foi de que o } \\
\text { farmacêutico desempenhou um papel importante na } \\
\text { integração da prestação de cuidados de TB e DM, } \\
\text { proporcionando gestão da assistência farmacêutica } \\
\text { individualizada. }\end{array}$ \\
\hline \multirow[t]{3}{*}{46} & \multirow[t]{3}{*}{2011} & $\begin{array}{l}\text { Effect of vitamin } D \text { supplementation in type } 2 \text { diabetes patients with } \\
\text { pulmonary tuberculosis. }\end{array}$ & PubMed (MEDLINE) & Hyderabad, India & \multirow{3}{*}{$\begin{array}{l}\text { Estudos têm demonstrado correlação entre baixos níveis de } \\
\text { vitamina } \mathrm{D} \text { e TB pulmonar (PTB) e os baixos níveis de } \\
\text { vitamina } \mathrm{D} \text { e resistência à insulina. Foram avaliados os } \\
\text { efeitos da suplementação de vitamina D em pacientes com } \\
\text { DMT2 com TB pulmonar (PTB). Quarenta e cinco } \\
\text { indivíduos (M: } \mathrm{F}=34: 11 \text { ) foram selecionados. Os } \\
\text { pacientes com deficiência de vitamina D nível de }<20 \mathrm{ng} / \\
\text { ml, e foram divididos aleatoriamente em dois grupos. } \\
\text { Grupo } 1 \text { recebeu cholecalceferol oral ( } 60.000 \text { unidades / } \\
\text { semana) e carbonato de cálcio (1g/dia), juntamente com o } \\
\text { tratamento anti TB (ATT), enquanto o grupo } 2 \text { não. Idade } \\
\text { dos pacientes foi de } 42,9 \pm 13,2 \text { anos e os níveis séricos de } \\
\text { vitamina } \mathrm{D} \text { foi de } 18,4 \pm 15,3 \text { ng / ml. Conversão } \\
\text { baciloscopia foi de } 6 \text { semanas no grupo } 1 \text { contra oito } \\
\text { semanas no grupo } 2(\mathrm{p}=0,067) \text {. Níveis de hemoglobina } \\
\text { glicada reduzida de } 11,1 \pm 1,3-7,7 \pm 0,9 \text { no grupo } 1 \text { versus } \\
10,3 \pm 1,2-7,8 \pm 1,1(\mathrm{p}>0,1) \text {. Os autores concluíram que a } \\
\text { vitamina D pode servir como tratamento adjuvante de TB } \\
\text { em diabéticos com deficiência de vitamina D. }\end{array}$} \\
\hline & & Kota SK, Jammula S, Kota SK, Tripathy PR, Panda S, Modi KD. & $\begin{array}{l}\text { Diabetes Metab } \\
\text { Syndr. }\end{array}$ & Ensaio Clínico & \\
\hline & & India & Inglês & Farmacológico & \\
\hline \multirow[t]{3}{*}{47} & \multirow[t]{3}{*}{2011} & $\begin{array}{l}\text { Diabetes, glycemic control, and risk of tuberculosis: a population- } \\
\text { based case-control study. }\end{array}$ & $\begin{array}{l}\text { PubMed (MEDLINE) } \\
\text { Web of Science } \\
\text { CINAHL }\end{array}$ & Dinamarca & \multirow{3}{*}{$\begin{array}{l}\text { Objetivou examinar a associação entre DM, controle } \\
\text { glicêmico e risco de TB. Foi realizado um estudo caso- } \\
\text { controle de base populacional no norte da Dinamarca. } \\
\text { Variáveis utilizadas para pareamento: idade semelhante, } \\
\text { sexo, lugar e tempo de residência na Dinamarca, e país de } \\
\text { emigração. Foi calculada a odds ratio (OR) para um } \\
\text { diagnóstico da TB pela primeira vez entre as pessoas com e } \\
\text { sem DM por meio de regressão para controlar outras } \\
\text { comorbidades, alcoolismo, medicamentos } \\
\text { imunossupressores, e marcadores socioeconômicos. Foram } \\
\text { identificados 2.950 pacientes, incluindo } 156 \text { indivíduos } \\
\text { diabéticos }(5,3 \%) \text {, com TB ativa e } 14.274 \text { indivíduos de }\end{array}$} \\
\hline & & $\begin{array}{l}\text { Leegaard A, Riis A, Kornum JB, Prahl JB, Thomsen Vø, Sørensen HT, } \\
\text { Horsburgh CR, Thomsen RW. }\end{array}$ & Diabetes Care. & $\begin{array}{l}\text { Caso-controle de base } \\
\text { populacional }\end{array}$ & \\
\hline & & Aarhus, Dinamarca. & Inglês & Epidemiológico & \\
\hline
\end{tabular}




\begin{tabular}{|c|c|c|c|c|c|}
\hline & & & & & $\begin{array}{l}\text { controle populacional, dos quais } 539 \text { tinham DM }(3,8 \%) \text {. O } \\
\text { OR ajustado para a TB ativa entre indivíduos com DM foi } \\
\text { de } 1,18 \text { (IC } 95 \% \text { 0 } \% 96-1,45) \text {, em comparação com } \\
\text { indivíduos não-diabéticos. }\end{array}$ \\
\hline \multirow[t]{3}{*}{48} & \multirow[t]{3}{*}{2011} & $\begin{array}{l}\text { The sensitivity of interferon-gamma release assays is not compromised } \\
\text { in tuberculosis patients with diabetes. }\end{array}$ & $\begin{array}{l}\text { PubMed (MEDLINE) } \\
\text { Web of Science }\end{array}$ & $\begin{array}{l}\text { Texas, EUA - Matamoros, } \\
\text { México }\end{array}$ & \multirow{3}{*}{$\begin{array}{l}\text { A sensibilidade dos ensaios de liberação de interferon- } \\
\text { gama (IGRA) na detecção da infecção pelo Mycobacterium } \\
\text { tuberculosis ou na doença podem ser afetados pela } \\
\text { alteração no sistema imunológico em pacientes com DM. } \\
\text { Como milhões de pacientes DM tipo } 2 \text { estão em risco para } \\
\text { a TB no mundo inteiro, o estudo é importante para } \\
\text { determinar se a sensibilidade do ELIG está comprometida } \\
\text { nesta população vulnerável. A sensibilidade do ELIG } \\
\text { QuantiFERON @ -TB Gold (QFT -G) e T- SPOT @ TB foi } \\
\text { avaliada entre amostras de adultos recém-diagnosticados } \\
\text { com TB microbiologicamente confirmada com e sem DM } \\
\text { Também foi avaliada a associação entre os resultados QFT } \\
\text {-G e as condições associadas ao DM (dislipidemia } \\
\text { obesidade). QFT -G sensibilidade foi de } 70 \% \text { entre os } \\
\text { pacientes com TB. Pacientes com DM, hiperglicemia } \\
\text { crônica ou com sobrepeso/obesidade foram mais de duas } \\
\text { vezes mais propensos a ter resultados positivos em } \\
\text { modelos multivariados (P < } 0,05 \text { ). A sensibilidade IGRA } \\
\text { não é comprometida pelo diabetes em pacientes com TB. } \\
\text { Assim, ELIG também pode ser adequado para o } \\
\text { diagnóstico de infecção por TB em pacientes com diabetes. }\end{array}$} \\
\hline & & $\begin{array}{l}\text { Walsh MC, Camerlin AJ, Miles R, Pino P, Martinez P, Mora-Guzmán } \\
\text { F, Crespo-Solis JG, Fisher-Hoch SP, McCormick JB, Restrepo BI. }\end{array}$ & $\begin{array}{l}\text { Int } \mathrm{J} \text { Tuberc Lung } \\
\text { Dis. }\end{array}$ & Estudo experimental & \\
\hline & & Texas, USA & Inglês & Imunológico & \\
\hline \multirow[t]{3}{*}{49} & \multirow[t]{3}{*}{2011} & $\begin{array}{l}\text { Diabetes mellitus and pulmonary tuberculosis, association or co- } \\
\text { incidence? }\end{array}$ & Web of Science & Irã & \multirow{3}{*}{$\begin{array}{l}\text { Objetivou avaliar o efeito do DM sobre os métodos } \\
\text { clínicos e diagnósticos e as características radiológicas da } \\
\text { TBpulmonar, em comparação com pacientes com TB } \\
\text { pulmonar não diabéticos, na província de Golestan, } \\
\text { Nordeste do Iran. Prontuários de pacientes com diagnóstico } \\
\text { definitivo de TB pulmonar foram revisados. Os dados } \\
\text { demográficos, o método clínico e diagnóstico e achados } \\
\text { radiológicos foram estudados. Dados radiológicos } \\
\text { tomografia computadorizada do tórax (pulmão TCAR) de } \\
\text { alta resolução foram feitas por dois radiologistas diferentes. } \\
\text { Cavidades multilobares foram significativamente mais } \\
\text { relatadas em pacientes diabéticos (p = } 0,014) \\
\text { Radiologicamente não foi observada diferença estatística } \\
\text { entre os dois grupos. }\end{array}$} \\
\hline & & Golshah E, Golshah R, Rahim RS, Hamid G, Aida M. & $\begin{array}{l}\text { Pakistan Journal of } \\
\text { Medical Sciences }\end{array}$ & $\begin{array}{ll}\text { Estudo } & \text { transversal } \\
\text { retrospective } & \end{array}$ & \\
\hline & & Irã & Inglês & Apresentação clínica & \\
\hline
\end{tabular}




\begin{tabular}{|c|c|c|c|c|c|}
\hline \multirow[t]{3}{*}{50} & \multirow[t]{3}{*}{2012} & $\begin{array}{l}\text { The Risk of Tuberculosis Disease Among Persons with Diabetes } \\
\text { Mellitus: A Porspective Cohort study }\end{array}$ & Web of Science & Taiwan, China & \multirow{3}{*}{$\begin{array}{l}\text { Esudo prospectivo que investigou o risco de TB entr } \\
\text { pessoas com DM estratificada por gravidade. Estudo de } \\
\text { coorte que envolveu } 17.715 \text { pessoas de Taiwan. Diabete } \\
\text { em geral foi significativamente associados com Th } \\
\text { (relação ajustada de risco } 2,09 \text { [95\% intervalo de } \\
\text { confiança }\{\mathrm{CI}\}, 1,10-3,95] \text { e } 2,60[95 \% \mathrm{CI}, 1,34-5,03 \\
\text { respectivamente). Em comparação com as pessoas sen } \\
\text { DM. O risco de TB dos participantes aumentou à medide } \\
\text { que o número de complicações de DM aumentol } \\
\text { significativamente }(\mathrm{P}=0,0016 \text { ), com > risco } 3 \text { vezes entr } \\
\text { aqueles com } \geq 2 \text { complicações relacionadas com O D } \\
\text { (odds ratio, } 3,45 ; \mathrm{CI}, 1,59-7,50) 95 \% \text {. }\end{array}$} \\
\hline & & Baker MA, Lin H, Chang H, Murray MB & $\begin{array}{l}\text { Clinical Infectious } \\
\text { Diseases }\end{array}$ & Coorte prospectivo & \\
\hline & & Boston, Massachusetts & Inglês & Epidemiológico & \\
\hline \multirow[t]{3}{*}{51} & \multirow[t]{3}{*}{2012} & $\begin{array}{l}\text { Analysis of The Impact of Diabetes on The Dynamical Transmission of } \\
\text { Tuberculosis }\end{array}$ & Web of Science & Yaoundé, Camarões & \multirow{3}{*}{$\begin{array}{l}\text { Este estudo teve como objetivo avaliar a força d } \\
\text { associação entre a TB e o DM. Foi apresentado um model } \\
\text { determinístico para a TB em uma comunidade, a fim d } \\
\text { determinar o impacto do DM na propagação da doença. O } \\
\text { recursos matemáticos importantes do modelo TB saa } \\
\text { cuidadosamente investigados. O limiar de epidemi } \\
\text { conhecida como o número de reprodução básica } \\
\text { equilíbrio para o modelo são determinados e estabilidade } \\
\text { analisado. O modelo é numericamente analisado par } \\
\text { avaliar o impacto do DM sobre a dinâmica de transmissã } \\
\text { da TB. Realizou-se análise de sensibilidade do } \\
\text { parâmetros-chave que impulsionam a dinâmica da doença } \\
\text { a fim de determinar sua importância relativa para } \\
\text { transmissão da doença e prevalência. Simulaçãe } \\
\text { numéricas sugerem que o DM aumenta a transmissão d } \\
\text { TB e progressão para TB ativa em uma comunidade. O } \\
\text { resultados sugerem que há uma necessidade de maio } \\
\text { atenção às estratégias de intervenção, como } \\
\text { quimioprofilaxia de TB indivíduos e tratamento d } \\
\text { tuberculose ativa em pessoas com DM, o que pode inclui } \\
\text { o teste de suspeita de diabetes, melhora o controle d } \\
\text { glicose e aumento da monitorização clínica e terapêutic } \\
\text { latentes a fim de reduzir a carga da doença. }\end{array}$} \\
\hline & & Moualeua DP, Bowonga S, Tewaa JJ, Emvudua Y. & $\begin{array}{l}\text { Mathematical } \\
\text { Modelling of Natural } \\
\text { Phenomena }\end{array}$ & Modelo Epidemiológico & \\
\hline & & Yaoundé, Camarões & Inglês & Epidemiológico - Social & \\
\hline 52 & 2012 & High Diabetes Prevalence among Tuberculosis Cases in Kerala, India & $\begin{array}{l}\text { PubMed (MEDLINE) } \\
\text { Web of Science }\end{array}$ & Kerala, India & $\begin{array}{l}\text { Foi realizado um estudo transversal de pacientes com TB } \\
\text { registrados a partir de junho-julho de } 2011 \text {, no estado de } \\
\text { Kerala, na Índia, para determinar a prevalência de DM. A } \\
\text { amostra representativa em todo o estado de pacientes com }\end{array}$ \\
\hline
\end{tabular}




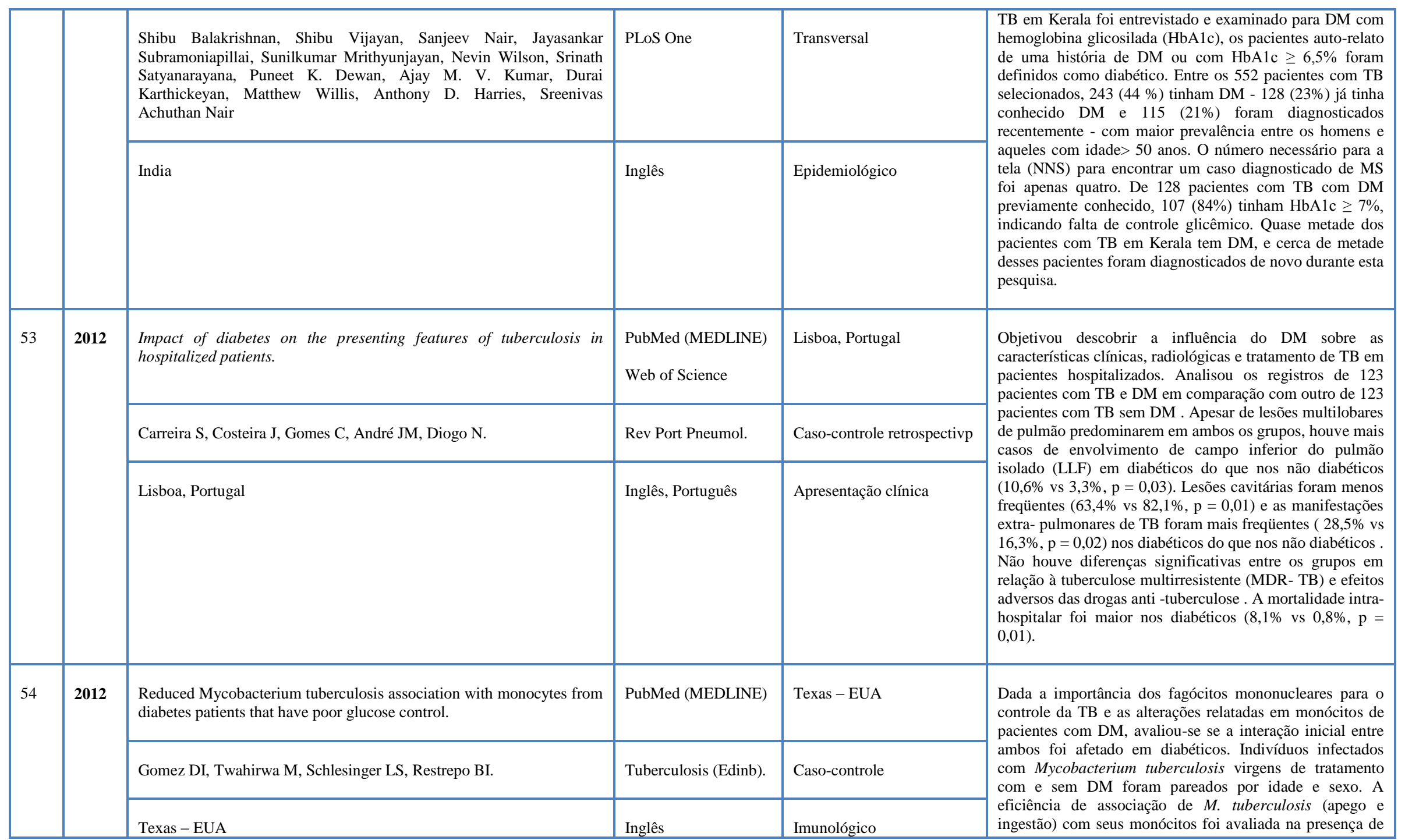




\begin{tabular}{|c|c|c|c|c|c|}
\hline & & & & & $\begin{array}{l}\text { soro autólogo. A associação de } \mathrm{M} \text {. tuberculosis com } \\
\text { monócitos foi significativamente menor nos diabéticos } \\
(19,2 \pm 6,1) \text { do que os não -diabéticos }(27,5 \pm 7,9, \mathrm{p}= \\
0,02) \text { A análise multivariada para o controle de } \\
\text { acolhimento sócio-demográficos, características DM e } \\
\text { lipídeos séricos indicou que sexo masculino }(\mathrm{p}=0,04) \text { e } \\
\text { DM mal controlado (alta HbA (1c) e hiperglicemia, p }= \\
0,01) \text { foram significativamente associados com a menor } \\
\text { interaçãa de } M \text {. tuberculose com monócitos. A inativação } \\
\text { sob calor do serum reduziu a associação de } M \text {. tuberculosis } \\
\text { a níveis semelhantes em ambos os grupos de estudo }(\mathrm{p}= \\
0,69) \text {, sugerindo alteraçães na via do complemento de } \\
\text { pacientes com DM. Esses achados sugerem uma rota } \\
\text { alterada de entrada do patógeno em pacientes com DM que } \\
\text { podem influenciar a ativação de vias de sinalização a } \\
\text { jusante no monócitos e para a sobrevivência de } \\
\text { micobactérias. }\end{array}$ \\
\hline \multirow[t]{3}{*}{55} & \multirow[t]{3}{*}{2012} & Screening patients with Diabetes Mellitus for Tuberculosis in China. & $\begin{array}{l}\text { PubMed (MEDLINE) } \\
\text { Web of Science }\end{array}$ & China & \multirow{3}{*}{$\begin{array}{l}\text { Projeto piloto na China, que teve como objetivo avaliar a } \\
\text { viabilidade e os resultados da triagem dos pacientes com } \\
\text { DM para TB dentro do ambiente de saúde. Implementação } \\
\text { começou em setembro de } 2011 \text {. Foram relatados } 7 \text { meses } \\
\text { de atividades até } 31 \text { de março de } 2012 \text {. Pacientes com DM } \\
\text { foram selecionados para a TB em cada atendimento clínico } \\
\text { utilizando um inquérito baseado em sintomas, e aqueles } \\
\text { positivos a qualquer sintoma de TB foram encaminhados } \\
\text { para investigações. Três quartos, } 72 \% \text { dos } 3.174 \text { pacientes, } \\
79 \% \text { dos } 7.196 \text { pacientes e } 68 \% \text { dos } 4.972 \text { pacientes foram } \\
\text { registrados como tendo sido rastreados para a tuberculose. } \\
\text { As taxas de notificação de casos de TB em pacientes com } \\
\text { DM pesquisados foram várias vezes superiores aos da } \\
\text { população em geral, foram maiores para os cinco locais } \\
\text { combinados no último trimestre ( } 774 / 100 \text { o00 ) e foram } \\
\text { maiores em uma das cinco clínicas no último trimestre } \\
804 / 100 \text { 000 ), onde houve intenso treinamento no } \\
\text { domicílio. Este projecto-piloto mostra que é viável para } \\
\text { realizar a triagem dos pacientes com DM para a TB, } \\
\text { resultando em altas taxas de detecção de tuberculose. }\end{array}$} \\
\hline & & $\begin{array}{l}\text { Lin Y, Li L, Mi F, Du J, Dong Y, Li Z, Qi W, Zhao X, Cui Y, Hou F, } \\
\text { Zachariah R, Kapur A, Lönnroth K, Harries AD. }\end{array}$ & Trop Med Int Health. & $\begin{array}{lr}\text { Projeto } & \text { observacional } \\
\text { prospectivo } & \text { de } \\
\text { implementação } & \end{array}$ & \\
\hline & & China & Inglês & Epidemiológico - social & \\
\hline 56 & 2012 & $\begin{array}{l}\text { Host susceptibility to tuberculosis: insights from a longitudinal study of } \\
\text { gene expression in diabetes. }\end{array}$ & $\begin{array}{l}\text { PubMed (MEDLINE) } \\
\text { Web of Science }\end{array}$ & Fronteira EUA-México & $\begin{array}{l}\text { O risco aumentado de } \mathrm{TB} \text { em pacientes com DM pode } \\
\text { servir como um modelo único para compreender a } \\
\text { susceptibilidade do hospedeiro ao agentes patogênicos }\end{array}$ \\
\hline
\end{tabular}




\begin{tabular}{|c|c|c|c|c|c|}
\hline & & & & & \multirow{3}{*}{$\begin{array}{l}\text { específicos em seres humanos. Para examinar esta razão, } \\
\text { foi investigada a expressão de genes em candidatos } \\
\text { notificados com TB em um estudo longitudinal de diabetes. } \\
\text { Dois genes, HK2 e CD28, surgiram como possíveis } \\
\text { culpados pelo aumento da susceptibilidade TB em } \\
\text { pacientes diabéticos. }\end{array}$} \\
\hline & & $\begin{array}{l}\text { Qu HQ, Rentfro AR, Lu Y, Nair S, Hanis CL, McCormick JB, Fisher- } \\
\text { Hoch SP. }\end{array}$ & $\begin{array}{l}\text { Int } \mathrm{J} \text { Tuberc Lung } \\
\text { Dis. }\end{array}$ & Coorte & \\
\hline & & Texas - EUA & Inglês & Imunológico & \\
\hline \multirow[t]{3}{*}{57} & \multirow[t]{3}{*}{2012} & $\begin{array}{l}\text { Pharmacokinetics of rifampin in Peruvian tuberculosis patients with } \\
\text { and without comorbid diabetes or HIV. }\end{array}$ & $\begin{array}{l}\text { PubMed (MEDLINE) } \\
\text { Web of Science }\end{array}$ & Lima, Peru & \multirow{3}{*}{$\begin{array}{l}\text { Objetivou determinar se a farmacocinética de drogas para } \\
\text { TB difere em pacientes peruanos com TB com DM ou } \\
\text { HIV. Pacientes com TB tiveram amostras de sangue } \\
\text { colhidas em } 2 \text { e } 6 \text { h após observado diretamente TB } \\
\text { ingestão de drogas, para determinar as concentrações } \\
\text { plasmáticas da rifampicina. Dos } 105 \text { pacientes, } 50 \text { tiveram } \\
\text { TB sem comorbidade, } 26 \text { tiveram coexistente DM, e } 29 \\
\text { tiveram coexistente HIV. Inesperadamente, a mediana da } \\
\text { amostra } 2 \text { - e } 6 \text {-H níveis de rifampicina foram de } 1,6 \text { e } 3,2 \\
\text { mg / l, respectivamente, e o tempo para a concentração de } \\
\text { pico foi de } 6 \text { horas (absorção lenta) em vez de } 2 \text { horas } \\
\text { (absorção rápida) para } 61 \text { pacientes ( } 62,2 \text { \%). A } \\
\text { rifampicina, C (max) foi significativamente menor nos } \\
\text { pacientes do sexo masculino do que no sexo feminino }(3,3 \\
\text { contra } 6,3 \text { mg / litro; } \mathrm{P}<0,001) \text {. Uma análise de variância } \\
\text { a análise de regressão mostrou que sexo feminino (P } \\
0,001) \text { e o tempo até à concentração máxima de } \\
\text { medicamento no soro (T (max) ) em } 2 \mathrm{~h}(\mathrm{P}=0,012) \text { foram } \\
\text { independentemente correlacionadas com o aumento da } \\
\text { exposição à rifampicina. A maioria da população estudada } \\
\text { apresentou farmacocinética da rifampcina diferente } \\
\text { daqueles convencionalmente relatado, com a absorção } \\
\text { retardada e baixas concentrações plasmáticas. }\end{array}$} \\
\hline & & $\begin{array}{l}\text { Requena-Méndez A, Davies G, Ardrey A, Jave O, López-Romero SL, } \\
\text { Ward SA, Moore DA. }\end{array}$ & $\begin{array}{l}\text { Antimicrob Agents } \\
\text { Chemother. }\end{array}$ & Estudo transversal & \\
\hline & & Lima, Peru. & $\begin{array}{l}\text { Idioma de publicação: } \\
\text { Inglês }\end{array}$ & Farmacológico & \\
\hline \multirow[t]{3}{*}{58} & \multirow[t]{3}{*}{2012} & $\begin{array}{l}\text { The co-management of tuberculosis and diabetes: challenges and } \\
\text { opportunities in the developing world. }\end{array}$ & $\begin{array}{l}\text { PubMed (MEDLINE) } \\
\text { Web of Science }\end{array}$ & Nova York - EUA & \multirow{3}{*}{$\begin{array}{l}\text { Pacientes com DM estão em maior risco de desenvolver } \\
\text { TB ativa, e têm maiores taxas de insucesso do tratamento } \\
\text { da morte, mesmo quando colocados no tratamento da TB } \\
\text { apropriado. } \\
\text { Este link pode tornar-se ainda mais significativo nos } \\
\text { próximos anos, como se espera que a prevalência de DM } \\
\text { suba dramaticamente nas áreas pobres em recursos, onde a } \\
\text { TB prospera. Discuti-se alguns dos desafios financeiros } \\
\text { inerentes no tratamento de DM em pacientes com TB, bem }\end{array}$} \\
\hline & & Sullivan T, Ben Amor Y. & PLoS Med. & Artigo de Opinião & \\
\hline & & Nova York, EUA. & Inglês & Epidemiológico - social & \\
\hline
\end{tabular}




\begin{tabular}{|c|c|c|c|c|c|}
\hline & & & & & $\begin{array}{l}\text { como algumas oportunidades para redução de custos e } \\
\text { colaboração na co-gestão dessas duas doenças. Também } \\
\text { propõem-se estratégias de financiamento e implementação } \\
\text { de ações de controle da TB e DM simultaneamente no } \\
\text { mundo em desenvolvimento. }\end{array}$ \\
\hline \multirow[t]{3}{*}{59} & \multirow[t]{3}{*}{2012} & $\begin{array}{l}\text { Significance of the frequency of CD4+CD25+CD127- T-cells in } \\
\text { patients with pulmonary tuberculosis and diabetes mellitus }\end{array}$ & $\begin{array}{l}\text { PubMed (MEDLINE) } \\
\text { Web of Science }\end{array}$ & Shanghai, China. & \multirow{3}{*}{$\begin{array}{l}\text { Ojetivou determinar se a expressão de células T CD4 + } \\
\text { CD25 + CD127 (células T reguladoras ( Treg)) está } \\
\text { associado com a TB. A citometria de fluxo foi utilizada } \\
\text { para determinar as frequências das células T CD4 + CD25 } \\
+ \text { e CD4 + CD25 + CD127 - células T no sangue } \\
\text { periférico, lavado broncoalveolar (LBA) e derrame pleural } \\
\text { em } 120 \text { pacientes ( } 30 \text { com TB pulmonar e DM (TBDM), } \\
30 \text { com TB pulmonar sem DM (TB), 30 com pleurisia } \\
\text { tuberculosa sem DM (TBP) e } 30 \text { voluntários saudáveis ). } \\
\text { As concentrações de interferON (IFN)- } \gamma \text { e interleucina } \\
\text { (IL) -10 no LBA e derrames pleurais foram determinadas } \\
\text { por ensaio imunoenzimático. Freqüências Treg no sangue } \\
\text { periférico foram significativamente maiores em pacientes } \\
\text { com TBDM, TB e TBP do que no grupo controle, com a } \\
\text { frequêencia em TBDM sendo o maior (P <0,01 para todos). } \\
\text { Em pacientes TBDM, frequências Treg foram } \\
\text { significativamente maiores do que no FLBA no sangue } \\
\text { periférico. A expressão de IL- } 10 \text { foi significativamente } \\
\text { maior, e de IFN- } \gamma \text { foi significativamente menor no FLBA } \\
\text { dos pacientes TBDM em comparação com LBA e derrames } \\
\text { pleurais de doentes com TB. Nos pacientes com TBDM, o } \\
\text { desequilíbrio entre Treg e células T efetoras em sítios } \\
\text { patológicos podem estar associados com a imunidade } \\
\text { enfraquecida e manifestações clínicas da TB. }\end{array}$} \\
\hline & & Sun Q, Zhang Q, Xiao H, Cui H, Su B. & Respirology. & Experimental & \\
\hline & & Shanghai, China. & Inglês & Imunológico & \\
\hline \multirow[t]{3}{*}{60} & \multirow[t]{3}{*}{2012} & $\begin{array}{l}\text { Role of Diabetes in the Prognosis and Therapeutic Outcome of } \\
\text { Tuberculosis }\end{array}$ & $\begin{array}{l}\text { PubMed (MEDLINE) } \\
\text { Web of Science }\end{array}$ & Malásia & \multirow{3}{*}{$\begin{array}{l}\text { Buscou-se avaliar os fatores de risco para a TB e o impacto } \\
\text { do DM sobre o resultado do tratamento da TB. Pacientes } \\
\text { com TB, os pacientes DM e pacientes TB-DM foram } \\
\text { divididos em três grupos de } 200 \text { indivíduos cada. Os dados } \\
\text { foram obtidos dos prontuários médicos dos pacientes no } \\
\text { início e no final do período de estudo. Prognóstico, } \\
\text { complicações relacionadas à TB, localização anatômica da } \\
\text { infecção, a duração da infecção e diabetes também foram } \\
\text { examinados. As taxas de prevalência de HIV e DM entre } \\
\text { pacientes com TB foram de } 7,7 \text { e } 30 \% \text {, respectivamente. } \\
\text { Aproximadamente } 74 \% \text { dos pacientes diabéticos tiveram }\end{array}$} \\
\hline & & $\begin{array}{l}\text { Suleiman SAS, Aweis DMI, Mohamed AJ, RazakMuttalif A, Moussa } \\
\text { MAA }\end{array}$ & $\begin{array}{l}\text { International Journal } \\
\text { of Endocrinology }\end{array}$ & Coorte prospectivo & \\
\hline & & Malásia & Inglês & Apresentação clínica & \\
\hline
\end{tabular}




\begin{tabular}{|c|c|c|c|c|c|}
\hline & & & & & $\begin{array}{l}\text { escarro positivo em comparação com apenas } 51 \% \text { dos } \\
\text { pacientes não-DM. Os pacientes diabéticos também foram } \\
\text { mais propensos a desenvolver a PTB (87\% em } \\
\text { comparação com pacientes com TB não-diabéticos (59\%). } \\
\text { Pacientes com TB diabéticos tiveram uma taxa de } \\
\text { mortalidade mais elevada }(7,5 \%) \text { em comparação com } \\
\text { apenas o TB e apenas os grupos DM (1 e } 2 \% \text {, resp). } \\
\text { Diabetes antecedeU TB por um período médio de } 4 \text { anos. }\end{array}$ \\
\hline \multirow[t]{3}{*}{61} & \multirow[t]{3}{*}{2012} & $\begin{array}{l}\text { Prevalence of diabetes and pre-diabetes and associated risk factors } \\
\text { among tuberculosis patients in India. }\end{array}$ & $\begin{array}{l}\text { PubMed (MEDLINE) } \\
\text { Web of Science }\end{array}$ & Tamil Nadu, India & \multirow{3}{*}{$\begin{array}{l}\text { Objetivo foi determinar a prevalência de DM entre uma } \\
\text { coorte de casos de TB registrados no Programa Nacional } \\
\text { de Controle da Tuberculose em unidades TB selecionados } \\
\text { em Tamil Nadu, na Índia, e avaliar padrão de gestão da } \\
\text { DM entre os casos conhecidos. Um questionário pré- } \\
\text { testado foi utilizado para coletar informações sobre as } \\
\text { características sociodemográficas, fatores de risco } \\
\text { habituais, e do tipo de TB. A prevalência de DM foi de } \\
25,3 \% \text { (IC } 95 \% \text { 22,6-28,5) e da pré- diabetes de } 24,5 \% \text { (IC } \\
95 \% 20,4-27,6) \text {. Os fatores de risco associados com DM } \\
\text { em pacientes com TB foram: idade (31-35, 36-40, } 41-45 \text {, } \\
46-50,>50 \text { anos vs }<30 \text { anos), a história familiar de DM, } \\
\text { ocupação sedentária, e IMC. Para o pré- diabetes, fatores } \\
\text { de risco foram: idade (36-40, } 41-45 \text {, } 46-50,>50 \text { anos vs } \\
<30 \text { anos), circunferência da cintura, fumando e renda } \\
\text { mensal. Risco de DM foi maior entre TB pulmonar [3,06 } \\
(1,69-5,52 \text { (p }<0,001)] \text {, especialmente de escarro positiva } \\
\text { que TB não- pulmonar. Quase } 50 \% \text { dos pacientes com TB } \\
\text { tiveram diabetes ou pré- diabetes. }\end{array}$} \\
\hline & & $\begin{array}{l}\text { Viswanathan V, Kumpatla S, Aravindalochanan V, Rajan R, } \\
\text { Chinnasamy C, Srinivasan R, Selvam JM, Kapur A. }\end{array}$ & PLoS One. & Coorte & \\
\hline & & India & Inglês & Epideiológico & \\
\hline \multirow[t]{3}{*}{62} & \multirow[t]{3}{*}{2012} & $\begin{array}{l}\text { Screening and intervention of diabetes mellitus in patients with } \\
\text { pulmonary tuberculosis in poverty zones in China: rationale and study } \\
\text { design }\end{array}$ & $\begin{array}{l}\text { PubMed (MEDLINE) } \\
\text { Web of Science } \\
\text { CINAHAL }\end{array}$ & China & \multirow{3}{*}{$\begin{array}{l}\text { Objetivo de compreender a prevalência de DM em } \\
\text { pacientes PTB ativos e avaliar os resultados da dieta e } \\
\text { hábitos de vida e intervenção em zonas de pobreza na } \\
\text { China. Uma investigação transversal e estudo de } \\
\text { intervenção será realizada. Pelo menos } 7.000 \text { pacientes } \\
\text { PTB ativos serão recrutados, em conjunto com } 7000 \\
\text { pessoas não-TB da mesma comunidade. O projeto será } \\
\text { dividido em duas fases. A primeira etapa é a formação de } \\
\text { trabalhadores, sobre o rastreio de TBDM e tramento } \\
\text { regular. Triagem e investigação relacionada será realizada } \\
\text { posteriormente. A segunda etapa está centrada na } \\
\text { intervenção. Uma estratégia global será utilizado para } \\
\text { realizar a promoção da saúde entre os pacientes, os }\end{array}$} \\
\hline & & Wang Q, Han X, Ma A, Wang Y, Bygbjerg IC, Li G, Sun Y, Zhou X & $\begin{array}{l}\text { Diabetes } \\
\text { Pract. }\end{array}$ & Estudo transversal & \\
\hline & & Qingdao, China & Inglês & Epidemiológico - social & \\
\hline
\end{tabular}




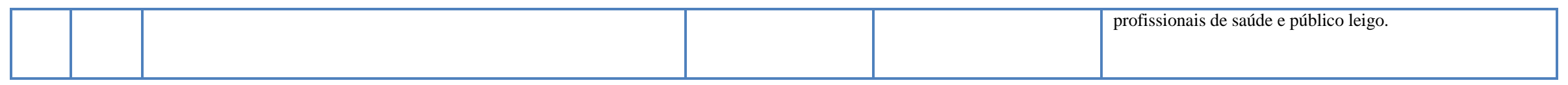


Apêndice B - Quadro de revisões

\begin{tabular}{|c|c|c|c|c|c|}
\hline & Ano & Título/ Autor/ Procedência & $\begin{array}{c}\text { Publicação/ } \\
\text { Revista/Idioma }\end{array}$ & $\begin{array}{c}\text { Local/ Delineamento/ } \\
\text { Enfoque }\end{array}$ & Resumo \\
\hline \multirow[t]{3}{*}{01} & \multirow[t]{3}{*}{2007} & $\begin{array}{l}\text { Convergence of the tuberculosis and diabetes epidemics: renewal } \\
\text { of old acquaintances }\end{array}$ & $\begin{array}{l}\text { PubMed (MEDLINE) } \\
\text { Web of Science }\end{array}$ & Texas - EUA & \multirow{3}{*}{$\begin{array}{l}\text { Objetivou compreender como a atual epidemia global de } \\
\text { DM2 está afetando o controle e a prevenção da TB. Muitas } \\
\text { perguntas estão ainda sem resposta: Qual é a magnitude e o } \\
\text { impacto dessas epidemias convergentes em todo o mundo? } \\
\text { Todos os pacientes com diabetes deveriam ser rastreados } \\
\text { para a infecção tuberculosa latente e, se positivos, como } \\
\text { deve ser monitorada a progressão da tuberculose ou } \\
\text { impedida? Pacientes com TB e DM devem ser tratados com } \\
\text { um regime de droga diferente em comparação com aqueles } \\
\text { apenas com TB? Qual é a base biológica da associação entre } \\
\text { a TB e DM? Qual é a medida mais rentável para avaliar DM } \\
\text { entre os pacientes com TB? }\end{array}$} \\
\hline & & Restrepo, B. & $\begin{array}{l}\text { Clinical Infectious } \\
\text { Diseases }\end{array}$ & Artigo de revisão & \\
\hline & & Texas, EUA & Inglês & Epidemiológico & \\
\hline \multirow[t]{3}{*}{02} & \multirow[t]{3}{*}{2007} & $\begin{array}{l}\text { Pulmonary tuberculosis and diabetes: aspects of its epidemiology, } \\
\text { pathophysiology, and symptoms. }\end{array}$ & PubMed (MEDLINE) & Dakar, Senegal & \multirow{3}{*}{$\begin{array}{l}\text { Artigo de revisão que ressalta que a TB pulmonar em } \\
\text { pacientes com DM é caracterizada pela sua gravidade, o que } \\
\text { alguns médicos consideram exigir cirurgia. Entre as } \\
\text { explicações fisiopatológicas propostas para a associação, } \\
\text { destaca-se a depressão da imunidade celular, com menos } \\
\text { linfócitos T no sangue e capacidade diminuída para } \\
\text { transformação blástica. Embora os pulmões não sejam } \\
\text { geralmente considerados órgão-alvo do DM, a literatura } \\
\text { parece demonstrar o contrário. Glicosilação não enzimática } \\
\text { e neuropatia autonômica estão envolvidas nestes fenômenos, } \\
\text { que fazem os pacientes com DM mais suscetíveis à infecção, } \\
\text { principalmente TB. O prognóstico é pior quando associado à à } \\
\text { excreção bacteriana e, portanto, à mortalidade por TB. Os } \\
\text { pacientes com DM são mais sensíveis a este tipo de infecção } \\
\text { devido à sua imunidade celular deprimida e à produção de } \\
\text { citocinas, em relação ao efeito nocivo da glicosilação não- } \\
\text { enzimática. Esses fatores sugerem a particularidade da } \\
\text { epidemiologia, fisiopatologia e sintomas de DM associada à } \\
\text { TB. }\end{array}$} \\
\hline & & Sidibè, ELH. & Cahiers Santé & Artigo de revisão & \\
\hline & & Dakar, Senegal & Francês & $\begin{array}{l}\text { Epidemiológico } \\
\text { Apresentação clínica } \\
\text { Imunológico }\end{array}$ & \\
\hline
\end{tabular}




\begin{tabular}{|c|c|c|c|c|c|}
\hline \multirow[t]{3}{*}{03} & \multirow[t]{3}{*}{2007} & $\begin{array}{l}\text { Diabetes and the risk of tuberculosis: a neglected threat to public } \\
\text { health? }\end{array}$ & $\begin{array}{l}\text { PubMed (MEDLINE) } \\
\text { CINAHL }\end{array}$ & Cambridge - Inglaterra & \multirow{3}{*}{$\begin{array}{l}\text { Pesquisa bibliográfica realizada na base Medline, } \\
\text { complementada pela verificação de referências e contato } \\
\text { com especialistas. Teve por objetivo avaliar a evidência da } \\
\text { associação entre TB/DM. Foram avaliados estudos que } \\
\text { quantificaram a associação entre a TB e o DM publicados } \\
\text { após } 1995 \text {. A qualidade do estudo foi avaliada de acordo } \\
\text { com critérios como tamanho da amostra, método de seleção } \\
\text { de casos e controles, perdas no acompanhamento, qualidade } \\
\text { e método de controle de fatores de confusão, e os resultados } \\
\text { foram resumidos de forma narrativa e tabular. Todos os } \\
\text { estudos identificaram associação estatisticamente } \\
\text { significativa e clinicamente importante, com aumento do } \\
\text { risco ou chance de TB variando entre } 1,5 \text { e } 7,8 \text { vezes para } \\
\text { aqueles com DM. O risco foi maior em idades mais jovens. }\end{array}$} \\
\hline & & $\begin{array}{l}\text { Stevenson, CR.; Critchley, JA.; Forouhi, NG.; Roglic, G; Williams, BG.; } \\
\text { Dye, C; Unwin, NC. }\end{array}$ & Chronic Illn & Revisão de literatura & \\
\hline & & Cambridge, Reino Unido & Inglês & Epidemiológica - social & \\
\hline \multirow[t]{3}{*}{04} & \multirow[t]{3}{*}{2008} & $\begin{array}{l}\text { Diabetes mellitus increases the risk of active tuberculosis: a systematic } \\
\text { review of } 13 \text { observational studies }\end{array}$ & $\begin{array}{l}\text { PubMed (MEDLINE) } \\
\text { Web of Science }\end{array}$ & Massachusetts - EUA & \multirow{3}{*}{$\begin{array}{l}\text { Revisão sistemática e metanálise de estudos observacionais } \\
\text { que avaliaram a associação entre o DM e TB, para sintetizar } \\
\text { as evidências de associação entre DM e TB, buscando } \\
\text { examinar a heterogeneidade subjacente aos diferentes } \\
\text { estudos e avaliar a qualidade metodológica dos estudos. } \\
\text { Pesquisados bancos de dados PubMed e EMBASE para } \\
\text { identificar os estudos observacionais que relataram } \\
\text { estimativa ajustada por idade, da associação entre a TB e o } \\
\text { DM. A busca resultou em } 13 \text { estudos observacionais (n = } \\
1,786,212 \text { participantes) com } 17.698 \text { casos de TB. Os efeitos } \\
\text { aleatórios de meta-análise de estudos de coorte mostraram } \\
\text { que o DM foi associado a risco aumentado de TB (RR = } \\
3,11 \text {, IC 95\% 2,27-4,26). Estudos caso-controle foram } \\
\text { heterogêneos e o odds ratio variou de 1,16-7,83. As análises } \\
\text { de subgrupos mostraram que estimativas de efeito foram } \\
\text { maiores nos estudos não-norte-americanos. Concluiu-se que } \\
\text { o DM foi associado a risco aumentado de TB, } \\
\text { independentemente do desenho do estudo e da população. }\end{array}$} \\
\hline & & Jeon, CY; Murray, MB. & PLoS & $\begin{array}{l}\text { Revisão Sistemática e } \\
\text { metanálise }\end{array}$ & \\
\hline & & Massachusetts - EUA & Inglês & Epidemiológico - social & \\
\hline 05 & 2009 & Tuberculosis and diabetes mellitus: merging epidemics. & PubMed (MEDLINE) & India & $\begin{array}{l}\text { Especialistas têm levantado a preocupação acerca das } \\
\text { epidemias emergentes de TB e DM particularmente em } \\
\text { países de baixo e médio desenvolvimento como Î́ndia e } \\
\text { China que têm as mais altas cargas de TB do mundo e estão }\end{array}$ \\
\hline
\end{tabular}




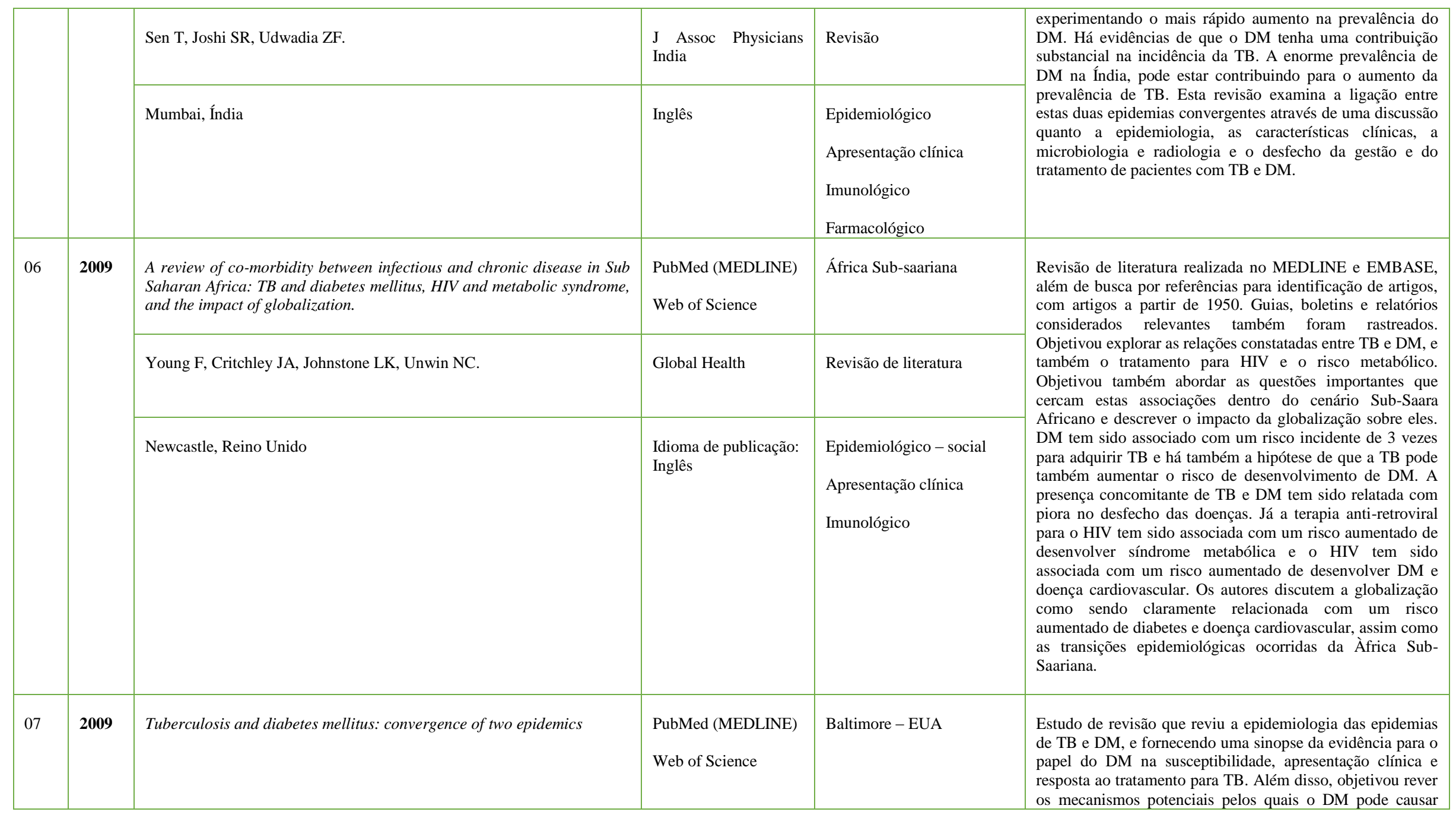




\begin{tabular}{|c|c|c|c|c|c|}
\hline & & Dooley, KE; Chaisson, RE & Lancet Infect Dis & Revisão & $\begin{array}{l}\mathrm{TB} \text {, os efeitos da } \mathrm{TB} \text { no controle do } \mathrm{DM} \text { e os problemas } \\
\text { farmacocinéticos relacionados à co-gestão do } \mathrm{DM} \text { e TB. }\end{array}$ \\
\hline & & EUA & Inglês & $\begin{array}{l}\text { Epidemiológico } \\
\text { Farmacológico } \\
\text { Apresentação clínica }\end{array}$ & \\
\hline \multirow[t]{3}{*}{08} & \multirow[t]{3}{*}{2009} & $\begin{array}{l}\text { Links between diabetes mellitus and tuberculosis: should we integrate } \\
\text { screening and care? }\end{array}$ & $\begin{array}{l}\text { PubMed (MEDLINE) } \\
\text { Web of Science }\end{array}$ & - & \multirow{3}{*}{$\begin{array}{l}\text { Artigo de revião que ressalta que recentes revisões } \\
\text { sistemáticas mostram que o DM aumenta o risco } \\
\text { probabilidades de desenvolver a tuberculose (TB), } \\
\text { especialmente em jovens e em países em desenvolvimento } \\
\text { com uma elevada incidência de TB. Não há dados que } \\
\text { mostram que a tuberculose aumenta o risco de DM. Esta } \\
\text { grande dupla carga de doenças pode tornar a gestão de } \\
\text { ambas as condiçães mais difíceis. Na maioria dos países em } \\
\text { desenvolvimento não há formas sitemásticas de } \\
\text { monitoramento ou avaliaão de pacientes com doenças não } \\
\text { comunicáveis (NCD). É necessária implementação de } \\
\text { pesquisa de alta qualidade para avaliar o valor e as formas } \\
\text { de triagem para DM em pacientes com TB e vice-versa, } \\
\text { para criar sistemas padronizados de monitoramento } \\
\text { avaliação com base no tratamento diretamente observado de } \\
\text { curta duração (DOTS) modelo utilizado para o controle da } \\
\text { TB. }\end{array}$} \\
\hline & & Harries AD, Billo N, Kapur A. & $\begin{array}{l}\text { Trans R Soc Trop } \\
\text { Med Hyg. }\end{array}$ & Mini revisão & \\
\hline & & Winchester, Reino Unido & Inglês & Epidemiológico & \\
\hline \multirow[t]{3}{*}{09} & \multirow[t]{3}{*}{2010} & $\begin{array}{l}\text { Implications of the global increase of diabetes for tuberculosis control } \\
\text { and patient care. }\end{array}$ & $\begin{array}{l}\text { PubMed (MEDLINE) } \\
\text { Web of Science }\end{array}$ & Indonésia & \multirow{3}{*}{$\begin{array}{l}\text { Objetivou revisar o conhecimento atual sobre a assistência } \\
\text { ao paciente com TB e DM. Usando bases de dados públicas, } \\
\text { pode-se estimar que } 12,6 \% \text { (IC } 95 \% \text { 9,2-17,3\%) de novos } \\
\text { casos de TB nos } 10 \text { países com maior carga da doença será } \\
\text { atribuído a TB em } 2030 \text {, um aumento relativo de } 25,5 \% \text { em } \\
\text { relação a } 2010 \text {. DM está associado com uma maior idade e } \\
\text { peso corporal entre os pacientes com TB, mas } \\
\text { provavelmente não com uma apresentação clínica específica } \\
\text { de TB. Rifampicina dificulta o controle glicêmico, } \\
\text { aumentando o metabolismo de fármacos antidiabéticos orais } \\
\text { mais, enquanto pacientes com DM podem ter menores } \\
\text { concentrações de fármacos anti-TB. Isso pode ser um fator } \\
\text { que contribui para maiores taxas de insucesso do tratamento } \\
\text { da TB. }\end{array}$} \\
\hline & & Ruslami R, Aarnoutse RE, Alisjahbana B, van der Ven AJ, van Crevel R. & Trop Med Int Health & Revisão sistemática & \\
\hline & & Bandung, Indonésia & Inglês & $\begin{array}{l}\text { Epidemiológico, } \\
\text { Apresentação clínica, } \\
\text { Farmacológico }\end{array}$ & \\
\hline
\end{tabular}




\begin{tabular}{|c|c|c|c|c|c|}
\hline \multirow[t]{3}{*}{10} & 2010 & $\begin{array}{l}\text { Bi-directional screening for tuberculosis and diabetes: a systematic } \\
\text { review. }\end{array}$ & $\begin{array}{l}\text { PubMed (MEDLINE) } \\
\text { Web of Science }\end{array}$ & Boston - EUA & \multirow{3}{*}{ 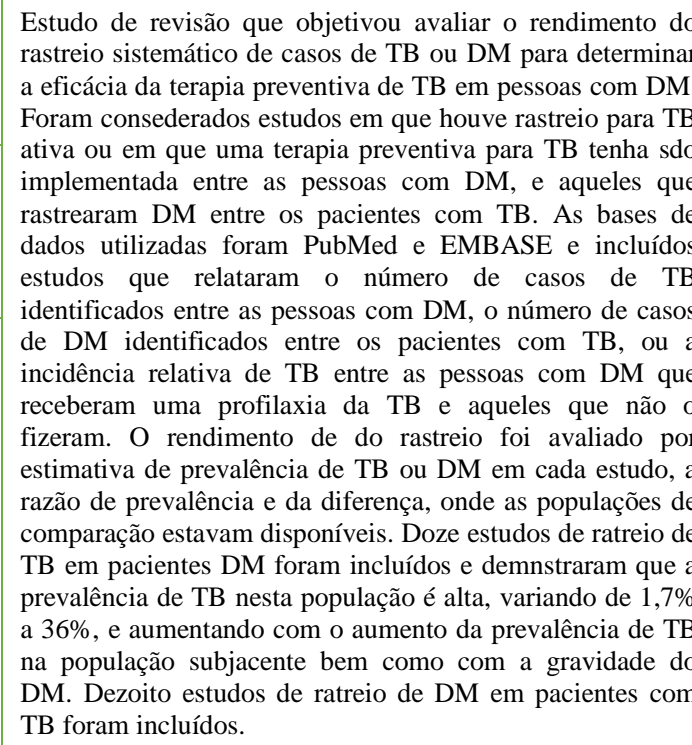 } \\
\hline & & $\begin{array}{l}\text { Jeon CY, Harries AD, Baker MA, Hart JE, Kapur A, Lönnroth K, } \\
\text { Ottmani SE, Goonesekera S, Murray MB. }\end{array}$ & Trop Med Int Health & Revisão Sistemática & \\
\hline & & EUA & Inglês & Epidemiológico & \\
\hline \multirow[t]{3}{*}{11} & 2010 & $\begin{array}{l}\text { Consultation meeting on tuberculosis and diabetes mellitus: meeting } \\
\text { summary and recommendations. }\end{array}$ & $\begin{array}{l}\text { PubMed (MEDLINE) } \\
\text { Web of Science }\end{array}$ & Genebra - Suíça & \multirow{3}{*}{ 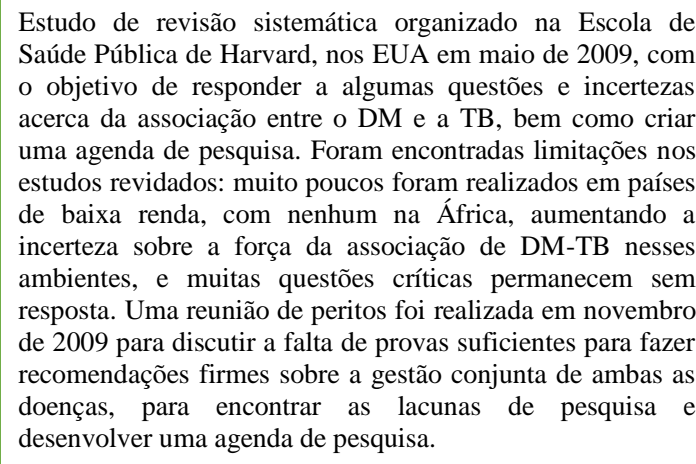 } \\
\hline & & $\begin{array}{l}\text { Ottmani SE, Murray MB, Jeon CY, Baker MA, Kapur A, Lönnroth K, } \\
\text { Harries AD. }\end{array}$ & Int J Tuberc Lung Dis & $\begin{array}{l}\text { Revisão sistemática com } \\
\text { meta-análise }\end{array}$ & \\
\hline & & Genebra, Suíça & Inglês & $\begin{array}{l}\text { Epidemiológico } \\
\text { Farmacológico }\end{array}$ & \\
\hline 12 & 2011 & $\begin{array}{l}\text { The impact of diabetes on tuberculosis treatment outcomes: a systematic } \\
\text { review. }\end{array}$ & $\begin{array}{l}\text { PubMed (MEDLINE) } \\
\text { Web of Science }\end{array}$ & Boston - EUA & $\begin{array}{l}\text { DM está associada com um aumento do risco de falha e e e } \\
\text { morte durante o tratamento da TB. Pacientes com DM têm } \\
\text { um risco relativo (RR) para o desfecho combinado de }\end{array}$ \\
\hline
\end{tabular}




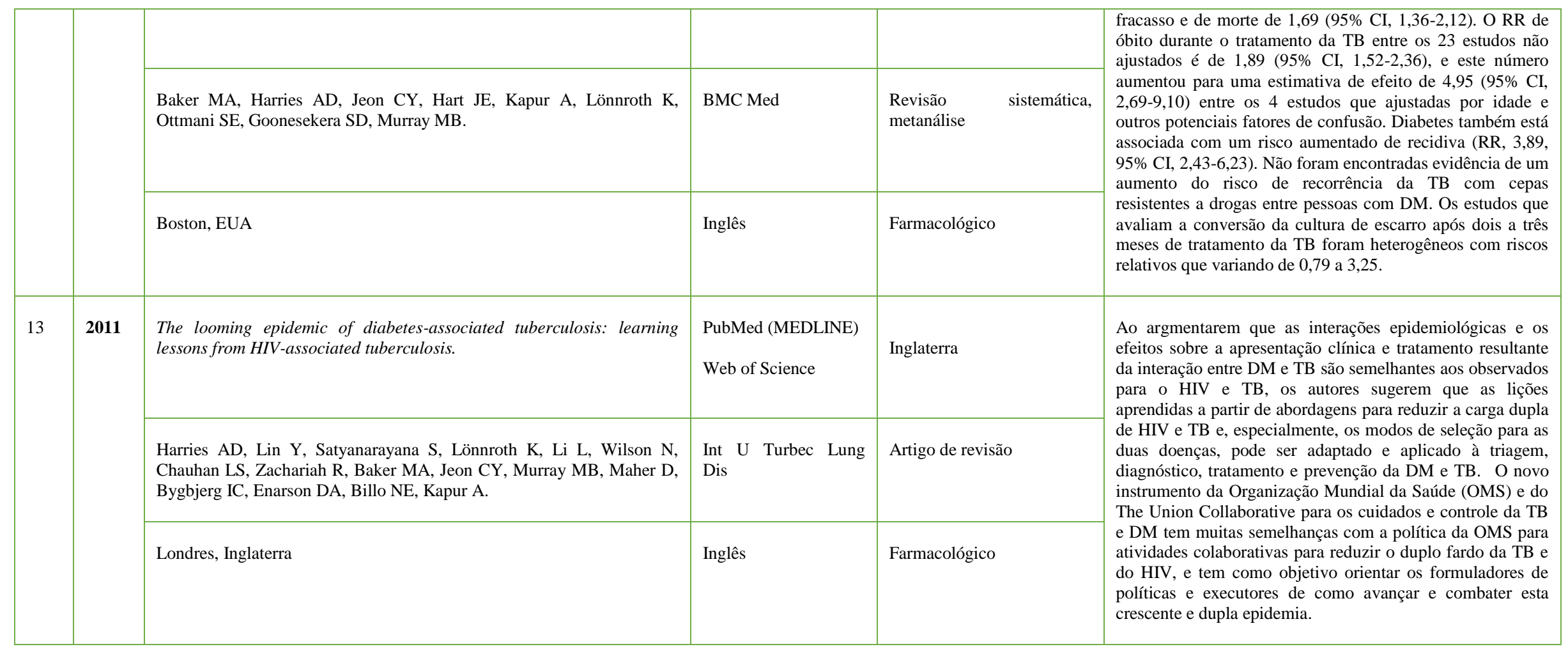


